Florida International University FIU Digital Commons

3-30-2018

\title{
Impact of Herbivory, Structural Complexity, and Sediment on Caribbean Coral Reefs
}

\author{
Alain Duran \\ adura023@fiu.edu
}

DOI: $10.25148 /$ etd.FIDC006531

Follow this and additional works at: https://digitalcommons.fiu.edu/etd

Part of the Behavior and Ethology Commons, Biodiversity Commons, Marine Biology

Commons, and the Terrestrial and Aquatic Ecology Commons

\section{Recommended Citation}

Duran, Alain, "Impact of Herbivory, Structural Complexity, and Sediment on Caribbean Coral Reefs" (2018). FIU Electronic Theses and Dissertations. 3708.

https://digitalcommons.fiu.edu/etd/3708 


\section{FLORIDA INTERNATIONAL UNIVERSITY}

Miami, Florida

\section{IMPACT OF HERBIVORY, STRUCTURAL COMPLEXITY, AND SEDIMENT ON CARIBBEAN CORAL REEFS}

A dissertation submitted in partial fulfillment of

the requirements for the degree of

DOCTOR OF PHILOSOPHY

in

BIOLOGY

by

Alain Duran

2018 
To: Dean Michael R. Heithaus

College of Arts, Sciences and Education

This dissertation, written by Alain Duran, and entitled Impact of Herbivory, Structural Complexity, and Sediment on Caribbean Coral Reefs, having been approved in respect to style and intellectual content, is referred to you for judgment.

We have read this dissertation and recommend that it be approved.

$\begin{array}{r}\hline \text { Kevin Boswell } \\ \hline \text { Alastair R. Harborne } \\ \hline \text { Dennifer Rehage } \\ \hline \text { Ligia Collado-Vides, Co-Major Professor }\end{array}$

Date of Defense: March 30, 2018

The dissertation of Alain Duran is approved.

Dean Michael R. Heithaus

College of Arts, Sciences and Education

Andrés G. Gil

Vice President for Research and Economic Development and Dean of the University Graduate School

Florida International University, 2018 


\section{COPYRIGHT PAGE}

Chapters II, III, IV and V have been formatted following instructions of peer-reviewed journals. Chapters II and III were submitted to "Environmental Biology of Fishes" and "Marine Biology" journals. Chapter IV is formatted for soon submission to "Coral Reefs" journal and Chapter IV has been published in the "Bulletin of Marine Science" that allows its use for educational purposes.

\section{CHAPTER II}

Duran A, Adam TC, Palma L, Moreno S, Collado-Vides L, Burkepile DE. Comparative analysis of resource-use by Caribbean surgeonfish reveals distinct trophic niches. In review, Environmental Biology of Fishes

\section{CHAPTER III}

Duran A, Collado-Vides L, Palma L, Burkepile DE. Interactive effects of herbivory and substrate orientation on algal community dynamics of a coral reef. In review, Marine Biology

\section{CHAPTER IV}

Duran A, Shantz AA, Burkepile DE, Collado-Vides L, Ferrer VM, Palma L, Ramos A, Gonzalez-Diaz SP (2018) Fishing, pollution, climate change, and the longterm decline of coral reefs off Havana, Cuba. Bulletin of Marine Science 94:Doi.org/10.5343/bms.2017.1061

(C) Copyright 2018 by Alain Duran

All rights reserved. 


\section{DEDICATION}

I dedicate my dissertation to my family, my extraordinary wife, my two wonderful kids, Amanda and Andy, and my mom. 


\section{ACKNOWLEDGMENTS}

A Ph.D. dissertation defense is a final step of a long journey from graduate student to young scientist. For me, it was a rigorous scientific process guided by two excellent scientists, Dr. Ligia Collado and Dr. Deron E. Burkepile, in the most professional and familiar environment. I consider myself lucky for having had their constant professional and personal support throughout almost seven years of graduate school. I want to thank Dr. Collado for opening the doors for me when I first appeared looking for an opportunity to continue my career. A few months after I started graduate school, I joined the Pile where I found a family founded by an extraordinary mentor and friend, Dr. Burkepile. I and my family will always be in debt to both of you.

I'm very thankful for the support and assistance given by my committee members, Dr. Jennifer Rehage, Dr. Kevin Boswell and Dr. Alastair R. Harborne. From the first committee meeting till the present, I've received only excellent professional guidance. I want also thank Dr. Adam, a Pile member that acted as my external advisor, for giving me excellent ideas and feedback during my data analysis and writing process. Thanks you Tom for your help and friendship.

The Pile, that diverse and awesome group of young scientists that welcomed and helped me during my entire career to the point that I never stopped missing them. I once told someone that part of my lab was far, but we always stick together. I want to start by thanking some of the funniest and most capable friends I've met, Dr. Shantz, Mark (soon to be called Dr. Ladd) and Sabrina (thanks for letting us (my family) be part of yours). Sharing field time, scientific meetings and shared times were the most enjoyable time in my career. I also want to thank Kelly for being such tough scientist with great ideas and 
an excellent vibe. I would like to also thank the rest of the Pile, especially Cory (I don't recall any person in my life working harder than her, however, The Pile needs to work harder for her to get involved in our G\&T's tradition) and Mallory (I don't recall either a more dynamic person), two hardcore young scientists with which I had the opportunity to work in the field.

I would like to acknowledge all the help from the volunteers in my other lab, the Marine Macroalgae Research lab. Among many others, I particularly thank Amanda, Janina, Daphney, Shalimar, Maria Rojas, Elizabeth Lago and family, Samantha, Mariangelica. A very special thank to Laura Palma for being the best field tech any research lab can have and excellent friend.

I would also acknowledge the support I received from FIU faculties, particularly Dr. Jim Fourqurean, Dr. Susan Koptur, Dr. Joel Trexler, Dr. Jose M Eirin-Lopez and Dr. Marcy Kravec for advising me at different stages of my career. I want to thank the FIU Aquarius staff (Roger Garcia, Otto, Mark, Henry, Tom, and Sean) for organizing two amazing missions. Likewise, I would like to thank the staff of the Cuban Marine Research Center (CIM) especially Dr. Patricia Gonzales, Ivan, Amanda and Victor for their assistant during our work in the Island.

I would like to acknowledge the funding support I obtained from Florida's State Wildlife Grant Program, Biology Department and the School of Arts and Sciences of FIU, from the Latin American and Caribbean Center (LACC), from the Kelly Foundation, and the International Center for Tropical Botany (ICTB) for research travels and scientific meetings. I also want to thank FIU for the Dissertation Year Fellowship that allowed me to complete my dissertation. 
Finally, I would like to thank my family (my puro, tia Gricel and tio Nelson) and friends (Yan, Pedri and Hector) for their patience and support during all these years. 


\section{ABSTRACT OF THE DISSERTATION \\ IMPACT OF HERBIVORY, STRUCTURAL COMPLEXITY, AND SEDIMENT ON CARIBBEAN CORAL REEFS}

by

Alain Duran

Florida International University, 2018

Miami, Florida

\section{Professor Ligia Collado-Vides, Co-Major Professor \\ Professor Deron E. Burkepile, Co-Major Professor}

The resilience of coral reefs depends, among others, upon local physical and biological characteristics. This dissertation focused on how herbivory, structural complexity, and sedimentation can impact the structure, function, and, ultimately, resilience of Caribbean coral reefs. We filled an important knowledge gap related to trophic niche and ecological roles of surgeonfishes (A. coeruleus and A. tractus), two of the most important herbivorous fishes in the Caribbean. We showed that both species feed primarily on turf algae preventing further progression of algal succession while $A$. tractus may also help reduce macroalgal abundance by targeting common macroalgal species such as Dictyota spp. We used a factorial experiment to analyze the interactive effects of herbivory (exclosure $v s$. open plots) and reef structural complexity (vertical $v s$. horizontal substrate orientation), on the development of benthic communities. We found that vertical substrates were quickly dominated by crustose algae regardless of herbivory treatment while succession of horizontal substrates was determined by herbivory. Our results suggest that at small scale, reef complexity is a major factor determining algal 
community structure. We investigated why, despite high levels of herbivory, coral cover in South Florida has failed to recover. We surveyed benthic composition, grazing and abiotic characteristics along six spur and groove reefs in the Florida Keys. Using boosted regression tree analyses, we found that sediment abundance was the best predictor of both juvenile and adult corals, which could explain the failure of coral recovery. We studied spatial and temporal changes of reef communities of reefs in Havana, Cuba where global and local stressors have affected coral communities while overfishing and nutrient enrichment has led to low herbivory levels. Our surveys revealed a region-wide high abundance of algae $(\sim 60 \%)$ as a consequence of heavy overfishing with likely negative consequences on coral recovery. In summary, my dissertation showed context-depend effects of herbivory, structural complexity, and sediment on Caribbean coral reefs. While reduction of herbivory can often suppress coral recovery, on coral reefs with robust herbivore populations, physical factors such as structural complexity and sediment may still limit coral recovery and fundamentally impact reef resilience. 


\section{TABLE OF CONTENTS}

CHAPTER

PAGE

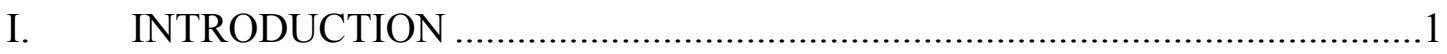

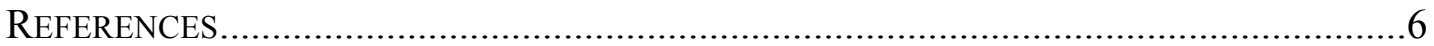

II. COMPARATIVE ANALYSIS OF RESOURCE-USE BY CARIBBEAN SURGEONFISHES REVEALS DISTINCT TROPHIC NICHES ..................10

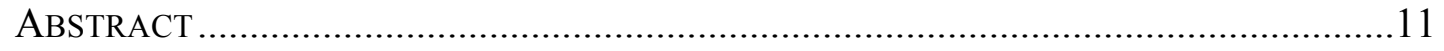

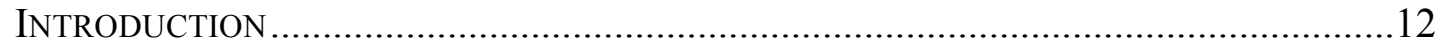

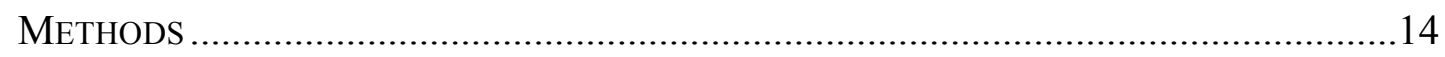

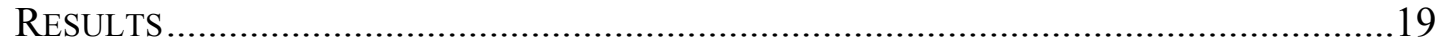

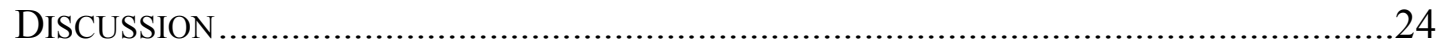

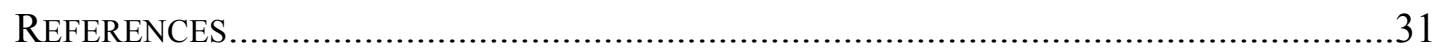

III. INTERACTIVE EFFECTS OF HERBIVORY AND SUBSTRATE ORIENTATION ON ALGAL COMMUNITY DYNAMICS ON A

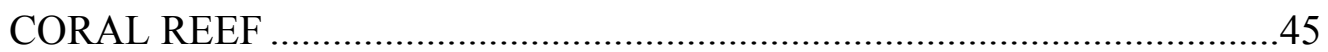

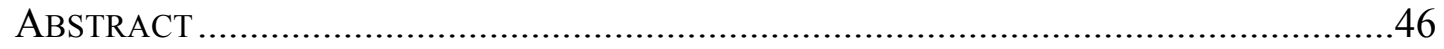

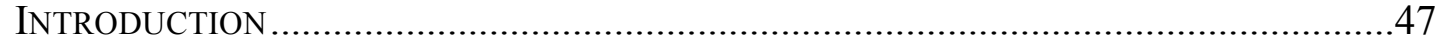

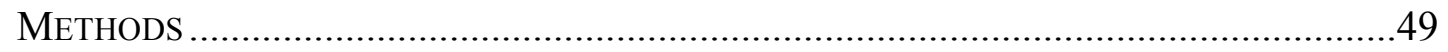

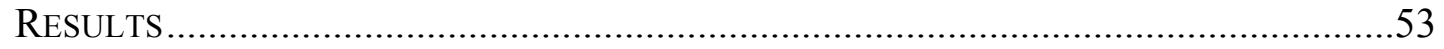

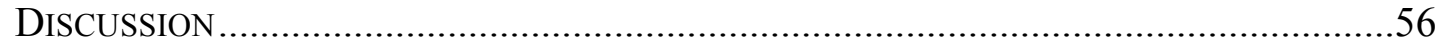

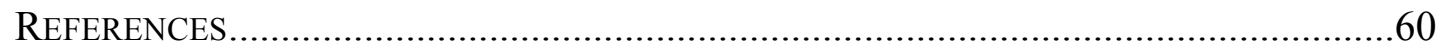

IV. SEDIMENT LOADING IMPEDES RECOVERY OF CORAL REEFS DESPITE HERBIVORE PROTECTION: THE CASE OF THE

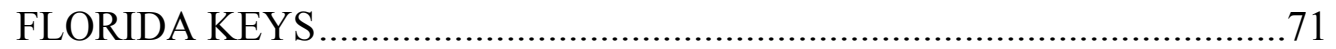

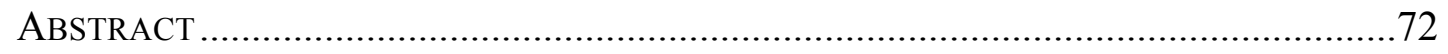

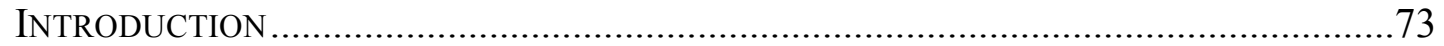




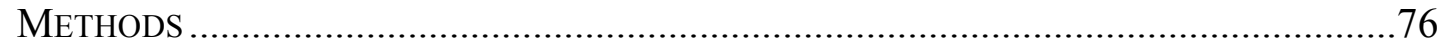

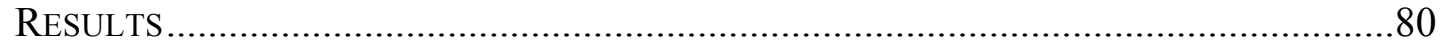

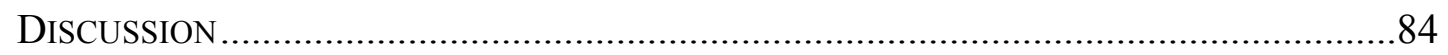

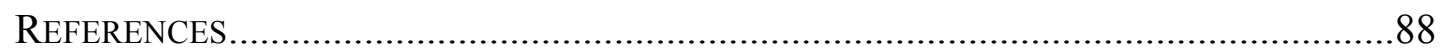

V. FISHING, POLLUTION, CLIMATE CHANGE, AND THE LONGTERM DECLINE OF CORAL REEFS OFF HAVANA, CUBA ...................100

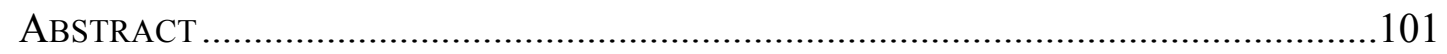

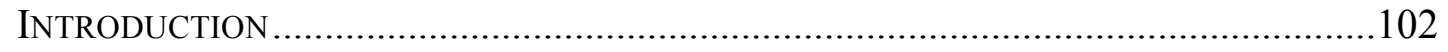

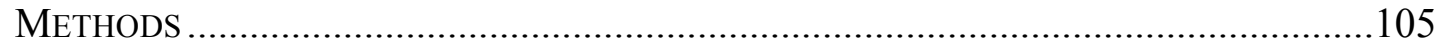

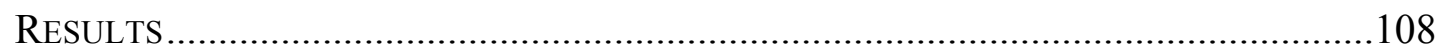

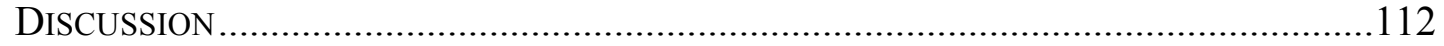

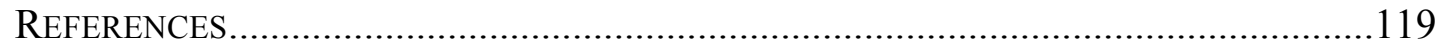

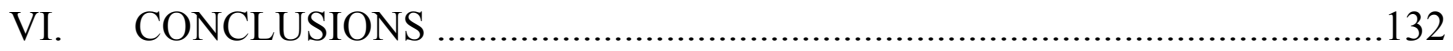

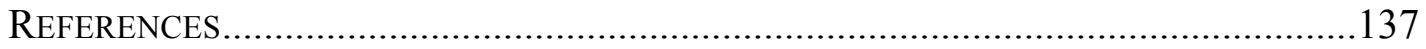

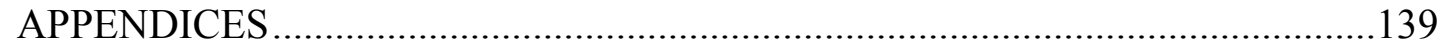

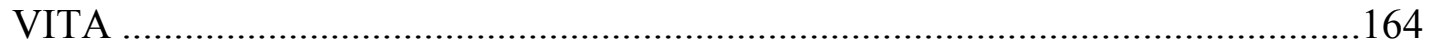




\section{LIST OF TABLES}

TABLE

PAGE

\section{CHAPTER II}

2.1 Results of Tukey post-hoc tests from analysis of fish communities, benthic communities and number of bites taken by foray

\section{APPENDIX A}

A1. Number of individuals by size class observed during the grazing rate surveys

A2. Number of individuals by size class surveyed during the fish feeding observations

\section{APPENDIX C}

C1. Average $( \pm \mathrm{SE})$ values of abiotic variables (slope, rugosity and sediment depth) and major benthic groups (sediment, turf, crustose coralline algae) by reef

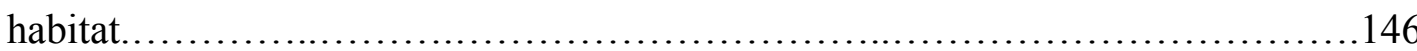

\section{APPENDIX D}

D1. List of data resources for temporal analysis (published, unpublished). The first four columns (Year, Month, Zone, Site and Habitat) indicate where and when the data (published or unpublished) of percent cover of coral, algae and sponge were collected. The farthest right column indicates the data source (list of data source references at the end).

D2. Frequency and intensity of bleaching events from 2003-2015 were obtained from the yearly coral bleaching technical report published by Dr. Pedro Alcolado (Alcolado 2003-2016) from the "Volunteer Monitoring Network of Early Coral

Reef Warning" (Red de monitoreo voluntario de alerta temprana de arrecifes coralinos) 
D3. Hurricane information, date, location and intensity, was extracted from the National Oceanographic and Atmospheric Administration

(https://coast.noaa.gov/hurricanes/) and the Cuban Weather Forecast

Department (Departamento de pronosticos, ISMET 2017). The " $x$ " indicates the province(s) where the Hurricane impacted 


\section{LIST OF FIGURES}

FIGURE

PAGE

\section{CHAPTER II}

2.1 Mean ( \pm SE) biomass (A) and density (B) of fish by trophic level across reef sites. Mean biomass(C) and density (D) of surgeonfishes species across reef sites. Statistical results from comparisons among sites using one-factor ANOVA. Significant results are highlighted in bold. See post-hoc test results in Table 2.1.

2.2 Mean abundance (percent cover) of benthic groups: Crustose (crustose algae), Dictyota (Dictyota spp.), Invertebrates (e.g. sponges, zoanthids), Stypopodium (Stypopodium zonale), TAS (turf associated with sediment), turf (turf forming algae), and calcareous (upright articulated calcareous algae) at each study site. Statistical results next to each benthic group indicate differences among sites using one-factor ANOVA. See post-hoc test results in Table 2.1. PERMANOVA result shows differences in community composition among study sites.

2.3 Mean $( \pm \mathrm{SE})$ grazing rate $(\mathrm{A})$ and the number of bites per foray (B) for $A$. tractus (open circles) and $A$. coeruleus (filled circles) across reef sites. Statistical results from a comparison between species and reef sites using a two-factor ANOVA. Significant results are highlighted in bold. See post-hoc test results in Table 2.1

2.4 Proportion of bites taken by surgeonfish species directly on benthic groups and on epiphytic algae across reef sites. Statistical values from PERMANOVA analysis contrasting the differences in diet composition between species and among reef sites.

2.5 Proportion of bites by size class for A. coeruleus (A) and A. tractus (B). Numbers on each bar indicates the sample size (number of bites). Statistical values calculated from logistic regression analysis for each surgeonfish separately testing whether the proportion of a given food item in the diet changes over the size range of the two species. Significant relationships are highlighted in bold. 
2.6 Chesson's selectivity index (SI) for different benthic taxa calculated for each surgeonfish species across reef sites. A. tractus (A-D), A. coeruleus (E-H). Dashed lines represent thresholds of selectivity calculated as $1 /$ number of available items $=0.14$. Values above this line suggest selection for these diet items while values below this line suggest avoidance of these diet items

\section{CHAPTER III}

3.1 Experimental design showing the dimensions of substrates in open (left) and exclosure (right) plots. Notice that each vertical substrate encompasses four $(10 \times 10 \mathrm{~cm})$ vertical walls that are the same area as horizontal substrates $(20 \times 20$ $\mathrm{cm}=400 \mathrm{~cm}^{2}$ ). Numbers indicate the dimensions in $\mathrm{cm} . \mathrm{N}=3$ for each open and exclosure plot

3.2 Grazing rates by herbivorous fishes obtained from videos recorded in open plots. Points represent the number of bites taken by (A) all species of herbivorous fishes, (B) Acanthurus spp., (C) Sparisoma spp., or (D) Scarus spp. Data are means \pm SE. Statistics are from Friedman tests 1.

3.3 Photographs of community composition on experimental substrates at the end of the year-long experiment: (A) Exclosure-Horizontal, (B) ExclosureVertical, (C) Open-Horizontal, and (D) Open-Vertical substrates. Photos were taken on $10 \times 10 \mathrm{~cm}$ section of the substrates

3.4 Abundance of different benthic groups through time in different treatments: horizontal substrates in exclosure plots (Exclosure-Horizontal), vertical substrates in exclosure plots (Exclosure-Vertical), horizontal substrates in open plots (Open-Horizontal) and vertical substrates in open plots (Open-Vertical). (A) crustose algae, (B) turf algae, (C) Dictyota spp., (D) articulated calcareous algae, (E) sediment and (F) turf associated with sediment (TAS). Data are means \pm SE. Statistics show significant effects from linear mixed models. See appendix for full model outputs

3.5 Trajectory of macroalgal community composition using non-metric multidimensional scaling (NMDS). The treatments represent: horizontal substrates in exclosure plots (Exclosure-Horizontal), vertical substrates in exclosure plots (Exclosure-Vertical), horizontal substrates in open plots (OpenHorizontal) and vertical substrates in open plots (Open-Vertical). Asterisk (*) represent the first time point after the benthic community developed (month 1) 
and pound symbol (\#) indicates the final time point. Statistics are results of

PERMANOVA. See appendix for full model outputs .70

\section{CHAPTER IV}

4.1 Study sites (A), graphical representation of the reef habitat within spur and groove formation, and $(\mathrm{C})$ proportion of habitats by study sites

4.2 Abundance of major taxa by reef habitat, groove (A), plain (B), flat spur top $(C)$, rugose spur top (D) and spur wall (E). The bars indicate average $( \pm S E)$. Non-Multidimensional Scaling Analysis (NMDS) contrasting reef habitats and sites (F). Statistics resulted from permutational analysis of variance (PERMANOVA)

4.3 Relationship between abundance of CCA (A) and turf (B) in relation to sediment depth. Panel C illustrates the relationship between the sediment depth and the length of turf algae found after removing the sediment layer. Points represent the average cover, the line indicates the linear relationship and shaded area the standard error. Statistics resulted from the Linear Mixed Model (LMM)

4.4 Relative influence of factors driving presence of juvenile $(\leq 4 \mathrm{~cm})$ (A) corals. Average ( \pm SE) density of juvenile corals as a function of sediment depth

4.5 Relative influence of factors driving presence of juvenile $(\leq 4 \mathrm{~cm})$ corals of the most abundant genera, Siderastrea (A), Agaricia (B) and Porites (C) .98

4.6 Relative influence of factors driving presence of adult ( $>4 \mathrm{~cm})$ (A) corals. Average $( \pm$ SE) density of adult corals as a function of sediment abundance

\section{CHAPTER V}

5.1 Study sites within each zone located at different distances from Havana, Cuba: Zone 0 (Havana) indicated by the circle, Zone 1, the closest to the city 
includes three study sites (Calle 16, Calle 30 and Santa Fe), Zone 2 includes sites at intermediate distances $(21-35 \mathrm{~km}$; Baracoa and Calderas) and Zone 3 the farthest away from the city with two sites (Henequen west and Bacuanayagua east)

5.2 Delta $\mathrm{N}^{15}$ (A) and nitrogen concentration (B) in Sargassum tissue samples by sites within each zone. Data are mean \pm SE. Probability values comes from ANOVA analysis among zones with bolded results distinguishing statistically significant values $(\mathrm{P}<0.05)$. Letters along the bottom indicate differences between zones based on Tukey HSD. Error bars of Delta $\mathrm{N}^{15}$ of Baracoa and Henequen are difficult to see because of small values

5.3 Average abundance of total and common algal taxa by site within each zone: (A) total algal (all species of algae), (B) Cyanobacteria, (C) Turf, (D) Dictyota spp., (E) Lobophora variegata, (F) Sargassum spp., (G) Jania spp., (H) Amphiroa spp. and (I) Halimeda spp. Data are mean \pm SE. Probability values comes from ANOVA with bold font indicating statistically significant values $(\mathrm{P}<0.05)$. Letters along the bottom indicate differences between zones based on Tukey HSD

5.4 Total abundance of corals (A) and density of juveniles $(<4 \mathrm{~cm}$ diameter) (B) by site within each zone. Data are mean \pm SE. Probability values comes from ANOVA with bold font indicating statistically significant values $(\mathrm{P}<$ $0.05)$. Letters along the bottom indicate differences between zones based on Tukey HSD

5.5 Biomass of fishes by trophic group by site within each zone: (A) Herbivores (e.g., parrotfish and surgeonfish); (B) Invertivores (e.g., grunts and wrasses); and (C) Piscivores (e.g., groupers, snappers and barracudas). Data are mean \pm SE. Probability values comes from ANOVA with bold font indicating statistically significant values $(\mathrm{P}<0.05)$. Letters along the bottom indicate differences between zones based on Tukey HSD

5.6 Macroalgal (A-D) and coral cover (E-H) by zone over time. Points represent average percent cover from individual sites taken from the literature and 
authors' unpublished data. Probability values indicates results of linear mixed effect model

\section{APPENDIX A}

A1. Photographic representation ( $5 \times 5 \mathrm{~cm}$ frame) of some common benthic groups quantified during surveys of benthic communities and fish feeding activities. A) crustose algae with arrows pointing to the turf algae growing on it (turf on crustose algae), B) different types of turf-forming algae (turf), C) turf algae associated with sediment (TAS), D) Dictyota spp., E) species of articulated calcareous algae, from left to right there is Galaxaura sp., Halimeda sp., Jania sp. and Amphiroa sp., and F) thallus of (likely old individual) of Stypopodium zonale with arrows indicating turf forming algae as epiphytes

A2. Average sediment depth at each reef site. Mean $( \pm \mathrm{SE})$. An analysis of variance (ANOVA) showed differences among all sites $\left(\mathrm{F}_{3,28}=6.60, p=0.002\right)$

A3. Boxplot distribution of sediment depth targeted (from fish bite) by surgeonfish species among among studied sites

A4. Boxplot distribution of turf height targeted (from fish bite) by surgeonfish species among studied sites

\section{APPENDIX B}

B1. Photographs of the two juvenile Porites spp. coral recruits found on vertical substrates. We found no recruits on horizontal substrates

\section{APPENDIX C}

C1. Relationship between abiotic variables. (A) Slope and rugosity, (B) slope and sediment depth, and (C) rugosity and sediment depth. Statistics indicates results of the linear mixed model. 
C2. Relationship between abundance sediment, turf, crustose coralline algae (CCA) and Dictyota with slope and rugosity of the substrate. Points represent the average cover, the line indicates the linear relationship and shaded area the standard error. Statistics resulted from the Linear Mixed Model (LMM) 148

C3. Density and community composition of of juvenile (A\&B) and adult corals $(\mathrm{C} \& \mathrm{D})$. Points represent average $( \pm \mathrm{SE})$

C4. Deviance plot resulted from boosted regression tree predicting relative influence of all studied factors on presence/absence of all juvenile corals. Mean deviance $=1.373$, mean residual deviance $=1.31$

C5. Deviance plot resulted from boosted regression tree predicting relative influence of all studied factors on presence/absence of Siderastrea juvenile corals. Mean deviance $=1.089$, mean residual deviance $=0.834$

C6. Deviance plot resulted from boosted regression tree predicting relative influence of all studied factors on presence/absence of Agaricia juvenile corals. Mean deviance $=1.024$, mean residual deviance $=0.778$.

C7. Deviance plot resulted from boosted regression tree predicting relative influence of all studied factors on presence/absence of Porites juvenile corals. Mean deviance $=1.001$, mean residual deviance $=0.908$

C8. Deviance plot resulted from boosted regression tree predicting relative influence of all studied factors on presence/absence of all adult corals. Mean deviance $=0.94$, mean residual deviance $=0.717$

\section{APPENDIX D}

D1. Relative abundance of brooder corals (gray) and broadcaster corals (black) across sites. Zone 1 (Calle 16, Calle 30 and Santa Fe), Zone 2 (Baracoa and Calderas) and Zone 3 (Henequen and Bacunayagua). 163 


\section{CHAPTER I}

INTRODUCTION 
Structure and dynamics of terrestrial and marine communities depend upon multiple factors and processes acting at multiple scales (Connell 1978, Levin 1992, Schneider 2001). For example, herbivory, water availability, seasonality, and fire frequency shape plant communities of terrestrial grazing ecosystems such as African savannas and North American grasslands (Douglas et al. 1998, Asner et al. 2009, Burkepile et al. 2013). Similarly, benthic communities of coral reefs, are controlled by herbivory (Carpenter 1986, Burkepile and Hay 2008), nutrient availability (Walsh 2011, Zaneveld et al. 2016), sedimentation (Rogers 1990, Goatley and Bellwood 2013) and structural complexity (Gratwicke and Speight 2005, Graham 2014, Brandl et al. 2016) that simultaneously can have a positive, negative or uncertain output on their structure (Harborne et al. 2016). The core of my dissertation is to elucidate how different levels of herbivory, structural complexity and sediment loading can influence benthic community dynamics on Caribbean coral reefs.

Foraging activity of herbivorous fishes strongly influences the dynamics of coral reef benthic communities (Lewis 1986, Smith et al. 2001, Walsh 2011). Field experiments excluding herbivores on coral reefs have resulted in a substantial increase of both biomass and density of some macroalgae species and consequently, changes in species composition at the community level (Lewis 1986, Miller et al. 1999, Burkepile and Hay 2009). In the Caribbean, herbivorous fishes such as parrotfishes (subfamily Scarinae) exhibit species-specific trophic niches that result in distinct ecological roles as controllers of algal communities (Adam et al. $2015 \mathrm{a}, \mathrm{b}$ ). However, the trophic niches of surgeonfishes (family Acanthuridae), the second most important group of Caribbean herbivorous fishes, has been less studied which limits our understanding of the overall 
ecological role of the guild of herbivorous fishes. The few studies addressing diet of surgeonfishes in the Caribbean (Randall 1967, Tilghman et al. 2001, Dromard et al. 2012) have showed inconsistencies in the diets of individual species, likely dependent on the methods used. Further, none of these works have taken into account possible intraspecific variation as a consequence of ontogenetic diet shift and food availability. Chapter II "Comparative analysis of resource-use by Caribbean surgeonfishes reveals distinct trophic niches" comprises a series of field observations to answer the following question: How does the trophic niche of Caribbean surgeonfishes vary within species, among species and in relation to reef composition? Our information helps complete our understanding of the whole range of trophic niches used by Caribbean herbivorous fishes and their impact on macroalgal communities.

The structural complexity of a coral reef, the physical structure constructed by reef-building organisms, provides multiple services to reef dwelling organisms that include shelter, food, and settlement substrates which explains its positive relationship with the diversity of reef organisms (Roberts and Ormond 1987, Idjadi and Edmunds 2006, Graham 2014). Structural complexity often depends on the spatial scale being considered including across reefs $(\mathrm{km})$, within reef habitats $(\mathrm{m})$ and at small scales $(\mathrm{cm})$. The different levels of complexity likely have different influence in reef organisms depending upon their size and ecological dependency on reef structures (Dahl 1973). While recruitment of small territorial fish such as damselfish (family Pomacentridae) are positively associated with structural complexity at small scales (Sale et al. 1994), abundance, feeding activity and community of large fish species (e.g., grunts and parrotfish) are influenced by complexity at large scales (e.g., reef-wide complexity) 
(Harbone et al. 2011, Catano et al. 2015, Newman et al. 2015). For example, abundance, grazing and feeding preferences of herbivorous fishes have been linked to reef structural complexity with species-specific variation apparently related to size and territory preferences (Choat and Bellwood, 1985, Gratwicke and Speight 2005, Verges et al. 2011). Surprisingly, less effort has been allocated to understanding the relationship between structural complexity and dynamics of benthic communities, particularly macroalgae (Graham and Nash 2013). In chapter III, we developed a field experiment to test the influence of small-scale structural complexity (depending on the vertical or horizontal orientation of the substrate) and herbivory on succession of algal communities. We predicted that substrate orientation at a small scale has stronger impact that herbivory on driving macroalgal communities. The information will further elucidate small scale factors affecting the recovery or loss of coral reefs.

By controlling macroalgae, herbivores play a fundamental role on coral reefs, freeing space for corals to settle and grow which enhances ecosystem resilience (Hughes et al. 2007). Thus, protecting herbivorous fishes has been one of the main conservation strategies used to facilitate resilience (Bellwood et al. 2004). However, despite years of effective protection of herbivorous fishes, coral reefs in the Florida Keys have failed to regain coral cover (Toth et al. 2014, van Woesik et al. 2014). In chapter IV "Sediment loading impedes recovery of coral reefs despite herbivore protection: The case of the Florida Keys" we performed an integrative analysis of herbivory, benthic composition and abiotic factors (e.g., habitat complexity and sediment) to investigate the potential factors compromising coral recovery of the Florida Keys reefs. We studied community structure across six spur and groove reefs, with distinct reef structural complexity, located 
in the upper section of the Florida Keys reef tract. We used data collected on herbivory, benthic community composition and physical variables (e.g., substrate slope, rugosity, sediment depth) to evaluate their role on the presence of juvenile and adult corals. The discoveries in this chapter provide new explanations to why coral cover in Florida Keys reefs remains low, which can have a direct practical application in conservation efforts (e.g., restoration and protective regulations) for the coral reefs Caribbean-wide.

Chapter V "Fishing, pollution, climate change, and the long-term decline of coral reefs off Havana, Cuba" was to our knowledge, the first integrative study of coral reefs conducted in Cuba and gives a geographic comparative site to test some of the general questions of my dissertation. We completed a series of field observations that included surveys of fish, benthic communities, and structural complexity as well as a compilation of historical data that allowed us to analyze past and present status of coral reefs around Havana. We analyzed temporal data of coral and algal abundance within their historical context (e.g., bleaching events, hurricane, fishing pressure) to elucidate the potential impacts of local and global stressors.

My dissertation was focused on how herbivory, habitat complexity, and sedimentation can shape the structure of coral reefs. We first completed our understanding of herbivore trophic niche, followed by experimentally examining the impact of herbivory and structural complexity at small scales. Later we looked at the role of both biotic and abiotic factors impacting juvenile and adult coral abundance across the reefs of South Florida. Finally, we were able to analyze current and historical factors impacting the ecology of a series of Cuban coral reefs where overfishing has led to low herbivory levels. Taken together, I demonstrated that herbivory is a context-dependent 
force driving the community composition of coral reefs, often modified by species-

specific traits, reef structural complexity, and abiotic forcing.

\section{REFERENCES}

Adam TC, Burkepile DE, Ruttenberg BI, Paddack MJ (2015b) Herbivory and the resilience of Caribbean coral reefs: knowledge gaps and implications for management. Mar Ecol Prog Ser 520:1-20

Adam TC, Kelley M, Ruttenberg BI, Burkepile DE (2015a) Resource partitioning along multiple niche axes drives functional diversity in parrotfishes on Caribbean coral reefs. Oecologia 175:173-1185

Asner GP, Levick SR, Kennedy-Bowdoin T, Knapp DE, Emerson R, Jacobson J, Colgan MS, Martin RE (2009) Large-scale impacts of herbivores on the structural diversity of African savannas. Proc Natl Aca Ssi 106:4947-4952

Bellwood DR, Hughes TP, Folke C, Nystrom (2004) Confronting the coral reef crisis. Nature 429:827-833

Brandl SJ, Bellwood DR (2016) Microtopography refuges shape consumer-producer dynamics by mediating consumer functional diversity. Oecologia 182:203-217

Burkepile DE, Burns CE, Tambling CJ, Amendola E, Buis GM, Govender N, Nelson V, Thompson DI, Zinn AD, Smith MD (2013) Habitat selection by large herbivores in a southern African savanna: the relative roles of bottom-up and top-down forces. Ecosphere 4:139. Doi.org/10.1890/ES13-00078.1

Burkepile DE, Hay ME (2008) Herbivore species richness and feeding complementary affect community structure and function on a coral reef. Proc Natl Acad Sci 105:16201-16206

Burkepile DE, Hay ME (2009) Nutrient versus herbivore control of macroalgal community development and coral growth on a Caribbean reef. Mar Ecol Prog Ser 389:71-84

Carpenter RC (1986) Partitioning herbivory and its effects on coral reef algal communities. Ecol Monogr 56:345-364

Catano LB, Gunn BK, Kelley MC, Burkepile DE (2015) Predation risk, resource quality, and reef structural complexity shape territoriality in a coral reef herbivore. PloS ONE. 10: e0118764. Doi:10.1371/journal.pone.0118764 
Choat JH, Bellwood DR (1985) The interactions amongst herbivorous fishes on a coral reef: influence of spatial variation. Mar Biol 89:221-234

Connell JH (1978) Diversity in tropical rain forest and coral reefs. Science 199:13021310

Dahl AL (1973) Surface area in ecological analysis: quantification of benthic coral-reef algae. Mar Biol 23:239-249

Douglas AF, McNaughton SJ, Tracy BF (1998) The ecology of the Earth's grazing ecosystems. BioScience 48:513-521

Dromard C, Bouchon-Navaro Y, Harmelin-Vivien M, Bouchon C (2012) Partitioning of trophic resources allows Multi-specific foraging groups of Acanthurid fishes (Guadalupe, Lesser Antilles). Proc 65th Gulf and Caribbean Fisheries Institute: 357-364

Goatley CHR, Bellwood DR (2013) Ecological consequences of sediment on high-energy coral reefs. PloS ONE 8:e77737. Doi.10.1371/journal.pone.0077737

Graham NAJ (2014) Habitat complexity: coral structural loss leads to fisheries declines. Curr Biol 24:360-361

Graham NAJ, Nash KL (2013) The influence of structural complexity in coral reef ecosystems. Coral reefs 32:315-326

Gratwicke B, Speight MR (2005) Effects of habitat complexity on Caribbean marine fish assemblages. Mar Ecol Prog Ser 292:301-310

Harborne AR, Mumby PJ, Ferrari R (2011) The effectiveness of different meso-scale rugosity metrics for predicting intra-habitat variation in coral-reef fish assemblages. Environ Biol Fishes 94:431-442

Harborne AR, Rogers A, Bozec Y-M, Mumby PJ (2016) Multiple stressors and the functioning of coral reefs. Annu Rev Mar Sci 9:5.1-5.24

Hughes TP, Rodrigues MJ, Bellwood DR, Ceccarelli D, Hoegh-Guldberg O, McCook L, Moltschaniwskyj N, Pratchett MS, Steneck RS, Willis B (2007) Phase shift, herbivory, and the resilience of coral reefs to climate change. Curr Biol 17:360365

Idjadi JA, Edmunds PJ (2006) Scleractinian corals as facilitators for other invertebrates on a Caribbean reef. Mar Ecol Prog Ser 319:117-127

Levin SA (1992) The problem of pattern and scale in Ecology. Ecology, 73:1943-1967 
Lewis SW (1986) The role of herbivorous fishes in the organization of a Caribbean reef community. Ecol Monogr 56:183-200

McNaughton SJ (1985) Ecology of a grazing ecosystem: The Serengeti. Ecol Monogr 55:260-294

Miller MW, Hay ME, Miller SL, Malone D, Sotka EE, Szmant AM (1999) Effects of nutrients versus herbivores on reef algae: a new method for manipulating nutrients on coral reefs. Limnol Oceanogr 44:1847-1861

Newman SP, Meesters EH, Dryden CS, Williams SM, Sanchez C, Mumby PJ, Polunin NVC (2015) Reef flattening effects on total richness and species responses in the Caribbean. J Anim Behav 84:1678-1989

Randall JE (1967) Food habits of reef fishes of the West Indies. Stud Trop Oceanogr $5: 665-847$

Roberts CM, Ormond RFG (1987) Habitat complexity and coral reef fish diversity and abundance on Red Sea fringing reefs. Mar Ecol Prog Ser 41:1-8

Rogers CS (1990) Responses of coral reefs and reef organisms to sedimentation. Mar Ecol Prog Ser 62:185-202

Sale PF (2004) Connectivity, recruitment variation, and the structure of reef fish communities. Integr Comp Biol 44:390-399

Schneider DC (2001). The rise of the concept of scale in ecology. BioScience 51:545-553

Tilghman GC, Klinger-Bowen R, Francis-Floyd R (2001) Feeding electivity indices in surgeonfish (Acanthuridae) of the Florida Keys. Aquarium Sciences and Conservation 3:215-223

Toth LT, van Woesik R, Murdoch TJT, Smith SR, Ogden JC, Precht WF, Aronson RB (2014) Do no-take reserves benefit Florida's corals? 14 years of changes and stasis in the Florida Keys National Marine Sanctuary. Coral Reefs 33:565-577

van Woesik R, Scott WJ, Aronson RB (2014) Lost opportunities: coral recruitment does not translate to reef recovery in the Florida Keys. Mar Pollut Bull 88:110-117

Verges A, Vanderklift MA, Doropoulos C, Hyndes GA (2011) Spatial patterns in herbivory on a Coral Reef are influenced by structural complexity but not algal traits. PLoS ONE. 6:e17115.Doi:10.1371/journal.pone.0017115

Walsh SM (2011) Ecosystem-scale effects of nutrients and fishing on coral reefs. J Mar Biol 187248.Doi.10.1155/2011/187248 
Zaneveld JR, Burkepile DE, Shantz AA, Pritchard CE, McMinds R, Payet JP, Welsh R, Correa AMS, Lemoine NP, Rosales S, Fuchs C, Maynard J, Vega-Thurber R (2016) Overfishing and nutrient pollution interact with temperature to disrupt coral reefs down to microbial scales. Nat. Commun 7:11833.Doi:10.1038/ncomms11833 
CHAPTER II

COMPARATIVE ANALYSIS OF RESOURCE-USE BY CARIBBEAN SURGEONFISHES REVEALS DISTINCT TROPHIC NICHES 
ABSTRACT

Feeding behavior of coral reef fishes often determines their species-specific ecological role. However, the diet choices of herbivorous fishes often vary depending on the foods available. We studied the two most common surgeonfishes (Acanthurus coeruleus and Acanthurus tractus) in the Caribbean to examine their species-specific feeding rates and diet preferences and how they differed with environmental context. We surveyed grazing activity and diet choice of both surgeonfishes at four spur and groove reefs in the Florida Keys, USA, that varied in fish abundance, rugosity, algal community composition, and sediment loading. Overall, A. tractus fed twice as fast as A. coeruleus. Both species selected for turf algae but avoided feeding on turf algae once they became laden with sediment. Selectivity for upright macroalgae was more complex with $A$. tractus targeting Dictyota spp. while A. coeruleus avoided Dictyota spp. relative to the alga's abundance. Both species selected for epiphytes growing on other organisms such as macroalgae, invertebrates, and crustose coralline algae. Some feeding preferences changed with fish size, as larger individuals of both species fed more frequently on sediment-laden algal turf and less frequently on Dictyota spp. compared to smaller sized individuals. Acanthurus tractus also increased its consumption of upright calcareous algae at larger sizes. Overall, the disparity in diet composition of surgeonfishes likely indicates subtle differences in species-specific ecological roles. Both $A$. coeruleus and $A$. tractus likely prevent turf algae from becoming large filaments and thus retard the succession of algal communities to later stages. Additionally, A. tractus may also help reduce macroalgal abundance by targeting common macroalgal species. 


\section{INTRODUCTION}

Herbivores can remove as much as $90 \%$ of the daily primary production on coral reefs, exerting significant control over algal communities (Carpenter 1986, Klumpp and Polunin 1989, Burkepile and Hay 2006). By controlling algae, herbivores indirectly regulate coral-algal competition (Lirman 2001, Jompa and McCook 2002, Burkepile and Hay 2009), often facilitating the recovery of corals after disturbances (Adam et al. 2011, Graham et al. 2015, Holbrook et al. 2016). In the Caribbean, parrotfishes (family Labridae, subfamily Scarinae after Westneat and Alfaro 2005) and surgeonfishes (Family Acanthuridae) are the most important herbivorous fishes structuring algal communities on coral reefs (Williams and Pollunin 2001). Their functional roles depend on speciesspecific feeding behaviors such as grazing rates and diet preferences (Burkepile and Hay 2010, Bonaldo et al. 2014, Adam et al. 2015a). Parrotfishes are abundant and diverse herbivores, stimulating a significant amount of research on the differences among species feeding modes, diet preferences, and their impact on Caribbean reefs (see reviews by Adam et al. 2015b, Burkepile et al. In press). However, surgeonfishes have received much less attention in the Caribbean, resulting in a knowledge gap about the feeding behavior and ecological role of common species (but see Tilghman et al. 2001, Dromard et al. 2012).

Surgeonfishes are one of the most common fish groups on Caribbean coral reefs, where they often represent over $25 \%$ of the total fish density and biomass (Kramer 2003, Robertson et al. 2005, Hernadez-Landa et al. 2015). The three species in the region, Acanthurus tractus, Acanthurus coeruleus and Acanthurus chirurgus are commonly seen forming schools that swim over the reef while feeding on benthic algae (Wolf 1987, 
Morgan and Kramer 2004). Similarities in their feeding behavior, as well as difficulties identifying their target food items, may have fostered the perception that all surgeonfishes in the Caribbean target similar food items and thus have a similar functional role. Yet, evidence from studies across the globe suggest that surgeonfishes generally have broad diets including many different types of macroalgae, filamentous algae, invertebrates, and detritus (Choat et al. 2002, Marshell and Mumby 2012, Kelly et al. 2016).

The limited work on Caribbean surgeonfishes suggests that they may have different diets (Randall 1967, Tilghman et al. 2001, Dromard et al. 2012) and therefore play distinct roles within the herbivore guild. Tilghman et al. (2001) used gut contents to show that both A. tractus and A. chirurgus preferred sediment and chlorophytes (green algae) while $A$. coeruleus selected rhodophytes (red algae) and chlorophytes but avoided sediment. In contrast, Dromard et al. (2012) used analyses of stomach contents and stable isotopes to place the three species at different trophic levels. A. coeruleus appeared to consume fleshy algae, turf, and invertebrates, $A$. tractus fed on unidentified matter and fleshy algae, and $A$. chirurgus showed a mixed diet with a noticeable high proportion of calcareous algae. Such variation in diet description might arise from the use of distinct methodologies and differing taxonomic resolution of diet items as well as different resource (food) availability across different research sites. Surprisingly, no work on interspecific differences in Caribbean surgeonfish diets to date has used behavioral observations of feeding in the field, which often reveal more cryptic differences among the niches of herbivore species than do other methods of assessing diet (e.g., Brandl and Bellwood 2014, Adam et al. 2015). 
Ontogenetic shifts in feeding behavior is common in herbivorous fishes. For instance, parrotfishes often feed primarily on filamentous turf algae when juveniles and switch to crustose coralline algae and larger macroalgae when adults (Lokrantz et al. 2008). In the case of surgeonfishes, ontogenetic changes in habitat use and feeding behavior may generate both intra- and interspecific differences in their functional roles. For example, small A. coeruleus are often most abundant on shallow back reefs and lagoons while large individuals are abundant on deepe fore reefs (Lawson et al. 1999, Hernandez-Landa et al. 2015). Furthermore, surgeonfishes' territory size often increases with size body (e.g., Bell and Kramer 2000) as does their probability of schooling (Wolf 1987) both of which may impact feeding behavior and diet.

Here, we addressed potential differences in diet niches within and between the two most common Caribbean surgeonfishes, A. coeruleus, and A. tractus, in the Florida Keys, USA. We focused our work on four spur and groove reefs with distinct levels of physical complexity and benthic composition and used in situ behavioral observations of surgeonfish feeding to quantify both feeding rates and species-specific diet preferences. We surveyed reef structural complexity (rugosity), benthic composition, and fish community composition to assess the context of intra and interspecific differences in feeding behavior. Our research aimed to answer the following questions: 1) Do the two species of surgeonfishes exhibit unique foraging behavior? 2) Do foraging behavior and feeding preferences vary intraspecifically with fish size? and 3) How do habitat complexity and benthic composition influence foraging behavior? 
METHODS

Study sites

The Florida Keys National Marine Sanctuary (FKNMS) encompasses a series of reefs in the Florida Keys where community structure of reef fishes differs across reefs within the sanctuary depending on protection status and reef type (Bohnsack et al. 1999). The study took place at two Sanctuary Preservation Areas (SPA) where fishing is completely prohibited and reef structural complexity is high [Molasses Reef $\left(80^{\circ} 22.374^{\prime}\right.$ W, $\left.25^{\circ} 00.646^{\prime} \mathrm{N}\right)$, French Reef $\left.\left(80^{\circ} 21.009^{\prime} \mathrm{W}, 25^{\circ} 02.026^{\prime} \mathrm{N}\right)\right]$ and two areas where fishing is allowed and reef structural complexity is low [Conch Reef $\left(80^{\circ} 27.230^{\prime} \mathrm{W}\right.$, $\left.24^{\circ} 57.695^{\prime} \mathrm{N}\right)$, Pickles Reef $\left.\left(80^{\circ} 24.964^{\prime} \mathrm{W}, 24^{\circ} 59.087^{\prime} \mathrm{N}\right)\right]$. We conducted our work at an average depth of 5-6 m from June-August 2016. Previous field observations have shown distinct differences in habitat complexity, benthic composition, and ecological processes (e.g., corallivory, herbivory) among Florida reefs (Paddack et al. 2006, Burkepile 2012, Catano et al. 2016).

\section{Fish community composition}

In order to examine how surgeonfish feeding may respond to the abundance of predators and competitors, we assessed how fish community structure varied across our sites. To quantify fish communities, we used visual censuses along 20 belt transects $(2 \mathrm{x}$ $30 \mathrm{~m}$ ) located haphazardly within each study site. All fishes were identified and their size estimated to the nearest $\mathrm{cm}$. Size estimates were converted to biomass for each fish using published length-weight relationships (Bohnsack and Harper 1988, Claro and Parenti 2001). Species were assigned to trophic groups following a modification from Claro and Parenti (2001). Herbivores were species that feed on algae, including parrotfishes, 
surgeonfishes and chubs (family Kyphosidae). Invertivores included species that mostly target benthic invertebrates, including grunts (family Haemulidae), snappers (family Lutjanidae) (except the cubera snapper [Lutjanus cyanopterus] which is a piscivore), wrasses (family Labridae), and other small species. Piscivores included fishes that usually prey on fish species and encompassed groupers (family Serranidae), barracudas (family Sphyraenidae), moray eels (family Muraenidae), and jacks (family Carangidae).

\section{Benthic community composition}

In order to address how feeding behavior of the surgeonfishes may change with benthic community composition and reef complexity, we characterized the benthic habitat at each site. We measured rugosity index (RI) as a proxy for structural complexity at each site using the chain method (Risk 1972) with a $5 \mathrm{~m}$ chain with $1.5 \mathrm{~cm}$ links $(n=80 /$ site $)$. We characterized benthic communities via $25(50 \times 50 \mathrm{~cm})$ photo-quadrats taken along $8(50 \mathrm{~m})$ transects at each study site $(\mathrm{n}=200$ photos/site). We used Coral Point Count (CPCe, Kohler and Gill 2006) to calculate abundance (percent cover) of each benthic taxon within each plot, using 25 points distributed in a randomly-stratified design. Benthic taxa were classified to the lowest taxonomic group possible, which was often genus for many algae. For algae that are difficult to identify in the field, we used two form-functional groups or categories: (1) "crustose" which included multiple genera of crustose coralline algae (CCA) and Peyssonnelia and (2) "turf" which encompassed the assemblage of short (generally $<1 \mathrm{~cm}$ ), filamentous algae with little to no sediment $(<2 \mathrm{~mm}$ thick sediment layer). In addition, we defined turf algae associated with sediment, hereafter "TAS", where longer (up to $\sim 3 \mathrm{~cm}$ ) filamentous algae were found holding a layer of sediment from $2 \mathrm{~mm}$ up to $\sim 20 \mathrm{~mm}$ thick (see Fig. A1 for pictures of 
the different benthic taxa classifications). We also measured the depth of the sediment layer within each plot (five random points per plot) using a pencil calibrated with $1 \mathrm{~mm}$ increments.

\section{Surgeonfish feeding behavior}

At each site, we selected random individuals across all sizes of both focal species of surgeonfishes to study their grazing rate [A. tractus, $\mathrm{n}=72$ (3-24 cm total length), $A$. coeruleus, $\mathrm{n}=83$ ( $3-25 \mathrm{~cm}$ total length), see table A1 for sample size details]. We first estimated total length while assessing whether the fish's behavior was impacted by the diver's presence. After showing no reaction to the diver's presence following 1 min of acclimation, we observed the fish to quantify grazing as the number of bites taken in ten minutes, including the number of bites taken per foray. A foray is defined as a discrete series of bites taken in the same area by an individual where bites are separated only by the time it takes to reapply the mouthparts to the substrate (Bellwood and Choat 1990).

We collected a second dataset on feeding behavior to focus on what the surgeonfishes were actually feeding on when they bit the benthos. We randomly selected individuals across all sizes $[$ A. coeruleus, $\mathrm{n}=361(1-28 \mathrm{~cm}, \mathrm{TL})$, A tractus, $\mathrm{n}=370(2-26$ $\mathrm{cm}, \mathrm{TL}$ ), see table A2 for sample size details] and identified the benthic group (as described above) the fish targeted on its third feeding foray. We also collected information about whether the fish fed on the target benthic group directly or on epiphytes on that benthic group (e.g., epiphytes on larger macroalgae such as Stypopodim zonale). For each foray, we also recorded substrate position [either vertical (slope $>45$ degree) or horizontal (slope $<45$ degree)] and substrate concavity (concave, convex or flat). If the focal individual targeted turf algae or TAS, we additionally measured the 
height of the turf $(\mathrm{mm})$ and thickness of the sediment layer $(\mathrm{mm})$ associated with the turf algae. All behavioral observations for grazing rates and feeding preferences were conducted throughout the day (10:00-17:00 hours) to minimize diurnal differences in feeding behavior that can be common in herbivorous fishes.

\section{Statistics}

Fish density and biomass, grazing rate (bites per minute), and bites per feeding foray were square root transformed to achieve normal distributions. We used one-factor ANOVA followed by post-hoc analysis (Tukey HSD test) to assess differences among reef sites for: (1) surgeonfish density and biomass, (2) density and biomass of different trophic groups, (3) reef rugosity, and (4) percent cover of different benthic taxa (except for abundance of Stypopodium that was compared using a Kruskall Wallis test because the data could not be normalized. In addition, we used the average percent cover of each benthic group within each transect to compare benthic community composition among reef sites using permutational analysis of variance (PERMANOVA).

Grazing rate (bites per minute) and bites per feeding foray were analyzed across sites and species using a two-factor ANOVA. To test for differences between species in whether bites differed relative to substrate orientation and concavity we used the Chisquare contingency test. Sediment depth and turf height at the location of fish bites were compared among species and sites using a two-factor ANOVA. The diet (proportion of feeding forays on target benthic groups) was compared between surgeonfish species across sites using PERMANOVA. We also used logistic regression to predict for each surgeonfish separately, the likelihood of consuming different benthic groups as a function of fish size. 
Ultimately, we wanted to understand how feeding preferences of the two species may change with different benthic communities. We used the data from benthic community surveys as a proxy of availability of each taxon $\left(\mathrm{p}_{\mathrm{i}}\right)$ and number of feeding forays as a proxy of its proportion in a diet of species $\left(\mathrm{r}_{\mathrm{i}}\right)$ to evaluate feeding preferences using Chesson's selectivity index $(\alpha)$ where $\alpha=\left(r_{i} / p_{i}\right) / \Sigma\left(r_{i} / p_{i}\right)$ (Chesson 1978). Chesson's index was chosen over other indices (e.g., Ivlev's selectivity index, Strauss index) because of its superiority for comparing among sites where the availability of food items varies (Lechowicz 1982). The index $(\alpha)$ varies between 0 to 1 with a selectivity threshold (neutral index) calculated as $1 /$ number of items, in our case $1 / 7=0.14$ (Chesson 1978). Values above this threshold indicate selection for these diet items while values below this threshold indicate avoidance of these diet items.

We performed all analyses using packages Vegan (Oksanen et al. 2017), doBy (Soren 2016), MASS (Venables and Ripley 2002), and ggplot2 (Wickham 2009) in R version, 3.2.2 (R Development Core Team 2016).

\section{RESULTS}

Fish community composition

Total fish biomass at Pickles Reef, Molasses Reef, and French Reef averaged over twice the fish biomass found at Conch Reef $\left(7926 \pm 1120 \mathrm{~g} 100 \mathrm{~m}^{2}\right)$ (one-factor ANOVA, Biomass, $\mathrm{F}_{3,76}=6.88, p<0.001$; Table 2.1). Herbivorous fishes (subfamily Scarinae and family Acanthuridae) encompassed approximately $65 \%$ of total fish biomass across all sites but varied among sites with Conch Reef having the lowest values $(6312 \pm 988 \mathrm{~g}$ $\left.100 \mathrm{~m}^{2}\right)$ while the other three reefs ranged from $10560( \pm 1584) \mathrm{g} 100 \mathrm{~m}^{2}$ to $14610 \pm 2062$ 
g $100 \mathrm{~m}^{2}$ (Fig. 2.1A, one-factor ANOVA, Biomass, $\mathrm{F}_{3,76}=4.12, p=0.009$; Table 2.1). Biomass of piscivorous fish (e.g., barracudas, groupers, and others) was 10 times higher

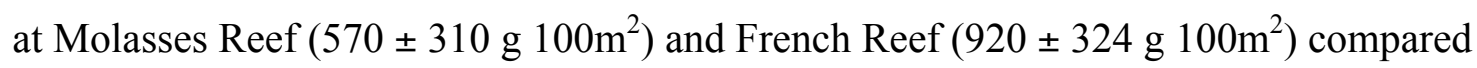
to Pickles Reef $\left(9 \pm 6\right.$ g $\left.100 \mathrm{~m}^{2}\right)$ and Conch Reef $\left(44 \pm 30\right.$ g 100m $\left.{ }^{2}\right)$ (Fig. 2.1A, onefactor ANOVA, $\mathrm{F}_{3,76}=6.79, p<0.001$; Table 2.1).

The total fish density at Conch Reef $\left(67 \pm 4\right.$ ind.100 $\left.\mathrm{m}^{-2}\right)$ was approximately half the total fish density found at the other three reefs (one-factor ANOVA, $\mathrm{F}_{3,76}=17.41, p<$ 0.001; Table 2.1). Density of herbivorous fish was also lowest at Conch Reef averaging $21 \pm 2$ ind $100 \mathrm{~m}^{-2}$ (Fig. 2.1B, one-factor ANOVA, $\mathrm{F}_{3,76}=3.50, p=0.019$; Table 2.1). Invertivorous fish (e.g. family Lutjanidae and family Haemulidae) encompassed around $50 \%$ of total fish density with higher values at Molasses Reef (Fig. 2.1B, one-factor ANOVA, $\mathrm{F}_{3,76}=7.60, p<0.001 ;$ Table 2.1).

Surgeonfish biomass accounted for approximately 11\% of herbivorous fish biomass across all sites. Acanthurus tractus had 2.5 times higher biomass and was twice as abundant as A. coeruleus across all sites (Fig. 2.1C\&D). No differences in density or biomass among reefs were detected for either species (Fig. 2.1C\&D, one-factor ANOVA, Biomass, A. tractus, $\mathrm{F}_{3,76}=0.94, \mathrm{P}=0.428$, A. coeruleus, $\mathrm{F}_{3,76}=2.23, p=0.091$, Density, A. tractus, $\mathrm{F}_{3,76}=1.58, p=0.201$, A. coeruleus, $\mathrm{F}_{3,76}=0.36, p=0.782$; Table 2.1). A. chirurgus was practically absent from these reefs $\left(<0.1\right.$ ind. $\left.100 \mathrm{~m}^{-2}\right)$ and thus not included in the study of feeding behavior.

Benthic community composition

Rugosity at both Conch Reef $(1.17 \pm 0.01)$ and Pickles Reef $(1.15 \pm 0.01)$ was significantly lower than at both Molasses Reef $(1.34 \pm 0.02)$ and French Reef $(1.33 \pm$ 
0.03) (one-factor ANOVA, $\mathrm{F}_{3,28}=13.85, p<0.001$; Table 2.1). Conch Reef and Pickles Reef were dominated by TAS ( $>50 \%$ cover) (Fig. 2.2) with Conch having the thickest sediment layer with depths over $7 \mathrm{~mm}$ (one factor ANOVA, $\mathrm{F}_{3,28}=6.60, p=0.002$, Table 2.1). Dictyota spp. ( $>35 \%$ cover) was most the abundant algae at French Reef compared to other three reefs (Fig. 2.2, one-factor ANOVA, Dictyota, $\mathrm{F}_{3,28}=14.81, p<0.001$; Table 2.1) while crustose algae, invertebrates (e.g. gorgonians, sponges) and turf were also more abundant at both Molasses Reef and French Reef (Fig 2.2, one-factor ANOVA, crustose algae, $\mathrm{F}_{3,28}=15.05, p<0.001$, invertebrates, $\mathrm{F}_{3,28}=13.17, p<0.001$, turf, $\mathrm{F}_{3,28}=$ $32.38, p<0.001$ ). Cover of upright articulated calcareous algae (e.g., Amphiroa, Jania, Galaxaura and Halimeda) was very low $(<0.3 \%)$ across all sites while Stypopodium was only present at Conch Reef (Fig. 2.2, one-factor ANOVA, upright articulated algae, $\mathrm{F}_{3,28}$ $=2.71, p=0.064$, Stypopodium, $\left.\mathrm{X}^{2}=21.39, p<0.001\right)$. As a result, benthic community composition differed among reef sites where French Reef and Molasses Reef appear more similar compared to Conch Reef and Pickles Reefs (PERMANOVA, $\mathrm{F}_{3,28}=37.23$, $p=0.010)$.

Surgeonfish feeding behavior

Acanthurus tractus $\left(38.8 \pm 1.7\right.$ bites $\left.\mathrm{min}^{-1}\right)$ fed twice as fast as A. coeruleus (19.6 \pm 1.0 bites $\mathrm{min}^{-1}$ ) regardless of site (Fig. 2.3A, two-factor ANOVA, site, $\mathrm{F}_{3,147}=1.86, p=$ 0.138 , species, $\mathrm{F}_{1,147}=68.51, p<0.001$, site:species, $\left.\mathrm{F}_{3,147}=0.32, p=0.809\right)$. The average number of bites taken during each foray by $A$. tractus was almost double those of A. coeruleus (Fig. 2.3B, two-factor ANOVA, species, $\mathrm{F}_{1,147}=70.21, p<0.001$ ). However, both surgeonfishes took significantly fewer bites per foray at reefs with higher 
complexity (Molasses and French) (Fig. 2.3B, two-factor ANOVA, site, $\mathrm{F}_{3,147}=6.85, p<$ 0.001, site:species, $\mathrm{F}_{3,147}=0.76, p=0.516$; Table 2.1).

The two surgeonfishes fed off of substrates with similar orientation as approximately $60 \%$ of the forays taken by both species were on horizontal substrates $(\mathrm{n}=$ $\left.715, \mathrm{X}^{2}=0.71, p=0.401\right)$. The shape of the substrates was also similar with more than $65 \%$ of bites on flat substrates, rather than convex or concave substrates $\left(n=715, X^{2}=\right.$ $1.64, p=0.440)$. For bites targeting turf algae, we did not detect differences in turf height (two-factor ANOVA, species, $\mathrm{F}_{1,175}=0.05, p=0.823$, site:species, $\mathrm{F}_{3,175}=0.20, p=$ 0.894,) or sediment depth (two-factor ANOVA, species, $\mathrm{F}_{1,175}=0.54, p=0.464$, site:species, $\left.\mathrm{F}_{3,175}=0.43, p=0.728\right)$ between species or site (appendix A).

Surgeonfishes directly consumed Dictyota spp., turf, and TAS with these groups consistently combining to represent over $50 \%$ of their bites (Fig. 2.4). They also targeted epiphytes (e.g., short filamentous turf algae including Polysiphonia spp., Ceramiun spp., Digenea sp.) living on crustose algae (denoted as 'turf on crustose'), invertebrates (e.g., gorgonians, sponges), and Stypopodium zonale (See appendix A for pictures of epiphytes and other taxa). We also observed that $A$. coeruleus periodically directly consumed gorgonians ( $\mathrm{n}=4$ fishes) and sponges ( $\mathrm{n}=1$ fish) rather than the epiphytes on these animals. Upright articulated calcareous algae represented a small portion of the diet of both species.

The two species of surgeonfishes differed in their distribution of feeding forays with $A$. coeruleus appearing to focus more on turf and turf on crustose algae while $A$. tractus fed more on Dictyota spp. (Fig. 2.4A\&B, PERMANOVA, species, $\mathrm{F}_{1,7}=7.15, p$ $=0.010)$. The distribution of feeding forays across the benthic groups also differed across 
sites (Fig. 2.4A\&B, PERMANOVA, site, $\mathrm{F}_{3,7}=4.96, p=0.010$ ). For example, the proportion of bites on turf on crustose was over five times greater at higher relief reefs (Molasses and French) whereas bites on TAS were noticeably higher at reefs with low relief (Conch and Pickles).

When we assessed feeding patterns across the size range of fishes, we found that while turf and turf on crustose seem to be similarly eaten across the different size classes, TAS was more frequently consumed by large fishes (Fig. 2.5, LRM, turf, A. tractus, $p=$ 0.149, A. coeruleus, $p=0.870$, turf on crustose, $A$. tractus, $p=0.658$, A. coeruleus, $p=$ 0.401 , TAS, $A$. tractus, $p<0.001, A$. coeruleus, $p<0.001)$ In contrast, Dictyota spp. was eaten less frequently by large individuals of each species (Fig. 2.5, LRM, Dictyota spp., A. tractus, $p<0.001$, A. coeruleus, $p=0.003)$. Furthermore, A. coeruleus and A. tractus showed approximately 50\% higher chance of feeding on invertebrates and upright articulated algae, respectively, with increasing size, although there were few bites on both diet items (Fig. 2.5).

Evaluating patterns in their selectivity showed that generally both surgeonfishes preferentially fed on turf while avoiding TAS (Fig. 2.6). Acanthurus tractus often selected for Dictyota spp. and fed on Stypopodium in proportion to its abundance (at the only site it was present), with fish targeting the epiphytes on the Stypopodium thallus rather than the macroalga itself (Fig. 2.6). Acanthurus coeruleus fed on Dictyota spp. but much less frequently than expected based on its abundance. Both species tended to select for crustose algae, likely consuming the filamentous algae growing on the crustose rather than the crustose algae itself. Both species tended to switch from turf to turf on crustose as the later resource became more available at Molasses and French Reefs (Fig. 2.6). 
Upright articulated algae (e.g., Amphiroa spp., Jania spp.) was preferably consumed by both species but at different sites (Fig. 2.6).

\section{DISCUSSION}

The ecological role of herbivorous fishes on coral reefs varies among groups (e.g., grazers vs. browsers) but also within these groups as some closely related species often have very different diets (Burkepile and Hay 2011, Adam et al. 2015b, Kelly et al. 2016). Although different species of herbivores often target different substrate types (Bruggeman et al. 1994, Brandl and Bellwood 2014), we did not see differences between these two surgeonfishes when evaluating the turf height, sediment depth, substrate concavity, or orientation of substrate where they were feeding. However, there were both similarities and differences between the two species when considering the selection of diet items. Acanthurus tractus fed frequently on the brown macroalga Dictyota spp., whereas A. coeruleus fed on Dictyota spp. less frequently and instead had a stronger selection for filamentous turf algae growing on crustose algae. Furthermore, both surgeonfishes fed frequently on epiphytes of macroalgae rather than the actual algal thallus (e.g., Stypopodium zonale, turf on crustose algae). We also showed that feeding preferences change over ontogeny with larger individuals of both species feeding more frequently on TAS and less frequently on macroalgae such as Dictyota spp.

The grazing rate of $A$. tractus was double that of $A$. coeruleus. While the two species do not have obvious morphological differences in their jaws which would influence feeding rates, these differences may be related to anatomical and morphological differences of their digestive system that lead to differential digestion capabilities and gut 
turnover times, which could limit feeding rate (Lobel 1981). For example, in large terrestrial herbivores, those with foregut fermentation, known as ruminants (e.g., deer, wildebeest, giraffe), have higher gut retention time and are more efficient in extracting nutrients from their diet. As a result, ruminants have lower intake rates compared to hindgut fermenters such as horses, elephants, and rhinoceros that have higher intake rates and faster gut passage times but are less efficient at extracting nutrients from their food (Hume 1989). While A. coeruleus has a long thin-walled digestive tract capable of digesting algae using acidic stomach secretions, $A$. tractus has a sand-filled, muscular gizzard-like stomach that breaks down algae via trituration (Tilghman et al. 2001). These differences in the digestive system might influence retention time of diet items and the nutrient uptake capabilities. Acanthurus coeruleus may need to allow its diet to have more contact time with acidic stomach secretions to efficiently extract nutrients, similar to terrestrial foregut fermenters. Yet, $A$. tractus likely requires a higher gut turnover as a result of a less efficient method of processing its food, akin to terrestrial hindgut fermenters.

Surprisingly, we found greater numbers of bites per foray at low relief reefs (Conch Reef and Pickles Reefs) than high relief reefs (French Reefs and Molasses Reefs) for both surgeonfish species. There could be a number of reasons for differences in the number of bites per foray between the reef types, such as the different diet items present on the different reef types may require different handling times which could alter the length of forays. The higher relief reefs tended to also have higher biomass of herbivorous fishes, which could have increased competition for food. More competitive interactions with other herbivorous fishes may have resulted in less time foraging and 
shorter feeding forays (Catano et al. 2014). This difference could also be the result of differences in predation risk between sites and more time devoted to vigilance at high relief reefs which had more predators. More time spent being vigilant would likely mean shorter feeding forays. Structural complexity frequently mediates the impact of predation risk on foraging behavior in herbivorous fishes (Verges et al. 2011, Catano et al. 2015). Even in the presence of the same level of predation risk, herbivorous fishes are more vigilant and consume less in high rugosity areas while feeding more in low rugosity areas (Catano et al. 2016). Thus, a host of factors could have influenced the different patterns in feeding rates we saw between high and low relief reefs.

Similar to previous studies (e.g., Tilghman et al. 2001), we found that both surgeonfish species targeted certain benthic groups such as filamentous turf algae and certain upright macroalgae. At our study sites, filamentous turfs were composed of multiple species of usually short $(<1 \mathrm{~cm})$, red filamentous algae (phylum Rhodophyta) such as Polysiphonia spp. Ceramium spp. and Hypnea spp. These taxa can be easily consumed by herbivorous fish with small mouths and dentition adapted to crop the tips of filamentous and thin branching algae (Choat et al. 2004). Indeed, previous studies that analyzed diet of surgeonfishes in detail (Randall 1967) have reported over 30 algal taxa comprising the diet of both species, of which over $30 \%$ are taxa commonly classified as turf-forming algae (Connell et al. 2014). Other studies have also shown the preference of surgeonfishes for feeding on turf-forming algae (Francini-Filho et al. 2010, Dromard et al. 2012, Kelly et al. 2016).

However, our data showed that once the turf assemblages become associated with sediment that gets entangled within algal branches, both surgeonfish species strongly 
avoided it. Indeed, less than $20 \%$ of all bites by $A$. coeruleus and $A$. tractus were taken on substrates with over $2 \mathrm{~mm}$ sediment depth. The phenomenon has been previously described for herbivorous fishes that display reduced feeding after sediments accumulate in turf algal communities (Bellwood and Fulton 2008, Goatley and Bellwood 2012, Clausing et al. 2014). Yet, others report significant amounts of sediment in the gut of $A$. tractus (Tilghman et al. 2001, Dromard et al. 2012). The sediment could be the result of accidental consumption when consuming turf algae. Alternately, A. tractus could ingest sediment that is used as a tool during mechanical digestion within their muscular gizzardlike stomach (Lobel 1981) rather than targeting sediment as a source of nutrition. It is not surprising that $A$. coeruleus avoids sediment on these reefs as the heavily calcium carbonate-based sediments in the Florida Keys (Lidz and Hallock 2000) could possibly impair their chemically-mediated digestive mechanism. Yet, sediment content is likely an important factor mediating these preferences (Goatley and Bellwood 2010) as Gordon et al. (2016) showed that parrotfishes fed less when grain size was large (mostly carbonate sediment) and organic content was low. Interestingly, we observed that smaller fish avoided TAS to a greater degree than larger fish, possibly because smaller individuals have more difficulty processing sediments. Regardless, sediments clearly make turf algae unpalatable to all size classes of surgeonfish, and more work is needed to understand sediment consumption in surgeonfishes in relation to variables such as species identity, fish size, sediment loading rates, sediment grain size, and the level of organic matter within the sediments.

Marine macroalgae often have multiple mechanisms of defenses such as calcification (precipitation of $\mathrm{CaCO}_{3}$ ) that toughens algal tissues and production of 
secondary metabolites that deter feeding by herbivorous fishes (Schupp and Paul 1994, Pereira and da Gama 2008). Our results show that surgeonfishes, particularly larger individuals, do consume some articulated calcified algae (e.g., Amphiroa spp., Jania spp., Galaxura spp.), which is surprising given that previous work suggested surgeonfishes avoid calcified algae (Schupp and Paul 1994, Burkepile and Hay 2008). While one might assume that the fishes are consuming the epiphytes off of the upright articulated corallines, we often see these algal species in the guts of these fishes (personal observation), suggesting they are, in fact, consuming these algae. Larger mouths and stronger jaws in adult individuals, compared to smaller individuals and juveniles, may facilitate the consumption of articulated calcareous algae. Further, these fishes may be focusing on young thalli of these algae which may be less calcified than the larger thalli that are often used in studies showing these species are unpalatable to surgeonfishes (e.g., Schupp et al. 1994, Burkepile and Hay 2008). However, a potential bias in our method is that small individuals of articulated calcareous algae can be difficult to observe in $50 \times 50$ $\mathrm{cm}$ photographs. The bias could have led to us underestimating their abundance, which could have resulted in an inflated selectivity index. However, the fact that we did observe surgeonfishes eating these algae and the fact that we frequently observe these algae in their guts shows that they do include them in their diets, even if they do not select for them as strongly as our data suggests.

In contrast to calcification, chemical defenses may be less effective against surgeonfish species (Schupp and Paul 1994, Hay 1997). For instance, Pennings et al. (1996) found that surgeonfishes preferred to feed on chemically-rich algae relative to calcified algae while parrotfishes avoided chemically rich algae in favor of calcified 
algae. However, we saw differences between the two surgeonfish species in how they responded to the chemically-defended brown algae Dictyota spp. Acanthurus tractus commonly fed on Dictyota spp., as other studies have shown (Burkepile and Hay 2008), while $A$. coeruleus ate Dictyota spp. but much less frequently. It is possible that $A$. coeruleus is more susceptible to algal chemical defenses as its digestion is chemicallymediated (acidic digestion, Lobel 1981) and chemical defenses could impair digestive mechanisms necessitating reduced inclusion in the diet. However, for both species, smaller individuals were more likely to feed on Dictyota spp. than larger individuals, the opposite pattern than for upright articulated corallines, further suggesting ontogenetic changes in feeding preferences of these fishes. Thus, these surgeonfishes' relationship to algal defenses are complex and may be dependent on fish identity, fish size, type of algal defense, digestive the nutritional value of the alga, and maturity of the alga (Duffy and Paul 1992, Cronin and Hay 1996).

Some authors have proposed that some species of nominal herbivorous fishes (surgeonfishes and parrotfishes) might be microphages that scrape the bottom looking for microorganisms living in the endolithic spaces of the seafloor (Clements et al. 2009, 2016). Although our two surgeonfish species clearly ingested larger algae such as Dictyota spp., they likely are also targeting cyanobacteria and microalgae given that they were clearly often feeding on the epiphytes growing on larger macroalgae and benthic invertebrates. To our surprise, we also observed that $A$. coeruleus took bites directly from gorgonians and sponges themselves, not merely on the epiphytes on these animals, although these bites constituted less than $2 \%$ of their diets. Indeed, other authors have reported that surgeonfishes sometimes consumes animal material, but its proportion is 
small relative to the algal material (Randall 1967, Dromard et al. 2012). The pattern appears similar to some herbivorous parrotfishes, which can take up to $8 \%$ of their bites off of live corals (Francini-Filho et al. 2008), possibly as an alternative source of nutrients (Rotjan and Lewis 2006).

Defining the ecological niche of herbivorous fishes is key for determining whether different species play unique functional roles (e.g., control different taxa of algae) or whether they are functionally redundant (Burkepile and Hay 2008, Fox and Bellwood 2013, Brandl and Bellwood 2014). Resource partitioning seems to be common among Pacific and Caribbean parrotfishes that display distinct diet preferences, feeding modes, and habitat preferences (Bellwood and Choat 1990, Bonaldo et al. 2014, Adam et al. 2015b, Burkepile et al. In press). Indo-Pacific surgeonfishes also appear to have specialized either their morphology or habitat use in order to reduce niche overlap (Brandl et al. 2015) leading to significant niche partitioning in diet (Kelly et al. 2016). Both of our studied species targeted mostly turf algae showing a high degree of resource use overlap. Yet, they differed in the location of turf algae with A. coeruleus often consuming turf growing on crustose algae while A. tractus consumed turf off of other substrates, suggesting subtle niche partitioning in the location of feeding despite targeting a similar resource. The feeding off on turf communities is also likely more complex than we could resolve given that turf communities are species diverse (Connell et al. 2014). It is quite possible that the two species are partitioning the turf community along axes that we did not resolve here.

The differences in diet we observed mean that the two species may have different impacts on benthic communities. Both species appear important for maintaining turf 
communities in early successional states. By targeting turf on crustose, A. coeruleus may be important for facilitating the growth of CCA, species of which are important for cementing together reef structure (Littler and Littler 2013) and facilitating coral settlement (Arnold and Steneck 2011). In contrast, A. tractus may be more important for removing larger macroalgae from reefs given its preferences for Dictyota spp. Overall, our results indicate that while Caribbean surgeonfishes in the Florida Keys do display a relatively high overlap of food resources they show some subtle niche partitioning that may translate into functionally complementarity roles within the herbivore guild.

\section{ACKNOWLEDGEMENTS}

This work was supported in part by a grant from a State Wildlife Grant from the Florida Fish and Wildlife Conservation Commission. We thank Dr. Alastair Harborne for his comments on our work. We wish to thank the FIU Marine Macroalgae Research lab and the Burkepile Lab at UCSB for their support throughout this work. Also, we appreciate the hard work of undergraduate volunteers in the field. This work was conducted under a permit from the Florida Keys National Marine Sanctuary \#2014-083A1. This is contribution \#x from the Center for Coastal Oceans Research in the Institute for Water and Environment at Florida International University.

\section{REFERENCES}

Adam TC, Schmitt RJ, Holbrook SJ, Brooks AJ, Edmunds PJ, Carpenter RC, Bernardi G (2011) Herbivory, connectivity, and ecosystem resilience: response of a coral reef to a large-scale perturbation. PLoS ONE 6:e23717.

Doi.10.1371/journal.pone.0023717 
Adam TC, Kelley M, Ruttenberg BI, Burkepile DE (2015a) Resource partitioning along multiple niche axes drives functional diversity in parrotfishes on Caribbean coral reefs. Oecologia 175:173-1185

Adam TC, Burkepile DE, Ruttenberg BI, Paddack MJ (2015b) Herbivory and the resilience of Caribbean coral reefs: knowledge gaps and implications for management. Mar Ecol Prog Ser 520:1-20

Arnold SN, Steneck RS (2011) Settling into an increasingly hostile world: The rapidly closing "recruitment window" for corals. PloS ONE 6:e28681.

Doi:10.1371/journal.pone.0028681

Bell T, Kramer DK (2000) Territoriality and habitat use by juvenile blue tangs, Acanthurus coeruleus. Environ Biol Fish 58:401-409

Bellwood DR, Fulton CJ (2008) Sediment-mediated suppression of herbivory on coral reefs: decreasing resilience to rising sea levels and climate change? Limnol Oceanogr 53:2695-2701

Bellwood DR, Choat JH (1990) A functional analysis of grazing in parrotfishes (Family Scaridae): the ecological implications. Environ Biol Fishes 28:189-214

Bohnsack JA, et al. (1999) Baseline data for evaluation reef fish populations in the Florida Keys, 1979-1998. NOAA Technical Memorandum NMFS-SEFSC-427

Bohnsack JA, Harper DE (1988) Length-weight relationships of selected marine reef fishes from southeastern United States and the Caribbean. NOAA Tech. Mem. NMFS-SEFC-215

Bonaldo RM, Hoey AS, Bellwood DR (2014) The ecosystem roles of parrotfishes on tropical reefs. Oceanogr Mar Biol Annu Rev 46:25-63

Brandl SJ, Bellwood DR (2014) Individual-based analyses reveal limited functional overlap in a coral reef fish community. J Anim Ecol 83:661-670

Brandl SJ, Robbins WD, Bellwood DR (2015) Exploring the nature of ecological specialization in a coral reef fish community: morphology, diet and foraging microhabitat use. Proc R Soc B 282:20151147.Doi.10.1098/rspb.2015.1147

Bruggemann JH, Kuyper MWM, Breeman AM (1994) Comparative analysis of foraging and habitat use by the sympatric Caribbean parrotfish Scarus vetula and Sparisoma viride (Scaridae). Mar Ecol Prog Ser 112:51-66

Burkepile DE (2012) Context-dependent corallivory by parrotfishes in a Caribbean reef ecosystem. Coral Reefs 31:111-120 
Burkepile DE, Hay ME (2006) Herbivore VS nutrient control of marine primary producers: context-dependent effects. Ecology 87:3128-3139

Burkepile DE, Hay ME (2008) Herbivore species richness and feeding complementarity affect community structure and function on a coral reef. Proc Natl Acad Sci USA 105:16201-16206

Burkepile DE, Hay ME (2009) Nutrient versus herbivore control of macroalgal community development and coral growth on a Caribbean reef. Mar Ecol Prog Ser 389:71-84

Burkepile DE, Hay ME (2010) Impact of herbivore identity on algal succession and coral growth on a Caribbean Reef. PLoS ONE 5:e8963.

Doi.10.1371/journal.pone.0008963

Burkepile DE, Hay ME (2011) Feeding complementarity versus redundancy among herbivorous fishes on a Caribbean reef. Coral Reefs 30:351-362

Burkepile DE, Rasher D, Adam T, Hoey A, Hay ME (In Press) Functional variation among parrotfishes: are they complementary or redundant? In: Hoey A, Bonaldo R (eds). The Biology and Ecology of Parrotfishes.

Carpenter RC (1986) Partitioning herbivory and its effects on coral reef algal communities. Ecol Monogr 56:345-364

Catano LB, Shantz AA, Burkepile DE (2014) Predation risk, competition, and territorial damselfishes as drivers of herbivore foraging on Caribbean coral reefs. Mar Ecol Prog Ser 511:193-207

Catano LB, Gunn BK, Kelley MC, Burkepile DE (2015) Predation risk, resource quality, and reef structural complexity shape territoriality in a coral reef herbivore. PLoS ONE 10: e0118764.Doi.10.1371/journal.pone.0118764

Catano LB, Rojas MC, Malossi RJ, Peters JR, Heithaus MR, Fourqrean JW, Burkepile DE (2016) Reefscapes of fear: predation risk and reef heterogeneity interact to shape herbivore foraging behavior. J Anim Ecol 1-11.Doi.10.1111/13652656.12440

Chesson J (1978) Measuring preference in selective predation. Ecology 59:211-215

Choat JH, Clements KD, Robbins WD (2002) The trophic status of herbivorous fishes on coral reefs. I. Dietary analyses. Mar Biol 140:613-624 
Choat JH, Robbins WD, Clements KD (2004) The trophic status of herbivorous fishes on coral reefs. Mar Biol 145:445-454

Claro R, Parenti L (2001) The marine ichthyofauna of Cuba. In: R. Claro, K. C. Lindeman and L. R. Parenti (eds) Ecology of the marine fishes of Cuba. Smithsonian Institution Press, Washington and London: pp 21-57

Clausing RJ, Annunziata C, Baker G, Lee C, Bittick SJ, Fong P (2014) Effects of sediment depth on algal turf height are mediated by interactions with fish herbivory on a fringing reef. Mar Ecol Prog Ser 517:121-129

Clements KD, Raubenheimer D, Choat JH (2009) Nutritional ecology of marine herbivorous fishes: ten years on. Functional Ecology 23:79-92

Clements KD, German DP, Piche J, Tribollet A, Choat JH (2016) Integrating ecological roles and trophic diversification on coral reefs: multiple lines of evidence identify parrotfishes as microphages. Biol J Linn Soc.Doi.10.1111/bij.12914

Connell SD, Foster MS, Airoldi L (2014) What are algal turf? Towards a better description of turfs. Mar Ecol Prog Ser 495:299-307

Cronin G, Hay ME (1996) Within-plant variation in seaweed palatability and chemical defenses: optimal defense theory versus the growth-differentiation balance hypothesis. Oecologia 105:361-368

Dromard C, Bouchon-Navaro Y, Harmelin-Vivien M, Bouchon C (2012) Partitioning of trophic resources allows Multi-specific foraging groups of Acanthurid fishes (Guadalupe, Lesser Antilles). Proc 65th Gulf and Caribbean Fisheries Institute: 357-364

Duffy JE, Paul VJ (1992) Prey nutritional quality and the effectiveness of chemical defenses against tropical reef fishes. Oecologia 90:333-339

Francini-Filho RB, Moura RL, Ferreira CM, Coni EOC (2008) Live coral predation by parrotfishes (Perciformes: Scaridae) in the Abrolhos Bank, eastern Brazil, with comments on the classification of species into functional groups. Neotrop Ichthyol 6:191-200

Francini-Filho RB, Moitinho C, Oliveira E, Coni C, Leao de Moura R, Kaufman L (2010) Foraging activity of roving herbivorous reef fish (Acanthuridae and Scaridae) in eastern Brazil: influences of resource availability and interference competition. J Mar Biol Assoc UK 90:481-492 
Fox RJ, Bellwood DR (2013) Niche partitioning of feeding microhabitats produces a unique function for herbivorous rabbitfishes (Perciformes, Siganidae) on coral reefs. Coral Reefs 32:13-23

Graham NA, Jennings S, McNeil MA, Mouillot D, Wilson SK (2015) Predicting climatedriven regime shifts versus rebound potential in coral reefs. Nature 518:94-97

Goatley CHR, Bellwood DR (2010) Biologically mediated sediment fluxes on coral reefs: sediment removal and of-reef transportation by the surgeonfish Ctenochaetus striatus. Mar Ecol Prog Ser 415:237-245

Goatley CHR, Bellwood DR (2012) Sediment suppresses herbivory across a coral reef depth gradient. Biol Lett 8:1016-1018

Gordon SE, Goatley CHR, Bellwood DR (2016) Low-quality sediments deter grazing by the parrotfish Scarus rivulatus on inner-shelf reefs. Coral Reefs 35:285-291

Hay ME (1997) The ecology and evolution of seaweed-herbivore interactions on coral reefs. Coral Reefs 16:67-76

Hernandez-Landa RC, Acosta-Gonzalez G, Nuñes-Lara E, Arias-Gonzalez (2015) Spatial distribution of surgeonfish and parrotfish in the north sector of the Mesoamerican Barrier Reef System. Mar Ecol 36:432-446

Holbrook SJ, Schmitt RJ, Adam TC, Brooks AJ (2016) Coral reef resilience, tipping points and the strength of herbivory. Sci Rep 6: 35817

Hume ID (1989) Optimal digestive strategies in mammalian herbivores. Physiol Zool 62:1145-1163

Jompa J, McCook LJ (2002) The effects of nutrients and herbivory on competition between a hard coral (Porites cylindrica) and a brown alga (Lobophora variegata). Limnol Oceanogr 47:527-534

Kelly ELA, Eynaud Y, Clements SM, Gleason M, Sparks RT, Williams ID, Smith JE (2016) Investigating functional redundancy versus complementary in Hawaiian herbivorous coral reef fishes. Oecologia 182:1151-1163

Klumpp DM, Polunin NVC (1989) Partitioning among grazers of food resources within damselfish territories on a coral reef. J Exp Mar Biol Ecol 125:145-169

Kohler KE, Gill SM (2006) Coral point count with Excel extensions (CPCe): A visual basic program for the determination of coral and substrate coverage using random point count methodology. Comput Geosci 32:1259-1269 
Kramer PA (2003) Synthesis of coral reef health indicators for the western Atlantic: Results of the AGGRA program (1997-2000). Atoll Res Bull 496:1-58

Lawson GL, Kramer D1, Hunte W (1999) Size-related habitat use and schooling behavior in two species of surgeonfish (Acanthurus bahianus and A. coeruleus) on a fringing reef in Barbados, West Indies. Environ Biol Fishes 54:19-33

Lechowicz MJ (1982) The sampling characteristics of electivity indices. Oecologia $52: 22-30$

Lidz BH, Hallock P (2000) Sedimentary petrology of a declining reef ecosystem, Florida Reef Track (U.S.A). J Coast Res 16:675-697

Littler MM, Littler DS (2013) The nature of crustose coralline algae and their interactions on reefs. Smithson Contrib Mar Sci 39:199-212

Lirman D (2001) Competition between macroalgae and corals: effects of herbivore exclusion and increased algal biomass on coral survivorship and growth. Coral Reefs 19:392-399

Lobel PS (1981) Trophic biology of herbivorous reef fishes: alimentary $\mathrm{pH}$ and digestive capabilities. J Fish Biol 19:365-397

Lokrantz J, Nystrim M, Thyresson M, Johansson C (2008) The non-linear relationship between body size and function in parrotfishes. Coral Reefs 27:967-974

Marshell A, Mumby PJ (2012) Revisiting the functional roles of the surgeonfish Acanthurus nigrofuscus and Ctenochaetus striatus. Coral Reefs.Doi 10.1007/s00338-012-0931-y

Morgan IE, Kramer DL (2004) The social organization of adult blue tangs, Acanthurus coeruleus, on a fringing reef, Barbados, West Indies. Environ. Biol. Fishes 71:261-273

Oksanen J, Blanchet FG, Friendly M, Kindt R, Legendre P, McGlinn D, Minchin PR, O'Hara RB, Simpson GL, Solymos P, et al. 2017. Community ecology package. https://cran.r-project.org, https://github.com/vegandevs/vegan

Paddack MJ, Cowen RK, Sponaugle S (2006) Grazing pressure of herbivorous coral reef fishes on low coral-cover reefs. Coral Reefs 25:461-472

Pennings SC, Puglisi MP, Pitlik TJ, Himaya AC, Paul VJ (1996) Effects of secondary metabolites and $\mathrm{Ca} \mathrm{CO}_{3}$ on feeding by surgeonfishes and parrotfishes: withinplant comparisons. Mar Ecol Prog Ser 134:49-58 
Pereira RC, da Gama BAP (2008) Macroalgal chemical defenses and their roles in structuring tropical marine communities. In Amsler CD (ed.) Algal Chemical Ecology Springer-Verlag Berlin Heidelberg, pp 25-53

R Core Team (2016) R: A language and environment for statistical computing. R Foundation for Statistical Computing, Vienna, Austria. ISBN 3-900051-07-0, URL http://www.R-project.org/

Randall JE (1967) Food habits of reef fishes of the West Indies. Stud Trop Oceanogr 5:665-847

Rotjan RD, Lewis SM (2006) Parrotfish abundance and selective corallivory on a Belizean coral reef. J Exp Mar Biol Ecol 335:292-301

Risk MJ (1972) Fish diversity on a coral reef in the Virgen Island. Atoll Res Bull 153:1-5

Robertson DR, Choat JH, Posada JM, Pitt J, Ackerman JL (2005) Ocean surgeonfish Acanthurus bahianus. II. Fishing effects on longevity, size, and abundance? Mar Ecol Pro Ser 295:245-256

Schupp PJ, Paul VJ (1994) Calcium carbonate and secondary metabolites in Tropical seaweeds: Variable effects on herbivorous fishes. Ecology 75:1172-1185

Soren H (2016) Grouping statistics, LS means, Linear contrasts, utilities. http://people.math.aau.dk/ sorenh/software/doBy/

Tilghman GC, Klinger-Bowen R, Francis-Floyd R (2001) Feeding electivity indices in surgeonfish (Acanthuridae) of the Florida Keys. Aquarium Sciences and Conservation 3:215-223

Venables WN, Ripley BD (2002) Modern Applied Statistics with S. Fourth Edition. Springer, New York. ISBN 0-387-95457-0

Verges A, Vanderklift MA, Doropoulos C, Hyndes GA (2011) Spatial patterns in herbivory on a coral reef are influenced by structural complexity but not by algal traits. PLoS ONE 6: e17115.Doi:10.1371/journal.pone.0017115

Wickham H (2009) Ggplot2: Elegant graphics for data analysis. Springer-Verlag New York

Wolf NG (1987) Schooling tendency and foraging benefit in the ocean surgeonfish. Behav Ecol Sociobiol 21:59-63

Williams I, Polunin NVC (2001) Large-scale associations between macroalgal cover and grazer biomass on mid-depth reefs in the Caribbean. Coral Reefs 19:358-366 
Table 2.1 Results of Tukey post-hoc tests from analysis of fish communities, benthic communities and number of bites taken by foray.

\begin{tabular}{|c|c|c|c|c|c|c|}
\hline Variable & $\begin{array}{l}\text { Conch } \\
\text { Reef }\end{array}$ & $\begin{array}{l}\text { Pickles } \\
\text { Reef }\end{array}$ & $\begin{array}{l}\text { Molasses } \\
\text { Reef }\end{array}$ & $\begin{array}{l}\text { French } \\
\text { Reef }\end{array}$ & $\mathbf{F}$ & $\mathbf{P}$ \\
\hline Total fish biomass & A & B & $\mathrm{B}$ & $\mathrm{B}$ & 6.88 & $<0.001$ \\
\hline $\begin{array}{c}\text { Herbivorous fish } \\
\text { biomass }\end{array}$ & A & B & B & $\mathrm{B}$ & 4.13 & 0.009 \\
\hline $\begin{array}{l}\text { Invertivorous fish } \\
\text { biomass }\end{array}$ & A & $\mathrm{AB}$ & $\mathrm{AB}$ & B & 3.89 & 0.012 \\
\hline $\begin{array}{c}\text { Piscivorous fish } \\
\text { biomass }\end{array}$ & A & A & $\mathrm{AB}$ & B & 6.79 & $<0.001$ \\
\hline Total fish density & A & B & B & $\mathrm{B}$ & 17.41 & $<0.001$ \\
\hline $\begin{array}{c}\text { Herbivorous fish } \\
\text { density }\end{array}$ & A & $\mathrm{AB}$ & B & B & 3.50 & 0.019 \\
\hline $\begin{array}{l}\text { Invertivorous fish } \\
\text { density }\end{array}$ & A & B & B & $\mathrm{AB}$ & 7.60 & $<0.001$ \\
\hline $\begin{array}{c}\text { Piscivorous fish } \\
\text { density }\end{array}$ & A & A & $\mathrm{AB}$ & B & 6.33 & $<0.001$ \\
\hline Rugosity & A & A & $\mathrm{B}$ & $\mathrm{B}$ & 13.86 & $<0.001$ \\
\hline TAS abundance & A & A & $\mathrm{B}$ & $\mathrm{C}$ & 74.29 & $<0.001$ \\
\hline $\begin{array}{c}\text { Dictyota } \\
\text { abundance }\end{array}$ & A & $\mathrm{AB}$ & B & $\mathrm{C}$ & 14.81 & $<0.001$ \\
\hline $\begin{array}{c}\text { Crustose } \\
\text { abundance }\end{array}$ & A & $\mathrm{AB}$ & B & $\mathrm{C}$ & 15.05 & $<0.001$ \\
\hline $\begin{array}{l}\text { Invertebrate } \\
\text { abundance }\end{array}$ & A & A & B & B & 13.17 & $<0.001$ \\
\hline Turf abundance & A & A & B & $\mathrm{C}$ & 32.38 & $<0.001$ \\
\hline Fish bite per foray & A & $\mathrm{AB}$ & B & $\mathrm{B}$ & 70.21 & $<0.001$ \\
\hline
\end{tabular}


Figure 2.1 Mean $( \pm$ SE) biomass $(A)$ and density $(B)$ of fish by trophic level across reef sites. Mean biomass (C) and density (D) of surgeonfishes species across reef sites.

Statistical results from comparisons among sites using one-factor ANOVA. Significant results are highlighted in bold. See post-hoc test results in Table 2.1.

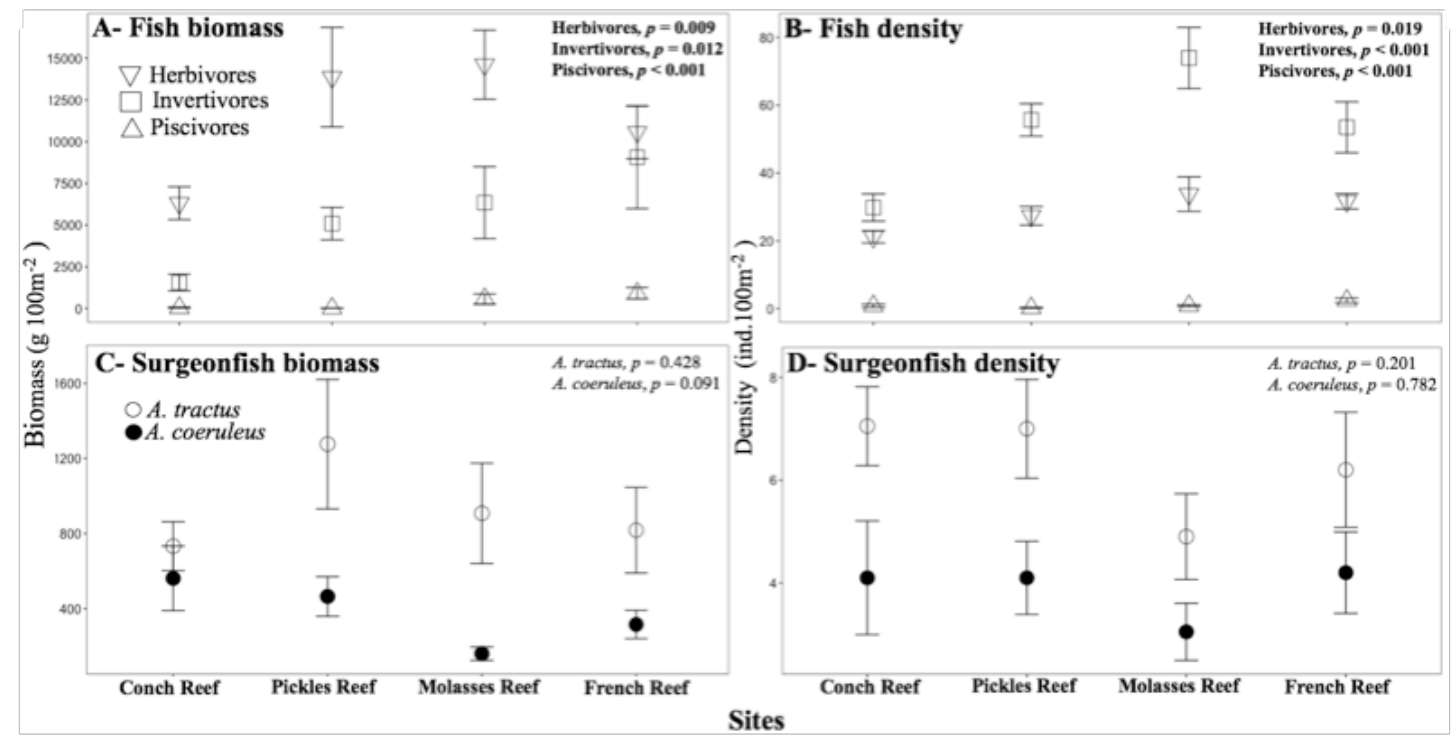


Figure 2.2 Mean abundance (percent cover) of benthic groups: Crustose (crustose algae), Dictyota (Dictyota spp.), Invertebrates (e.g. sponges, zoanthids), Stypopodium

(Stypopodium zonale), TAS (turf associated with sediment), turf (turf forming algae), and calcareous (upright articulated calcareous algae) at each study site. Statistical results next to each benthic group indicate differences among sites using one-factor ANOVA. See post-hoc test results in Table 2.1. PERMANOVA result shows differences in community composition among study sites.

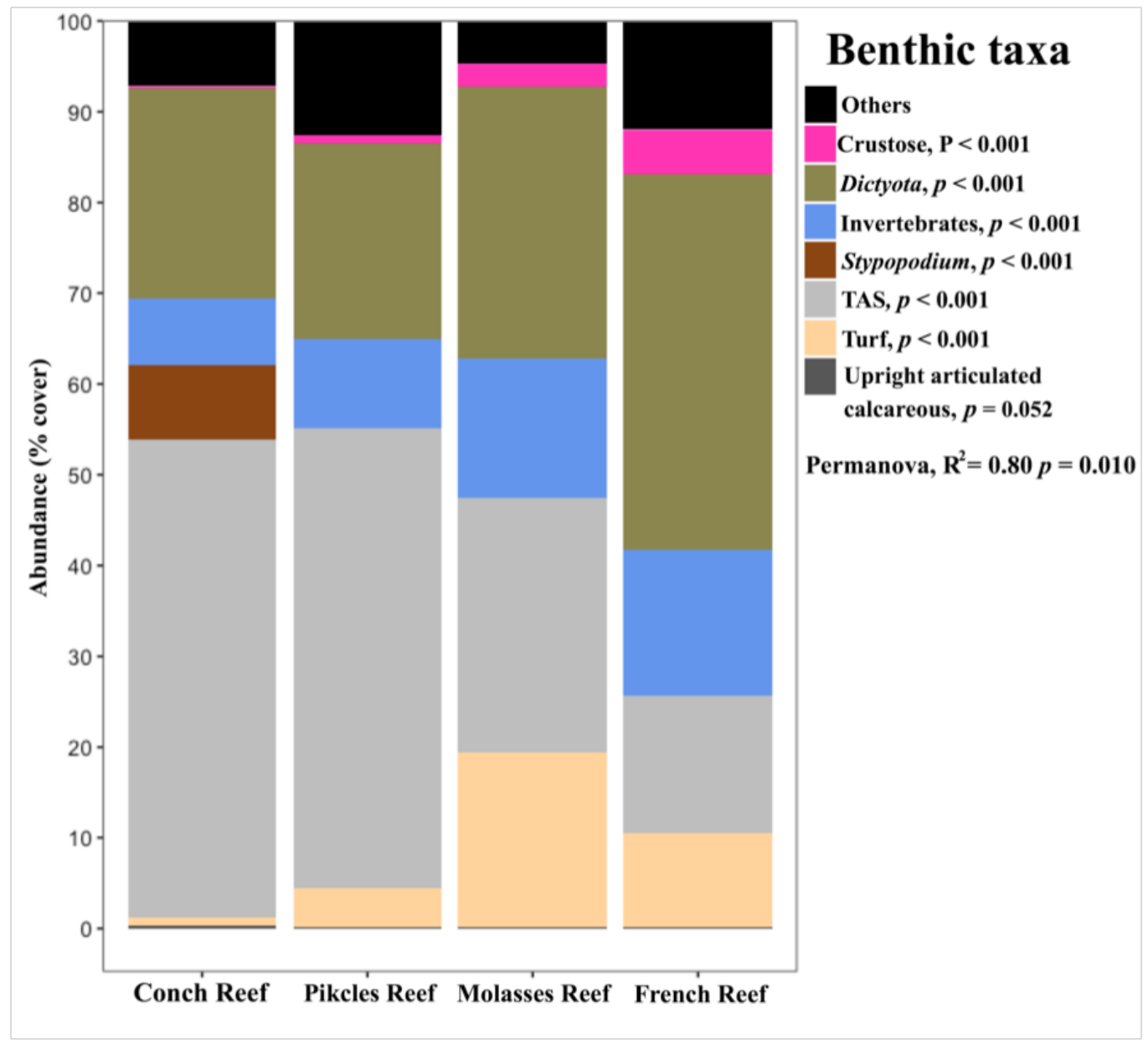


Figure 2.3 Mean $( \pm \mathrm{SE})$ grazing rate $(\mathrm{A})$ and the number of bites per foray $(\mathrm{B})$ for $A$. tractus (open circles) and $A$. coeruleus (filled circles) across reef sites. Statistical results from a comparison between species and reef sites using a two-factor ANOVA. Significant results are highlighted in bold. See post-hoc test results in Table 2.1.

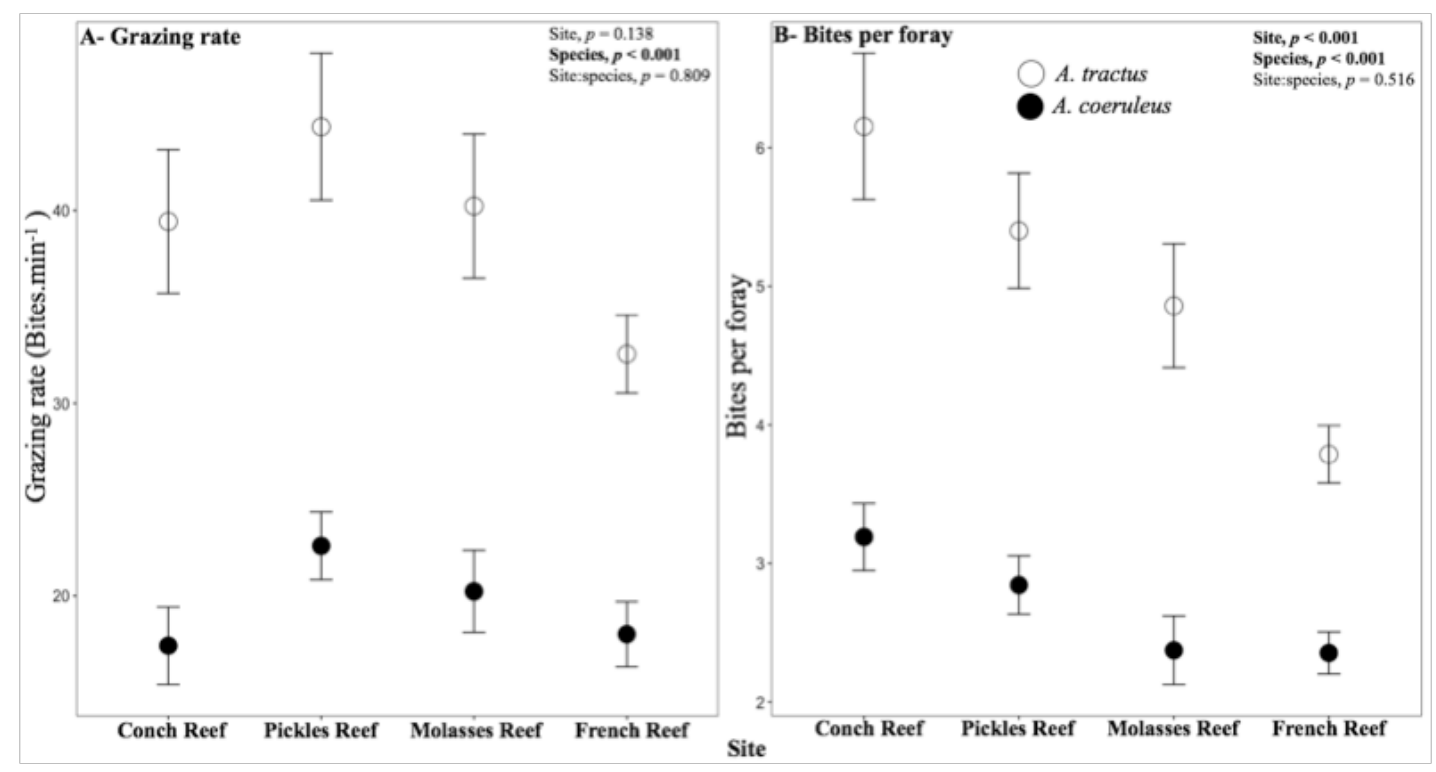


Figure 2.4 Proportion of bites taken by surgeonfish species directly on benthic groups and on epiphytic algae across reef sites. Statistical values from PERMANOVA analysis contrasting the differences in diet composition between species and among reef sites.

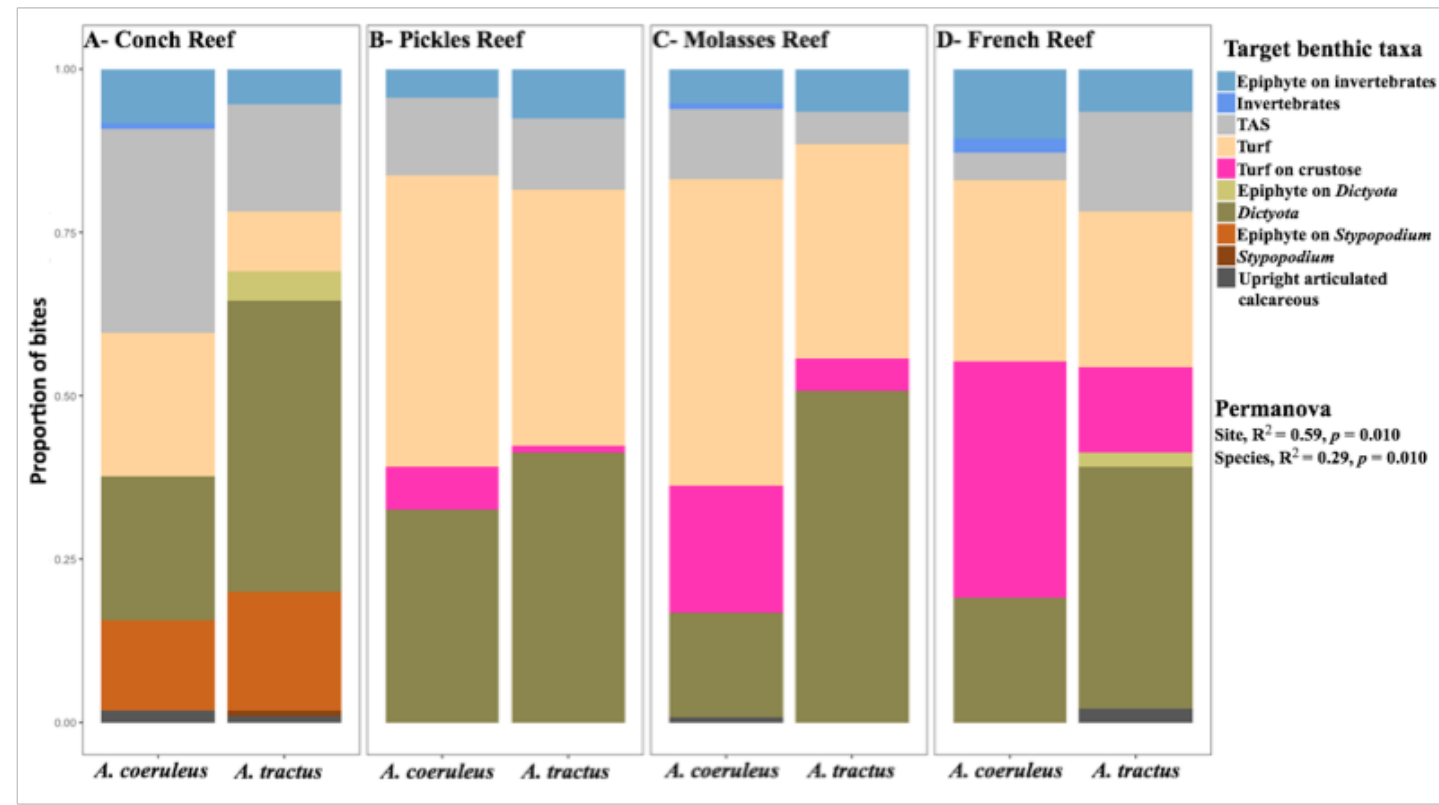


Figure 2.5 Proportion of bites by size class for A. coeruleus (A) and A. tractus (B). Numbers on each bar indicates the sample size (number of bites). Statistical values calculated from logistic regression analysis for each surgeonfish separately testing whether the proportion of a given food item in the diet changes over the size range of the two species. Significant relationships are highlighted in bold.

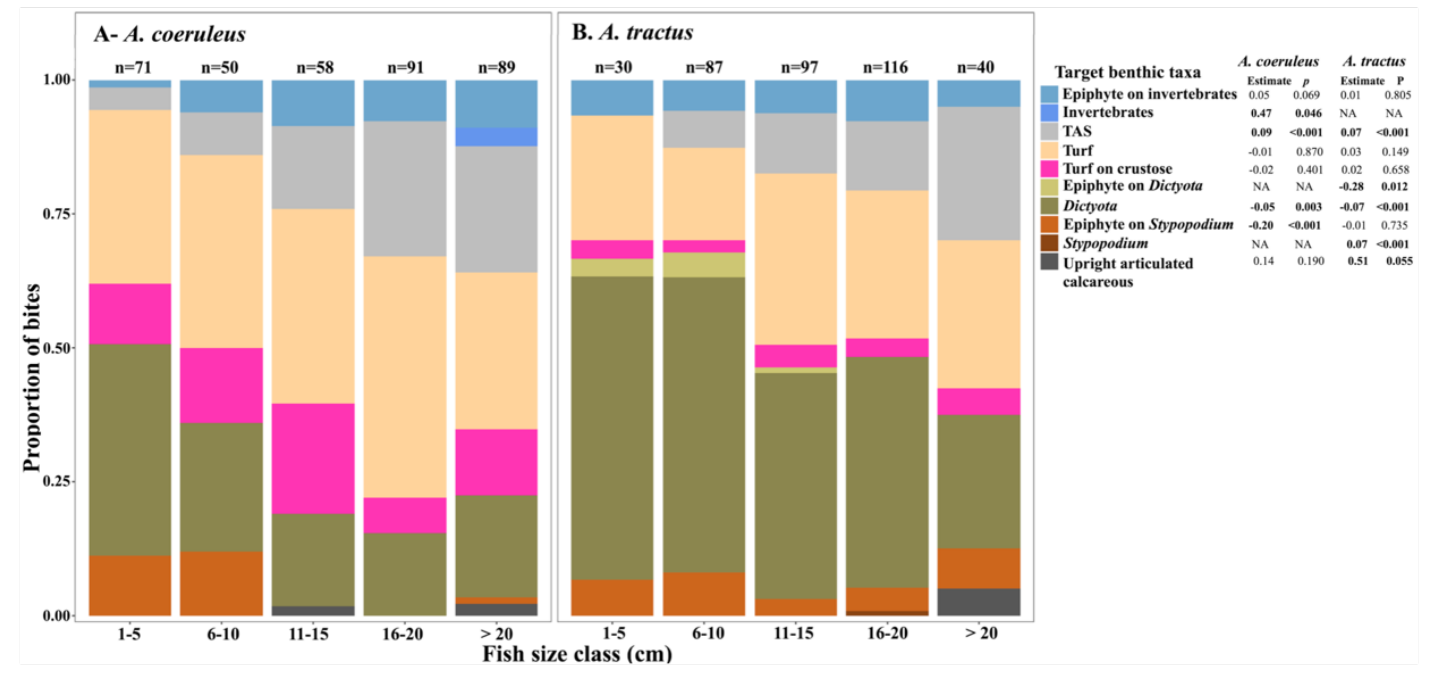


Figure 2.6 Chesson's selectivity index (SI) for different benthic taxa calculated for each surgeonfish species across reef sites. A. tractus (A-D), A. coeruleus (E-H). Dashed lines represent thresholds of selectivity calculated as $1 /$ number of available items $=0.14$. Values above this line suggest selection for these diet items while values below this line suggest avoidance of these diet items.

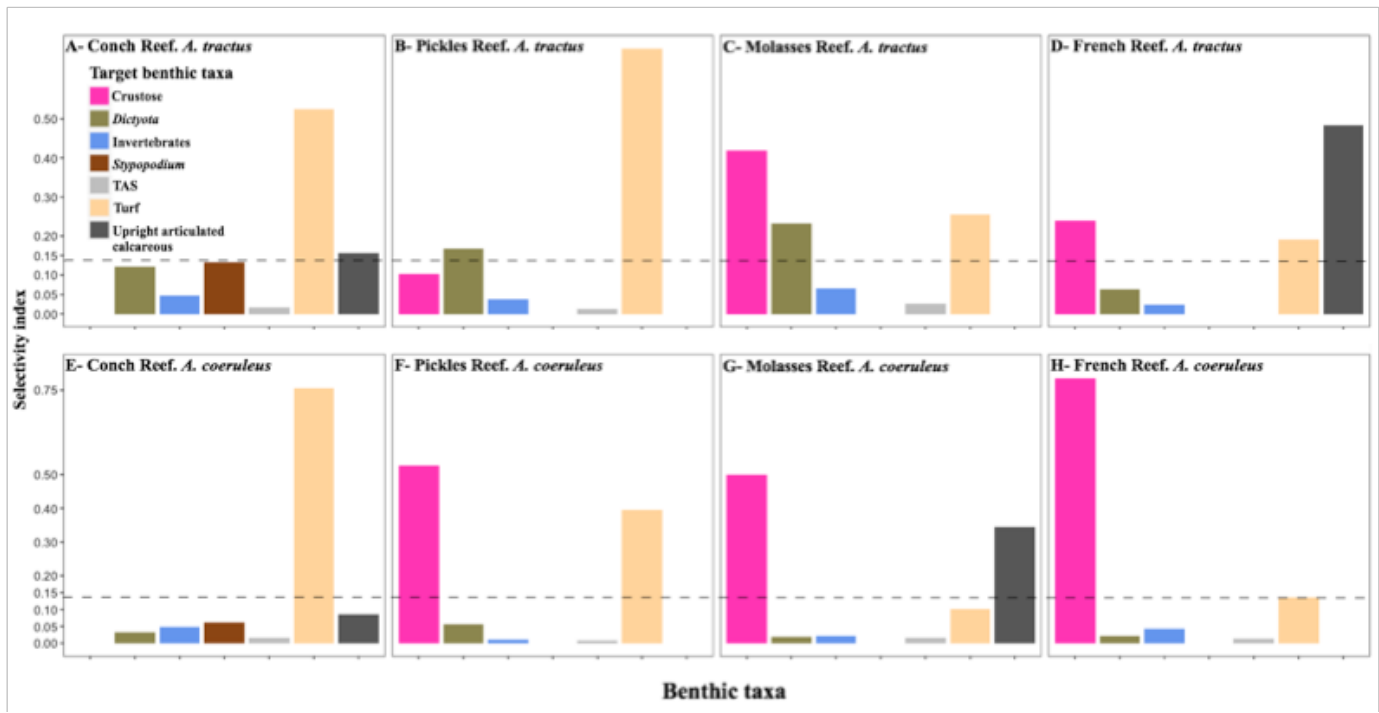


CHAPTER III

INTERACTIVE EFFECTS OF HERBIVORY AND SUBSTRATE ORIENTATION ON

ALGAL COMMUNITY DYNAMICS ON A CORAL REEF 
ABSTRACT

Herbivory is one of the strongest drivers of algal community dynamics on coral reefs. However, abiotic factors such as structural complexity often mediate the impact of herbivores on benthic communities. We experimentally evaluated the independent and interactive effects of substrate orientation and fish herbivory on algal community dynamics on a coral reef in the Florida Keys, USA. We created horizontal and vertical substrates, mimicking the trend in the reduction of vertical surfaces of coral reefs, to assess how algal communities develop either with herbivory (open areas) or without herbivory (in herbivore exclosures). We found that substrate orientation was the dominant influence on macroalgal community composition. Herbivores had little impact on vertical substrates as crustose algae dominated these substrates in exclosures and open areas. In contrast, herbivores strongly impacted horizontal substrates, evidenced by upright macroalgae (e.g., Dictyota spp., articulated coralline algae) dominating herbivore exclosures, while open areas were dominated by filamentous algal turf and sediment. Outside of exclosures, differences between vertical and horizontal substrates exposed to herbivores persisted despite similar levels of herbivory as herbivorous fishes showed no preference for feeding on either substrate orientation. Our results suggest that the orientation of the reef benthos has an important impact on benthic communities. On vertical surfaces, abiotic factors may be more important for structuring algal communities while herbivory may be more important for controlling algal dynamics on flat areas. Thus, as structural complexity of Caribbean coral reefs declines and reefs become increasingly flat, higher levels of herbivory may be required to keep macroalgal populations in check. 


\section{INTRODUCTION}

Herbivory is a fundamental process on coral reefs that regulates algal species composition, algal abundance (Odgen and Lobel 1978, Lewis and Wainwright 1985, Carpenter 1986) and the interactions between corals and algae (Mapstone et al. 2007, Trapon et al. 2013a, Zaneveld et al. 2016). On Caribbean coral reefs, sea urchins like the long-spined sea urchin (Diadema antillarum) and herbivorous fishes [Family Acanthuridae (surgeonfishes) and Family Scaridae (parrotfishes)] are often the most abundant herbivores (Steneck 1983, Adam et al. 2015a). Unfortunately, a massive die-off of sea urchins in the 1980's left fishes as the main herbivores on reefs (Lessios 1988), although they are currently overfished in many places across the Caribbean (Jackson et al. 2014). Reduced herbivory and concurrent declines in coral cover have facilitated increases in macroalgal cover, which has doubled Caribbean-wide since the 1970s (Jackson et al. 2014). Declines in coral abundance coupled with increased bioerosion rates have resulted in an overall negative carbon budget on many reefs, driving reductions of structural complexity on reefs (Perry et al. 2014).

The structural complexity of coral reefs is largely comprised of the threedimensional physical structure built by scleractinian corals and other calcifying organisms that provide shelter, settlement opportunities, and foraging habitat to reefdwelling organisms (Wilson et al. 2007, Graham and Nash 2013). Areas with higher structural complexity often have more abundant sea urchins (Fabricius et al. 2014) and herbivorous fishes (Luckhurst and Luckhurst 1978, Graham 2014, Rogers et al. 2014), which may increase top-down control on algal communities (Verges et al. 2011). For instance, crustose coralline algae (CCA) is often found in a high abundance on reefs with 
high complexity and thus a steep average of substrate slope (Fabricius and De'ath 2001), which commonly dominate in heavily grazed areas (Steneck 1997). However, in the Caribbean, the structural complexity of coral reefs has declined by more than $50 \%$ since the 1960s, creating more horizontal reef surfaces defined as reef flattening (Alvarez-Filip et al. 2009, 2011). Thus, there is a critical need to understand how structural complexity and the flattening of coral reefs influences the herbivory and algal community structure.

Reduced structural complexity on reefs could alter herbivory, and consequently algal dynamics, through several mechanisms (Bozec et al. 2013, 2015). For instance, reduced complexity reefs provide reduced number of shelter sites for herbivorous fishes, which may reduce herbivory pressure resulting in increased macroalgal abundance (Verges et al. 2011). On the contrary, complex reefs may require high grazing pressure as a consequence of having large area that needs to be grazed by herbivores (Bozec et al. 2013). At a small scale, the flattening of reef substrates could increase sediment accumulation, which, in turn, can reduce grazing activity and promote the growth of filamentous algae (Goatley and Bellwood 2013, Clausing et al. 2014). Conversely, benthic areas with steep slopes tend to have less sediment and higher abundance of CCA, including species (e.g., Titanoderma prototypum (Foslie) Woelkerling, Y.M. Chamberlain \& P.C.Silva) that can facilitate coral recruitment (Arnold and Steneck 2010, Ritson-Williams et al. 2016). Therefore, the ongoing flattening of Caribbean coral reefs may have a strong impact on herbivores and their role as drivers of algal dynamics.

Here, we investigated how structural complexity can mediate the influence of herbivory on algal community dynamics on a reef in the Florida Keys, USA. We manipulated the orientation of experimental substrates (horizontal vs. vertical) as a 
proxy for structural complexity using quarried coral limestone tiles to simulating bare substrate created after a disturbance. To examine the interaction between substrate orientation and herbivory, we established these substrates in areas with low (herbivore exclosure plots) and high (open plots) herbivory. We expected that substrate orientation would determine whether herbivores strongly impact the dynamics of benthic macroalgae. We predicted that herbivory would strongly impact algal communities on horizontal substrates with filamentous turf algae dominating in open areas and upright macroalgae dominating in exclosures as herbivores tend to retard algal succession (Diaz-Pulido and McCook 2002). On vertical substrates, we expected that herbivory would be less important and that crustose algae would dominate vertical surfaces in open areas and in herbivore exclosures.

\section{METHODS}

Study site

We conducted our experiment from August 2013 to August 2014 on a low relief spur and groove coral reef near Conch Reef $\left(24^{\circ} 57.695^{\prime} \mathrm{W}, 80^{\circ} 27.230^{\prime} \mathrm{N}\right)$ in $\sim 7 \mathrm{~m}$ of water located in the upper Florida Keys, USA. These reefs are regularly dominated by turf algae, often in association with sediment forming a sedimented turf matrix with seasonal peaks of Stypopodium zonale in the spring months and Dictyota spp. in the summer months (Zaneveld et al. 2016). Reefs in the Florida Keys are characterized by a very low sea urchin density $\left(<0.1\right.$ Ind. $\mathrm{m}^{-2}$, Chiappone et al. 2008) and high abundance of herbivorous fishes (Burkepile et al. 2013) including large parrotfishes currently considered rare Caribbean-wide (Adam et al. 2015b). 


\section{Experimental manipulation}

We used quarried coral limestone tiles $(2.5 \times 10 \times 10 \mathrm{~cm})$ to create bare vertical and horizontal substrates that mimic areas of reef with distinct substrate orientation (Fig. 3.1). We assembled four tiles next to each other to construct squares $(20 \mathrm{x} 20 \mathrm{~cm}$; $400 \mathrm{~cm}^{2}$ total area) of horizontal substrate and four tiles stacked to create vertical substrates with similar surface area $\left(10 \times 10 \mathrm{~cm}\right.$ per side for $400 \mathrm{~cm}^{2}$ total area by adding all 4 sides; Fig. 3.1), without including the horizontal surface on the top of the vertical tiles. Because of the nature of our setup, the horizontal substrates had $40 \mathrm{~cm}$ of cracks, spaces where tiles met each other, while the vertical tiles had $120 \mathrm{~cm}$ of cracks. Thus, we only collected data on the exposed tile surfaces to minimize this difference confounding our measures of surface communities.

In order to test the impact of herbivory on algal communities, we created four treatments: (1) horizontal substrates in open areas, (2) vertical substrates in open areas, (3) horizontal substrates in exclosures, and (4) vertical substrates in exclosures. We placed two sets of each substrate type inside each exclosure plot $(1 \times 1 \times 0.5 \mathrm{~m})$ framed with stainless steel round bar and covered with PVC-coated wire mesh with $2.5 \mathrm{~cm}$ diameter holes to exclude herbivorous fishes ( 2 horizontal substrates and 2 vertical substrates within one exclosure). Another two sets of each substrate orientation were placed in each open plot with open access to herbivorous fishes. Thus, the substrate orientation treatment was nested within either exclosures or open areas. Each of these treatments was replicated three times ( $n=3$ exclosures and $n=3$ open plots). All substrates were deployed in August 2013 and data collection began a month after (September 2013). We did not include exclosure controls as previous research suggested minimal effects of 
exclosure artifacts on algal communities in these shallow reef systems (Miller et al. 1999, Smith et al. 2001, Burkepile and Hay 2007). In fact, our recent study on a nearby reef showed no effects of exclosure controls on water flow, sedimentation, or algal communities using similarly designed exclosures (Zaneveld et al. 2016). However, the exclosures do decrease light availability to the benthos by $\sim 15 \%$ (Ferrari et al. 2012). Given that the light availability common at shallow depths saturates the photosystems of primary producers (Carpenter 1985), the slight decrease in light availability likely had minimal impact on primary production or interactions among benthic organisms.

\section{Herbivorous fish feeding}

We recorded the grazing activity of parrotfishes and surgeonfishes on vertical and horizontal substrates in open plots using GoPro video cameras. Grazing activity was evaluated six times during the experiment: in September, October, and December of 2013, and February, April, and May of 2014. Cameras were placed $50 \mathrm{~cm}$ away from each plot between 10:00 and 14:00 hours to film grazing activity on both horizontal and vertical substrates simultaneously. To quantify grazing intensity on tile substrates we selected 20 random five-minute periods from the 3 to 4 hours of film recorded during each deployment. We identified every fish that fed to the species level and recorded life history stage (juvenile, intermediate, adult), as well as the type of substrate bitten, and the number of bites during a feeding event. We did not include bites on the top of the vertical substrates (the flat horizontal portion) to ensure we quantified bites in the same area on both vertical and horizontal substrates.

\section{Algal community dynamics}

Every 30 to 45 days between August 2013 and August 2014 we visually 
surveyed the benthic community on the vertical and horizontal substrates at Conch Reef at eight different time points. To do so, we placed a $10 \times 10 \mathrm{~cm}$ grid divided into four quadrants over the substrate and visually estimated the percent of the substrate covered by different algal taxa to the nearest $5 \%$. We identified algae to the lowest taxonomic level possible and also binned them into form-functional groups (FFG) following a modification of Steneck and Dethier (1994). We considered turf algae (hereafter "turf") as all short $(<1 \mathrm{~cm})$ filamentous algal species with little to no sediment trapped in the filaments. When filamentous algal communities became longer ( $2-10 \mathrm{~cm}$ height), they often trapped sediment within the filaments. Therefore, we classified this matrix as turf algae associated with sediment (henceforth "TAS"). When sediment was on the substrate but not associated with turf algae, we simply classified as sediment.

\section{Statistical analysis}

We evaluated the effect of substrate orientation on herbivore grazing rate obtained from videos, via a Friedman test that considered "month" as block. In order to meet assumptions of homoscedasticity and normality, we transformed the benthic percent cover data via BoxCox transformations. After transformation, we used a linear mixed model (LMM) to test the effects of herbivory and substrate orientation over time (month) for each benthic group with plot as a random factor. We assessed changes in community composition through time for each treatment using non-metric multidimensional scaling (NMDS) analyses and permutational multivariate analysis of variance (PERMANOVA) with the distance matrix calculated using Bray-Curtis dissimilarity. We also conducted a PERMANOVA to test for the combined and 
independent effects of herbivory and substrate orientation on community composition at the end of the experiment. We performed descriptive and inferential analyses using packages vegan (Oksanen et al. 2017), doBy (Soren 2016), MASS (Venables and Ripley 2002), ggplot2 (Wickham 2009) from R program created by R Development Core Team (2016), version, 3.2.2.

RESULTS

Herbivorous fish feeding

Overall grazing rates of herbivores grazing varied between $18.5 \pm 2.8$ bites hr$^{-1}$ $400 \mathrm{~cm}^{-2}$ (mean $\pm \mathrm{SEM}$ ) but did not differ across time or between substrate orientation (horizontal or vertical) (Fig. 3.2A, Friedman test, Month, $\chi^{2}{ }_{5}=7.1, p=0.210$, Orientation, $\left.\chi_{5}^{2}=0.7, p=0.414\right)$. Grazing rates by surgeonfishes were similar on both substrate orientations with an average of $7.4 \pm 2.0 \mathrm{bites}^{-1} 400 \mathrm{~cm}^{-2}$ on horizontal substrates and $4.5 \pm 1.5$ bites hr $^{-1} 400 \mathrm{~cm}^{-2}$ on vertical substrates (Fig. 3.2B, Friedman test, Orientation, $\chi^{2}{ }_{5}=2.7, p=0.103$, Month, $\chi^{2}{ }_{5}=9.2, p=0.101$ ). Sparisoma spp. parrotfishes displayed the lowest grazing rate with approximately $1.5 \pm 0.6$ bites $\mathrm{hr}^{-1}$ $400 \mathrm{~cm}^{-2}$ on horizontal substrates and $2.5 \pm 1.1 \mathrm{bites}^{-1} 400 \mathrm{~cm}^{-2}$ on vertical substrates (Fig. 3.2C). Scarus spp. parrotfishes averaged $11.1 \pm 3.4 \mathrm{bites}^{-1} 400 \mathrm{~cm}^{-2}$ and $10.5 \pm$ 4.6 bites $\mathrm{hr}^{-1} 400 \mathrm{~cm}^{-2}$ on horizontal and vertical substrates, respectively (Fig. 3.2D). Neither genus exhibited preferences for substrate orientation (Friedman test, Orientation, Sparisoma, $\chi^{2}{ }_{5}=2.0, p=0.849$, Scarus, $\left.\chi^{2}{ }_{5}=0.2, p=0.655\right)$. 


\section{Algal community dynamics}

Substrate orientation was a strong determinant of algal community composition with horizontal and vertical substrates often differing regardless of herbivory (Fig. 3.3). On vertical substrates, crustose algae covered more than $50 \%$ of the substrate after six months and remained the dominant benthic group regardless of herbivory treatment (Fig. 3.4A, LMM, Orientation, $\mathrm{F}_{1,62}=261.0, p<0.001$; Herbivory, $\mathrm{F}_{1,62}=0.9, p=$ 0.358; Month, $\mathrm{F}_{7,62}=5.1, p<0.001$; see appendix B for complete model results). Turf algae were often the second most abundant algal group on vertical substrates ranging from $3.4 \pm 0.6 \%$ to $7.3 \pm 1.8 \%$ in exclosures and open treatments, respectively, and marginally differed between orientations (Fig. 3.4B, LMM, Orientation, $\mathrm{F}_{1,62}=3.7, p=$ 0.059). Upright macroalgae (Dictyota spp. and articulated calcareous algae), sediment, and TAS were rarely present on vertical substrates throughout the entire study regardless of herbivory (Fig. 3.4C-F).

Herbivory strongly impacted algal communities on the horizontal substrates. On horizontal substrates in open areas, turf abundance remained below $25 \%$ for the first nine months after which turf cover sharply increased to more than $50 \%$ (Fig. 3.4B, LMM, Month, $\mathrm{F}_{7,62}=7.0, p<0.001$; Month:Herbivory, $\mathrm{F}_{7,62}=2.7, p=0.016$ ). Macroalgal abundance on horizontal substrates varied through time depending on the presence of herbivory. Dictyota spp. dominated horizontal substrates in exclosures during early succession with a peak of $\sim 35 \%$ in February 2014 followed by a drop of abundance to less than $10 \%$ (Fig. 3.4C, LMM, Herbivory, $\mathrm{F}_{1,62}=19.6, p<0.001$; Month:Orientation, $\left.\mathrm{F}_{7,62}=4.8, p<0.001\right)$. Turf associated with sediment (TAS) developed on horizontal substrates after a previous accumulation of sediment on the 
substrates (Fig. 3.4E\&F). By May 2014, TAS was the most abundant group on horizontal substrates covering close to $100 \%$ of the substrate (Fig. 3.4F, LMM, Orientation, $\mathrm{F}_{1,62}=414.1, p<0.001$; Month, $\left.\mathrm{F}_{7,62}=106.8, p<0.001\right)$. However, after the peak in TAS on horizontal substrates, articulated calcareous algae (e.g., Amphiroa spp. and Jania spp.) became the dominant macroalgal group on horizontal substrates in exclosure treatments, covering over $45 \%$ of the substrate by the end of the experiment (Fig. 3.4D, LMM, Month, $\mathrm{F}_{7,62}=24.0, p<0.001$; Herbivory, $\mathrm{F}_{1,62}=54.0, p<0.001$; Orientation, $\mathrm{F}_{1,62}=27.6, p<0.001$; Herbivory:Orientation, $\left.\mathrm{F}_{1,62}=7.9, p=0.007\right)$. Articulated calcareous algae were rare on horizontal tiles exposed to herbivores. When we assessed the overall composition of macroalgal communities, both substrate orientation and herbivory led to differences in community composition over time (Fig. 3.5, PERMANOVA, Month, $\mathrm{F}_{7,191}=18.3, p=0.010$, Orientation, $\mathrm{F}_{1,191}=102.63, p=0.010$, Herbivory, $\mathrm{F}_{1,191}=11.0, p=0.010$, Month:Herbivory, $\mathrm{F}_{7,191}=$ $3.85, p=0.010$, Month:Orientation, $\left.\mathrm{F}_{1,191}=12.31, p=0.010\right)$. However, substrate orientation explained the highest proportion (PERMANOVA, $\mathrm{R}^{2}=0.19$ ) of change in algal community compared to herbivory (PERMANOVA, $\mathrm{R}^{2}=0.02$ ) and showed significant interaction with time (PERMANOVA, Month:Orientation, $\mathrm{F}_{1,191}=12.31, p$ $=0.010)$.

The NMDS suggested that the algal communities on vertical substrates followed similar temporal patterns regardless of herbivory. However, on horizontal substrates, herbivory appeared to drive a divergence of algal communities over time. An analysis of community similarity on communities at the end of the experiment showed that both herbivory and substrate orientation influenced algal community 
composition (PERMANOVA, Orientation, $\mathrm{F}_{1,23}=30.6, p=0.010$, Herbivory, $\mathrm{F}_{1,23}=$ $5.8, p=0.020)$. There was also an interaction between substrate orientation and herbivory (PERMANOVA, Herbivory: Orientation, $\mathrm{F}_{1,23}=3.61, p=0.020$ ). Again, substrate orientation explained most of the variance in community composition $\left(\mathrm{R}^{2}=\right.$ $0.55)$ with herbivory explaining little of the variance $\left(R^{2}=0.08\right)$

\section{DISCUSSION}

The extent to which the loss of structural complexity on coral reefs mediates the influence of herbivory and consequently influences macroalgal and the accumulation of sediments on the benthos is an important, yet under-addressed topic. Here, we show that substrate orientation is a key driver of algal community dynamics. We found that vertical substrates, regardless of the presence of herbivorous fishes, were primarily dominated by crustose algae and little upright macroalgae. In contrast, upright macroalgae such as Dictyota spp. and articulated calcareous algae dominated horizontal substrates when herbivorous fishes were excluded. However, even in the presence of herbivores horizontal substrates were dominated by filamentous turf algae and sediments as opposed to the crustose algae that dominated vertical substrates. These distinct differences in algal communities on vertical and horizontal substrates persisted despite herbivory exerting similar grazing on both orientations.

The influence of substrate orientation on macroalgal community composition that we observed may be driven by multiple abiotic and biotic factors that differ between the orientations. Vertical substrates are less likely to accumulate sediment, which can slow growth rates of CCA and reduce their abundance (Steneck 1997, Fabricius and De'ath 
2001). Therefore, the lack of sediment on vertical tiles likely facilitated crustose algae, starkly contrasting horizontal substrates, which had abundant sediment (maximum of $\sim$ $60 \%$ cover during some periods). High sediment cover likely affected the algal community composition, as sediment can enable retention and growth of new algal propagules (Steneck 1997) and facilitate the formation of a sediment-turf matrix (TAS). Indeed, we observed that after eight months of sediment accumulation on horizontal substrates there was an increase of TAS to more than $75 \%$ cover, followed by an increased abundance of turf in open plots. The dominance of turf algae on horizontal substrates in open plots may be explained by the accumulated sediment protecting turf forming algae from consumption by herbivorous fishes.

In contrast, reduced grazing pressure by herbivores drove dynamics of macroalgae on horizontal substrates within exclosure treatments. Herbivores on reefs strongly impact macroalgal succession, with macroalgae increasing rapidly when herbivores were absent (Smith et al. 2010, Zaneveld et al. 2016). Our results corroborate previous findings, as horizontal substrates exposed to herbivores consistently had low cover of macroalgae and high cover of filamentous turf algae that are adapted to environments with intense grazing from herbivores (Carpenter 1986). Yet, in herbivore exclosures macroalgae, particularly articulated calcareous algae that are typically rare where herbivory is high (e.g., Zaneveld et al. 2016), replaced turf algae over time. In contrast, herbivory had a negligible effect on algal communities growing on vertical substrates that were dominated by crustose algae regardless of exclosure status. Crustose algae, potentially facilitated by their ability to proliferate under lower light conditions on the vertical substrates, are often well defended against herbivores by their crustose thallus 
(Steneck and Dethier 1994). In fact, herbivores often facilitate crustose algae by removing upright algae that would otherwise outcompete crustose taxa (Smith et al. 2010). These results suggest that the slope of reef habitats can strongly influence benthic community composition, at least at small scales.

In addition to sedimentation, light intensity could have mediated the differences in algal composition found between the two substrates. Although we did not measure light levels in our experiment, light exposure on vertical tiles was likely significantly lower compared to horizontal substrates as similar experiments have shown (Strader et al. 2015). For instance, certain CCA species (e.g., Titanoderma sp.) often occur in areas with low light intensity (Steneck and Dethier 1994) such as deep reefs and crevices of shallow reefs, while other CCA species (e.g., Porolithon sp. and Lythophylum sp.) can dominate shallow and systems with high light exposure like algal ridges (Steneck 1986, Littler and Littler 2013, Dean et al. 2015). Yet, high light intensity can also reduce the growth of some CCA via photoinhibition (Burdett et al. 2014). The high light intensity combined with the inhibitory effects of increased sedimentation on the horizontal substrates may have made horizontal substrates more conducive for the growth of non-crustose algae such as filamentous algae and contributed to the differences in algal communities we observed (Cheroske et al. 2000, Trapon et al. 2013a, b).

The structural complexity of reefs is often positively related to coral cover (Alvares-Filip et al. 2009, Graham and Nash 2013) but the relationship between complexity and coral recruitment is less clear. Davies et al. (2013) observed that despite high species-specific variation, coral recruitment was double on vertical substrates compared to horizontal substrates and that corals also displayed a lower mortality rate on 
vertical substrates. The differences in algal communities between horizontal and vertical substrates that we saw could have a significant impact on the recruitment of corals (Trapon et al. 2013a, b). The abundant sediment and macroalgae on horizontal substrates would likely represent poor habitats for coral recruitment (Birrell et al. 2005). In contrast, some species of crustose coralline algae, which were abundant on vertical substrates regardless of herbivory, are strong facilitators of coral recruitment (Littler and Littler 2013, Ritson-Williams et al. 2016). In fact, the few coral recruits that we found during our experiment were on vertical substrates with abundant crustose algae (Photos appendix B). Our observations suggest that the ongoing reduction of structural complexity in the Caribbean might negatively impact coral recruitment.

Most of the work investigating the impact of structural complexity on coral reef dynamics has focused on its influence on community composition, and the behavior and recruitment of mobile species, particularly fishes (Holbrook et al. 2000, Verges et al. 2011, Catano et al. 2015a, b). Fewer studies have looked at how small-scale $\left(<500 \mathrm{~cm}^{2}\right)$ habitat characteristics could influence important reef processes such coral recruitment and species competition (but see Vemeij 2006, Edmunds et al. 2014, Brandlt and Bellwood. 2016). Our data demonstrate that the flattening of reefs at a small scale can significantly influence how herbivores control macroalgal communities. Therefore, coral reefs in transition to a less structurally complex state, as is the case for reefs across the globe (Alvarez-Filip et al. 2011) may need higher herbivory pressure to control enhanced algal growth as they become flatter. The phenomenon could represent an important negative feedback detracting from the resilience of coral reefs, and suggests that as a consequence of the ongoing flattening phenomenon of Caribbean coral reefs maintaining 
robust stocks of herbivorous fishes is increasingly important to facilitate high levels of herbivory.

\section{ACKNOWLEDGMENTS}

We want to thank Dr. Alastair Harborne and Dr. Shantz for providing valuable suggestions that improved the manuscript. Additional, we want to thank Mark Ladd for Andy Shantz for their help in the field. We also want to thank members of the FIU marine macroalgae research lab and the Burkepile Lab at UCSB that collaborated with field data collection, in particular, Amanda Brannon and Alexandra Simmons. This is contribution \#x from the Center for Coastal Oceans Research in the Institute for Water and Environment at Florida International University.

FUNDING

This work was facilitated by grant OCE 1130786 from the National Science Foundation to DE Burkepile. The funders had no role in study design, data collection, and analysis, decision to publish, or preparation of the manuscript.

\section{REFERENCES}

Adam TC, Burkepile DE, Ruttenberg BI, Paddack MJ (2015a). Herbivory and the resilience of Caribbean coral reefs: knowledge gaps and implications for management. Mar Ecol Prog Ser 520:1-20

Adam TC, Kelley M, Ruttenberg BI, Burkepile DE (2015b) Resource partitioning along multiple niche axes drives functional diversity in parrotfishes on Caribbean coral reefs. Oecologia 179:1173-1185 
Alvares-Filip L, Dulvy NK, Gill JA, Cote IM, Watkinson AR (2009) Flattening of Caribbean coral reefs: region-wide declines in architectural complexity. Proc R Soc B:1-7.Doi:10.1098/rspb.2009.0339

Alvares-Filip L, Gill JA, Dulvy NK, Perry AL, Watkinson AR, Cote IM (2011) Drivers of region-wide declines in architectural complexity on Caribbean reefs. Coral Reefs 30:1051-1060

Arnold SN, Steneck RS (2010) Settling into an increasingly hostile world: the rapidly closing "recruitment window" for corals. PLoS ONE 6:e28681.Doi:10.1371/journal.pone.0028681

Brandl SJ, Bellwood DR (2016) Microtopography refuges shape consumer-producer dynamics by mediating consumer functional diversity. Oecologia 182:203-217

Birrell CL, McCook LJ, Willis BT (2005) Effects of algal turfs and sediment on coral settlement. Mar Poll Bull 51:408-414

Bozec Y-M, Yakob L, Bejarano S, Mumby PJ (2013) Reciprocal facilitation and nonlinearity maintain habitat engineering on coral reefs. Oikos 122:428-440

Bozec Y-M, Alvarez-Filip L, Mumby PJ (2015) The dynamics of architectural complexity on coral reefs under climate change. Glob Change Biol 21:223-235

Burdett HL, Keddie V, MacArthur N, McDowall L, Spielvogel E, Hatton AD, Kamenos NA (2014) Dynamic photoinhibition exhibited by red coralline algae in the red sea. BMC Plant Biol 139:1-10

Burkepile DE, Hay ME (2007) Predator release of the gastropod Cyphoma gibbosum increases predation on gorgonian corals. Oecologia 154:167-173

Burkepile DE., Allgeir JE, Shantz AA, Pritchard CE, Lemoine NP, Bhatti LH, Layman CA (2013) Nutrient supply from fishes facilitates macroalgae and suppresses corals in a Caribbean coral reef ecosystem. Sci Rep 3:e1493.Doi.10.1038/srep01493

Carpenter RC (1985) Relationships between primary production and irradiance in coral reef algal communities. Limnol Oceanogr 30:784-793

Carpenter RC (1986) Partitioning herbivory and its effects on coral reef algal communities. Ecol Monogr 56:345-364

Catano LB, Gunn BK, Kelley MC, Burkepile DE (2015a) Predation risk, resource quality, and reef structural complexity shape territoriality in a coral reef herbivore. PLos ONE 10:e0118764.Doi:10.1371/journal.pone.0118764 
Catano LB, Rojas MC, Malossi RJ, Peters JR, Heithaus MR, Fourqrean JW, Burkepile $\mathrm{DE}$ (2015b) Reefscapes of fear: predation risk and reef heterogeneity interact to shape herbivore foraging behavior. J Anim Ecol. Doi.10.1111/1365-2656.12440

Cheroske AG, Willimas SL, Carpenter RC (2000) Effects of physical and biological disturbances on algal turfs in Kaneohe Bay, Hawaii. J Exp Mar Bio Ecol 248:1-34

Chiappone M, Rutten LM, Swanson DW, Miller SL (2008) Population status of the urchin Diadema antillarum in the Florida Keys 25 years after the Caribbean mass mortality. Proc 11th Int Coral Reef Sym, Florida, 7-11

Clausing RJ, Annunziata C, Baker G, Lee C, Bittick SJ, Fong P (2014) Effects of sediment depth on algal turf height are mediated by interactions with fish herbivory on a fringing reef. Mar Ecol Prog Ser 517:121-129

Diaz-Pulido G, McCook LJ (2002) The fate of bleached corals: pattern and dynamics of algal recruitment. Mar Ecol Prog Ser 232:115-128

Davies SW, Matz MV, Vize PD (2013) Ecological complexity of coral reef recruitment processes: Effects of invertebrate herbivores on coral recruitment and growth depends upon substratum properties and coral species. PLoS ONE 8:e72830. Doi:10.1371/journal.pone.0072830

Dean AJ, Steneck RS, Tager D, Pandolfi JM (2015) Distribution, abundance and diversity of crustose coralline algae on the Great Barrier Reef. Coral Reefs 34:581-594

Edmunds PJ, Nozawa Y, Villanueva RD (2014) Refuges modulate coral recruitment in the Caribbean and the Pacific. J Exp Mar Bio Ecol 454:78-84

Fabricius K, De'ath G (2001) Environmental factors associated with the spatial distribution of crustose coralline algae on the Great Barrier Reef. Coral Reefs 19:303-309

Fabricius K, De'ath G, Noonan S, Uthicke S (2014) Ecological effects of ocean acidification and habitat complexity of reef-associated macroinvertebrate communities. Proc R Soc B 281:20132479.Doi.org/10.1098/rspb.2013.2479

Ferrari R, Gonzalez-Rivero M, Ortiz JC, Mumby PJ (2012) Interaction of herbivory and seasonality on the dynamics of Caribbean macroalgae. Coral Reefs 31:683-692

Goatley CHR, Bellwood DR (2013) Ecological consequences of sediment on high-energy coral reefs. PLoS ONE 8:e77737.Doi:10.1371/ journal.pone.0077737 
Graham NAJ (2014) Habitat complexity: coral structural loss leads to fisheries declines. Curr Biol 24:359-361

Graham NAJ, Nash KL (2013) The influence of structural complexity in coral reef ecosystems. Coral reefs 32:315-326

Holbrook SJ, Graham EF, Schmitt (2000) Spatial patterns in abundance of a damselfish reflect availability of suitable habitat. Oecologia 122:109-120

Jackson JBC, Donovan MK, Cramer KL, Lam VV (2014). Status and Trends of Caribbean Coral Reefs: 1970-2012. Global Coral Reef Monitoring Network, IUCN, Gland, Switzerland

Lessios HA (1988) Mass mortality of Diadema antillarum in the Caribbean: What have we learned? Ann Rev Ecol Syst 19:371-93

Lewis SM, Wainwright PC (1985) Herbivore abundance and grazing intensity on a Caribbean coral reef. J Exp Biol Ecol 87:215-228

Littler MM, Littler DS (2013) The nature of crustose coralline algae and their interactions on reefs. Smithsonian contributions to the marine sciences 39:199-212

Luckhurst BE, Luckhurst K (1978) Analysis of the influence of substrate variables on coral reef fish communities. Mar Biol 49:317-323

Mapstone BD, Andrew NL, Chancerell Y, Salvat B (2007) Mediating effects of sea urchins on interactions among corals, algae and herbivorous fish in the Moore lagoon, French Polynesia. Mar Ecol Prog Ser 332:143-153

Miller MW, Hay ME, Miller SL, Malone D, Sotka EE Szmant AM (1999) Effects of nutrients versus herbivores on reef algae: A new method for manipulating nutrient on coral reefs. Limnol Oceanogr 44:1847-1861

Ogden JC, Lobel PS (1978) The role of herbivorous fishes and urchins in coral reef communities. Env Biol Fish 3:49-63

Oksanen J, Blanchet FG, Friendly M, Kindt R, Legendre P, McGlinn D, Minchin PR, O'hara RB, Simpson GL, Solymos P, et al. 2017. Community ecology package. https://cran.r-project.org, https://github.com/vegandevs/vegan

Perry CT, Murphy GN, Kench PS, Edinger EN, Smithers SG, Steneck RS, Mumby PJ (2014) Changing dynamics of Caribbean reef carbonate budget: emergence of reef bioeroders as critical controls on present and future reef growth potential. Proc R Soc B 281:20142018.Doi.org/10.1098/rspb.2014.2018 
R Core Team (2016) R: A language and environment for statistical computing. $\mathrm{R}$ Foundation for Statistical Computing, Vienna, Austria. ISBN 3-900051-07-0, URL http://www.R-project.org/

Ritson-Williams R, Arnold SN, Paul VJ (2016) Patterns of larvae settlement preferences and post-settlement survival for seven Caribbean corals. Mar Ecol Prog Ser $548: 127-138$

Rogers A, Blanchard JL, Mumby PJ (2014) Vulnerability of coral reef fisheries to a loss of structural complexity. Curr Biol 24:1000-1005

Smith JE, Smith CM, Hunter CL (2001) An experimental analysis of the effects of herbivory and nutrient enrichment on benthic community dynamics on a Hawaiian reef. Coral Reefs 19:332-342

Smith JE, Hunter CL, Smith CM (2010) The effects of top-down versus bottom-up control on benthic coral reef community structure. Oecologia 163:497-507

Soren H (2016) Grouping statistics, LS means, Linear contrasts, utilities. http://people.math.aau.dk/ sorenh/software/doBy/

Steneck RS (1997) Crustose corallines, other algal functional groups, herbivores and sediments: complex interactions along reef productivity gradients. Proc 8th Int Coral Reef Sym 1:675-700

Steneck RS (1983) Quantifying herbivory on coral reefs: Just scratching the surface and still biting off more than we can chew. En "The ecology of deep and shallow coral reefs". L. Reaka (ed.), Symposia Series for Undersea Research, NOAA'S Undersea Research Program 1:103-111

Steneck RS (1986) The ecology of coralline algal crusts: convergent patterns and adaptive strategies. Ann Rev Ecol Syst 17:273-303

Steneck RS, Dethier MN (1994) A functional group approach to the structure of algaldominated communities. Oikos 69:476-498

Strader ME, Davies SW, Matz MV (2015) Differential responses of coral larvae to the colour of ambient light guide them to suitable settlement microhabitat. R Soc Open Sci 2:150358.Doi.org/10.1098/rsos. 150358

Trapon ML, Pratchett MS, Hoey AS (2013a) Spatial variation in abundance, size and orientation of juvenile corals related to the biomass of parrotfishes on the Great Barrier Reef, Australia. PloS ONE 8:e57788.Doi:10.1371/journal.pone.0057788 
Trapon ML, Pratchett MS, Hoey AS, Baird AH (2013b) Influence of fish grazing and sedimentation on the early post-settlement survival of the tabular coral Acropora cytherea. Coral Reefs 32:1051-1059

Venables WN, Ripley BD (2002) Modern Applied Statistics with S. Fourth Edition. Springer, New York. ISBN 0-387-95457-0

Verges AM, Vanderklift A, Doropoulos C, Hyndes GA (2011) Spatial patterns in herbivory on a coral reef are influenced by structural complexity but not algal trait. PLoS ONE 6:e17115.Doi:10.1371/journal.pone.0017115

Vermeij MJA (2006) Early life-history dynamics of Caribbean coral species on artificial substratum: the importance of competition, growth and variation in life-history strategy. Coral Reefs 25:59-71

Wickham H (2009) Ggplot2: Elegant graphics for data analysis. Springer-Verlag New York

Wilson SK, Graham NAJ, Polunin NVC (2007) Appraisal of visual assessments of habitat complexity and benthic composition on coral reefs. Mar Biol 151:10691076

Zaneveld JR, Burkepile DE, Shantz AA, Pritchard CE, McMinds R, Payet JP, Welsh R, Correa AMS, Lemoine NP, Rosales S, Fuchs C, Maynard J, Vega-Thurber R (2016) Overfishing and nutrient pollution interact with temperature to disrupt coral reefs down to microbial scales. Nat. Commun

7:11833.Doi:10.1038/ncomms11833 
Figure 3.1 Experimental design showing the dimensions of substrates in open (left) and exclosure (right) plots. Notice that each vertical substrate encompasses four $(10 \times 10 \mathrm{~cm})$ vertical walls that are the same area as horizontal substrates $\left(20 \times 20 \mathrm{~cm}=400 \mathrm{~cm}^{2}\right)$. Numbers indicate the dimensions in $\mathrm{cm} . \mathrm{N}=3$ for each open and exclosure plot.

\section{Experimental design}
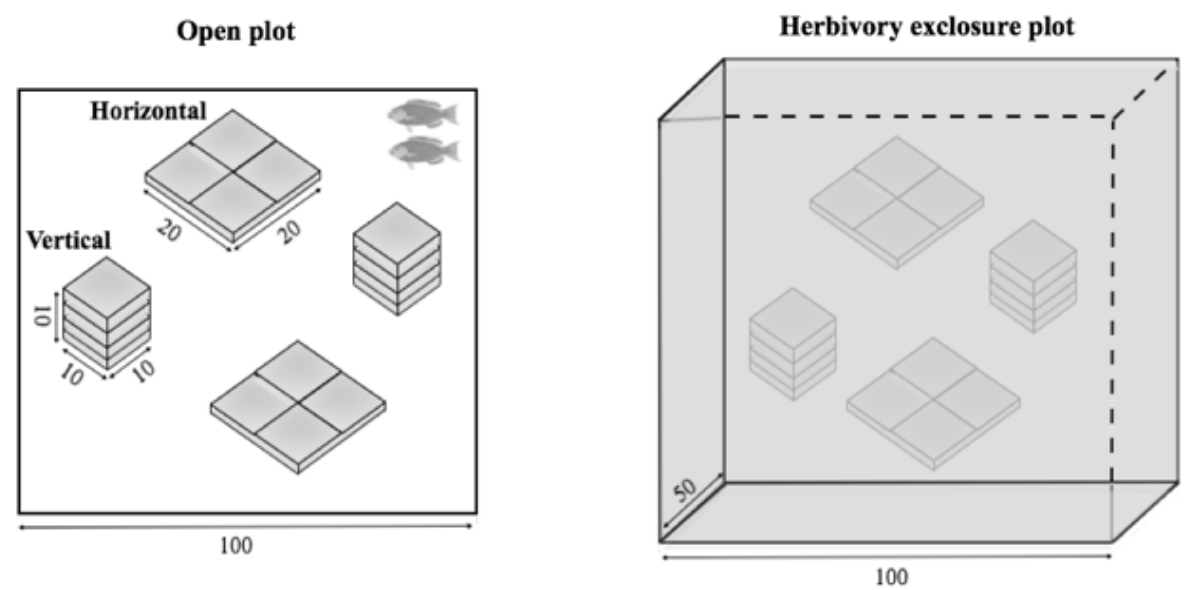
Figure 3.2 Grazing rates by herbivorous fishes obtained from videos recorded in open plots. Points represent the number of bites taken by (A) all species of herbivorous fishes, (B) Acanthurus spp., (C) Sparisoma spp., or (D) Scarus spp. Data are means \pm SE. Statistics are from Friedman tests.
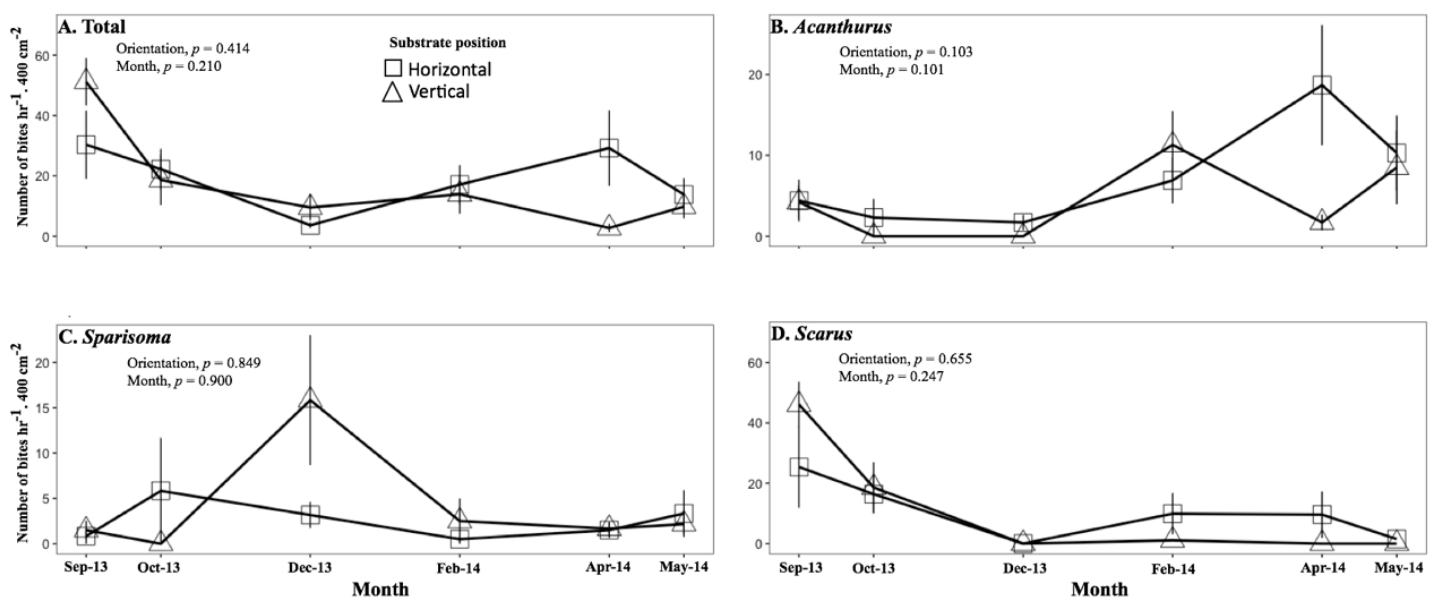
Figure 3.3 Photographs of community composition on experimental substrates at the end of the year-long experiment: (A) Exclosure-Horizontal, (B) Exclosure-Vertical, (C) Open-Horizontal, and (D) Open-Vertical substrates. Photos were taken on $10 \mathrm{x} 10 \mathrm{~cm}$ section of the substrates.

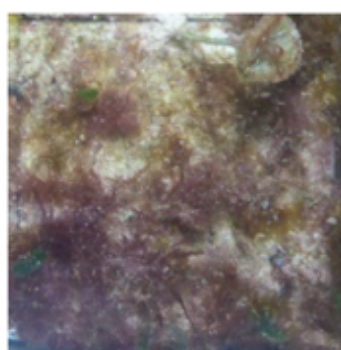

A. Exclosure-Horizontal

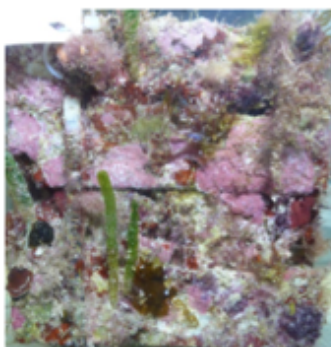

B. Exclosure-Vertical

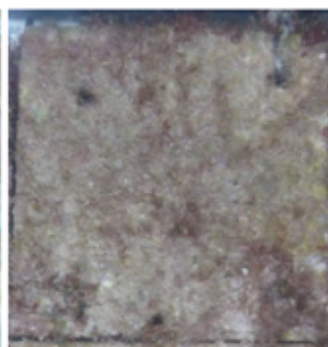

C. Open-Horizontal

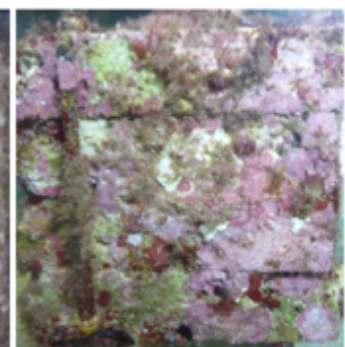

D. Open-Vertical 
Figure 3.4 Abundance of different benthic groups through time in different treatments: horizontal substrates in exclosure plots (Exclosure-Horizontal), vertical substrates in exclosure plots (Exclosure-Vertical), horizontal substrates in open plots (OpenHorizontal) and vertical substrates in open plots (Open-Vertical). (A) crustose algae, (B) turf algae, (C) Dictyota spp., (D) articulated calcareous algae, (E) sediment and (F) turf associated with sediment (TAS). Data are means \pm SE. Statistics show significant effects from linear mixed models. See appendices for full model outputs.
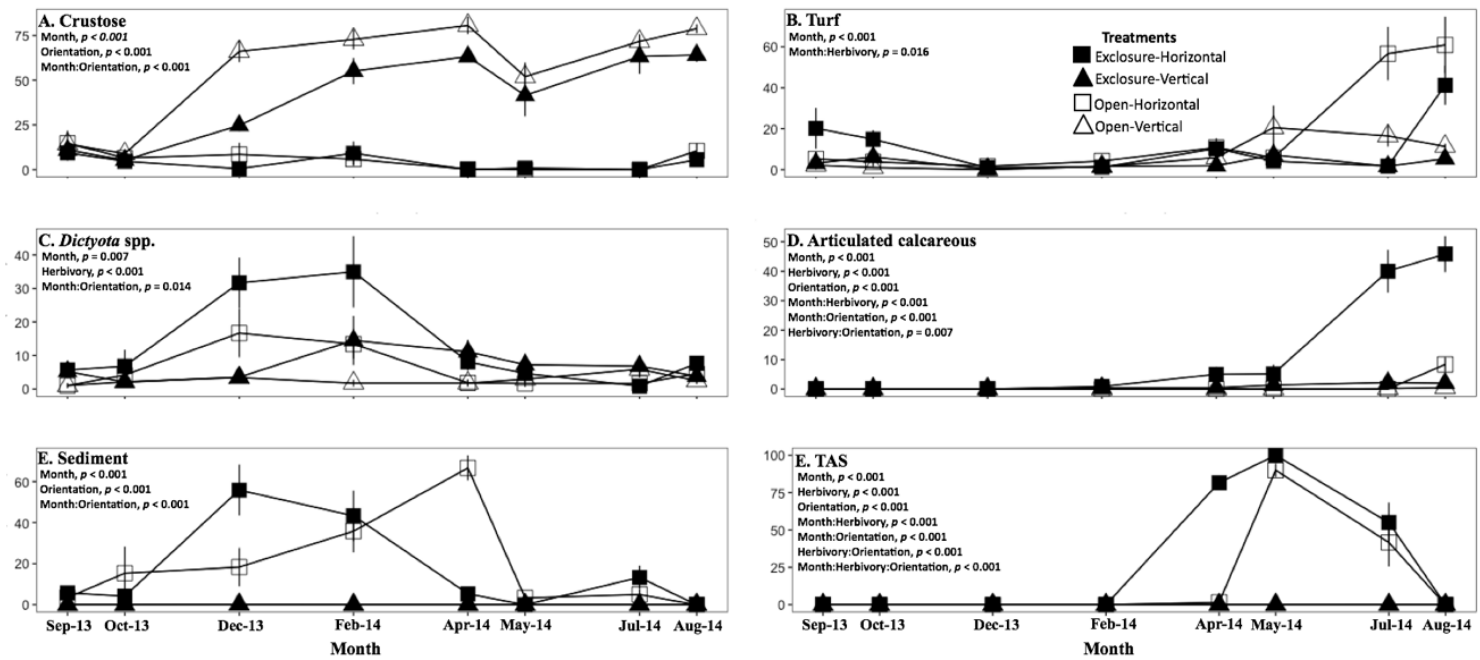
Figure 3.5 Trajectory of macroalgal community composition using non-metric multidimensional scaling (NMDS). The treatments represent: horizontal substrates in exclosure plots (Exclosure-Horizontal), vertical substrates in exclosure plots (ExclosureVertical), horizontal substrates in open plots (Open-Horizontal) and vertical substrates in open plots (Open-Vertical). Asterisk $(*)$ represent the first time point after the benthic community developed (month 1) and pound symbol (\#) indicates the final time point. Statistics are results of PERMANOVA. See appendices for full model outputs.

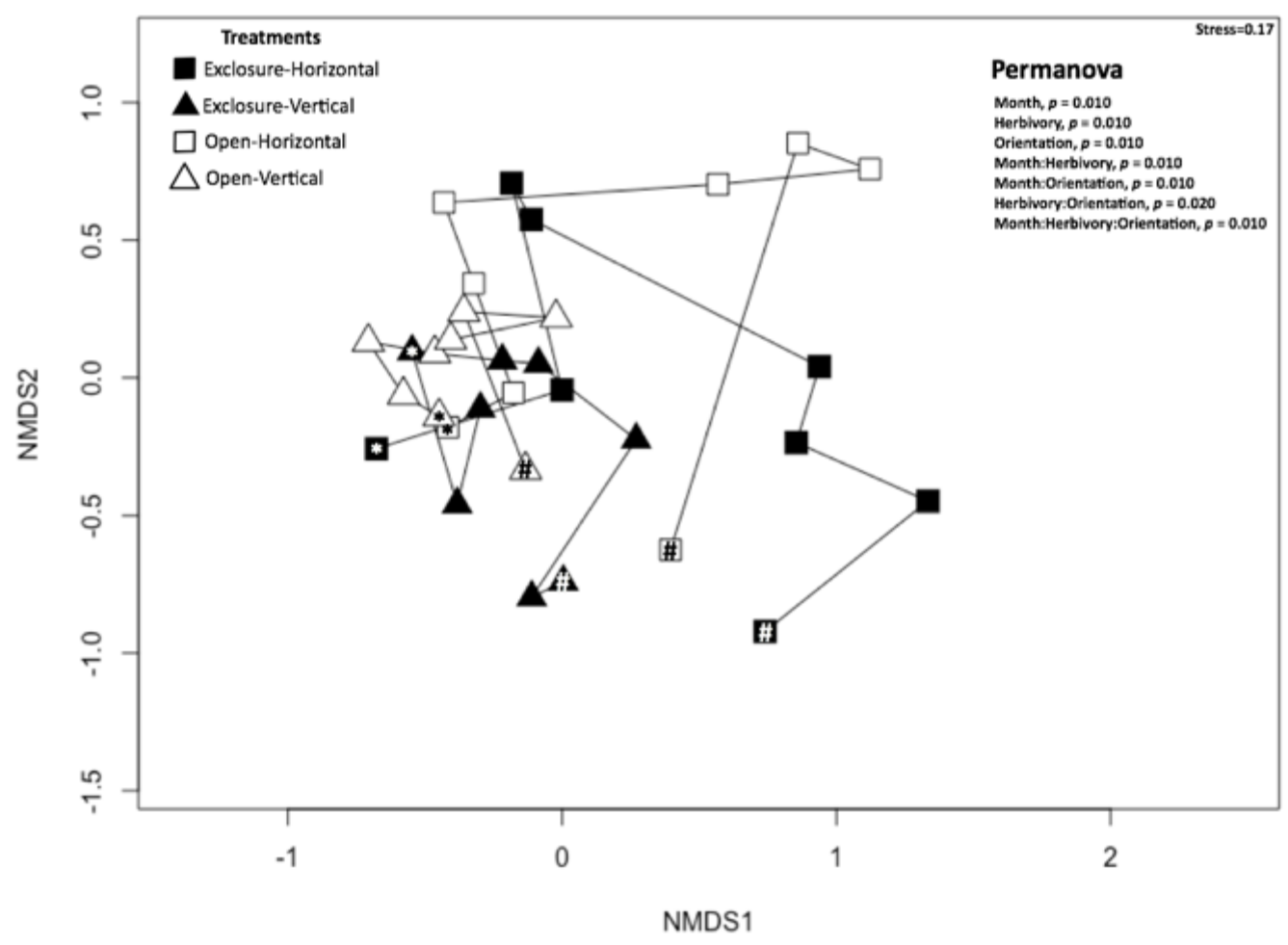




\section{CHAPTER IV}

SEDIMENT LOADING IMPEDES RECOVERY OF CORAL REEFS DESPITE HERBIVORE PROTECTION: THE CASE OF THE FLORIDA KEYS 


\section{ABSTRACT}

Coral reefs in the Florida Keys remain a challenge to a common paradigm describing the resilience of western Atlantic reefs. Despite high abundance of large herbivorous fishes that graze macroalgae and limit their deleterious effects on coral demographics, corals have continued to decline in recent decades. While disease, bleaching, and storm damage are important for adult coral mortality, other factors may be compromising the recruitment, post-settlement survival, and growth of small corals necessary for positive trajectories of coral cover. To study the potential factors affecting coral recovery in the Florida Keys, we assessed abiotic variables (substrate slope, depth, and abundance of sediment and structural complexity) and biotic variables (benthic composition and herbivory pressure) along multiple habitats found in six spur and groove reefs. We then used abiotic and biotic variables to test for the relative influence of each factor for explaining the abundance of corals using boosted regression tree (BRT) analysis. We found overall low coral cover $(\sim 1 \%)$ and low density (approximately 1 coral $\mathrm{m}^{2}$ ) of small adult corals, which likely reflecting the cumulative effects of years of diseases and bleaching events. Our BRT analyses suggest that the high abundance of sediment is contributing to limited coral recovery. The presence of juvenile corals was negatively correlated with sediment depth and abundance of Dictyota spp. and positively correlated with substrate slope (steeper slopes have reduced sediment build up). Increased abundance and depth of sediment also reduce the presence of the three most commonly found coral genera (Siderastrea, Agaricia, and Porites). While the abundance of turf algae appears to positively correlate with abundance of the adult corals, the abundance of sediment had a negative impact on corals. Furthermore, adult communities were 
dominated by Siderastrea, a stress-tolerant genus. Our results illustrate that abundant sediments may be an important factor preventing recovery of corals in the coraldepauperated Florida Keys reefs, despite relatively high grazing pressure that is typically associated with coral recovery. Consequently, grazing and coral cover trajectories are decoupled in the region, and additional management initiatives are required to aid reef resilience.

\section{INTRODUCTION}

Several biotic factors (e.g., larval input, primary production, herbivory pressure), abiotic factors (e.g., light intensity, water temperature, nutrient levels, sedimentation), and natural disturbances (e.g., tropical storms, outbreaks of predators and diseases), influence structure and dynamics of coral reefs (Done et al. 1996, Harborne et al. 2016). Alterations of one or more factors (e.g., increased nutrient availability and sediment deposition, reduction of herbivorous fishes) as well as intensification of natural disturbances, can stress and kill corals, the foundation species of coral reefs, leading to overall ecosystem degradation (Baker et al. 2008, Bozec et al. 2015). Anthropogenic stressors such as overfishing of herbivores and eutrophication can then limit reef coral resilience after disturbance (Mumby 2006, Hughes et al. 2010). Therefore, protection of herbivorous fishes that control macroalgae, a major competitor of corals, as well as reduction of nutrient input that fuels algal growth, have shown to facilitate coral reef resilience (Mumby et al. 2007, Adam et al. 2015a, D’Angelo and Wiedenmann 2014). Nevertheless, many coral reefs (e.g., South Florida) have failed to regain coral cover despite years of effective protection of herbivorous fishes (Toth et al. 2014) suggesting 
that alternative factors (e.g., natural or human-produced sedimentation) might be limiting processes of coral recovery (Burkepile et al. 2013, Begin et al. 2015, Suchley et al. 2016).

The Florida Keys reefs are bounded to the north by a transitional zone from tropical to temperate characteristics that limits their northward expansion (Engle and Summers 1999, Walker 2012, Walker and Guilliam 2013). Multiple habitats on Florida's reefs were historically characterized by high, though variable coral cover and the presence of massive and branching reef-building coral species (Dustan 1977, Jaap 1984, Burns 1985). Repetitive disease outbreaks (e.g., black band disease in Orbicella, white band disease in Acropora, Porter and Meier 1992, Aronson and Precht 2001, Dendrogyra cylindrus, Lewis et al. 2017) and extreme thermal stress events (Lirman et al. 2011, Manzello 2015) have led to current low $(<5 \%)$ coral cover across much of the Florida Keys (Ruzicka et al. 2013). However, macroalgal abundance remains low ( 28\%, Schutte et al. 2010), despite the abundant free space for colonization, likely because the Florida Keys have large, well-protected populations of herbivorous parrotfishes. Parrotfishes, including large scarids such as Scarus guacamaia and S. coelestinus that are absent from much of the wider Caribbean as a result of overharvesting, exert strong top-down control over macroalgal communities (Paddack et al. 2006, Adam et al. 2015a, b). Coraldepauperate reefs in the Caribbean are usually associated with overfishing of herbivorous fishes and or nutrient pollution causing uncontrolled growth of algae (e.g., Lobophora variegata and Dictyota spp., Mumby 2009, Lapointe et al. 2011, Jackson et al. 2014). The fact that reefs in the Florida Keys are located at the latitudinal margins of reefs systems, have abundant herbivorous fishes leading to low algal cover, and have low coral cover despite significant coral larvae input (Toth et al. 2014, van Woesik et al. 2014), 
make Florida Keys reefs an atypical case within the wider Caribbean. In addition, the offshore reefs are also relatively nutrient limited suggesting that nutrients should not be inhibiting corals or be facilitating algal growth (Zaneveld et al. 2016).

The processes that impact the recruitment of corals and subsequent coral recovery are multifaceted and complex (Doropoulos et al. 2016). The removal of turf and upright macroalgae by herbivores is important to facilitate coral recruitment, as abundant algae can limit space available for larval settlement and reduce survival and growth of new recruits (Kuffner et al. 2006, Box and Mumby 2007, Hoey et al. 2011). However, other factors also strongly impact coral recruitment such as substrate properties (e.g. texture, color, orientation, sediment load) (Birrell et al. 2005, Davies et al. 2013) and microhabitat benthic composition including relative abundance of coral recruitment facilitators (e.g., crustose coralline alga Titanoderma prototypum) and coral recruitment inhibitors such as invertebrates (Nozawa 2008, Arnold and Steneck 2011, Brandl et al. 2013). For instance, coral larvae preferentially settle and have higher survival on vertical and rough substrates covered by crustose coralline algae, but avoid turf and sediment-rich substrates (Birrell et al. 2008, Arnold and Steneck 2011, Davies et al. 2013). Thus, given the high herbivory (Adam et al. 2015a, b), the above factors might be contributing to the lack of coral resilience in the Florida Keys reefs.

Our study investigated the role of abiotic (sediment, substrate slope, and rugosity) and biotic factors (herbivory and benthic community composition) in influencing the composition of coral communities on reefs in the Upper Florida Keys, USA. We focussed our research on the following primary question: What is the relative influence of abiotic and biotic factors on abundance of juvenile and adult corals, and which factors appear to 
limit reef recovery in Florida? Since physical characteristics of the substrate likely influence benthic community composition, including the abundance of corals, we first studied benthic communities along with multiple physical characteristics (slope and rugosity of the substrate and depth of the sediment layer) across six spur and groove coral reefs. Our benthic data revealed intra-habitat differences thus we recorded grazing activity of herbivorous fishes in plots covering the range of intra-habitat variability. We used boosted regression trees to evaluate the relationship between biotic and abiotic characteristics and their relative influence on the presence/absence of juvenile and adult corals. We predicted that presence of juvenile and adult corals is primarily impacted by abiotic factors, particularly sediment, given that rates of herbivory are likely very high at the studied sites. Since sediment is more likely to accumulate on horizontal and flat substrates, we also hypothesize that less physically complex substrates (less rugose) with lower slope will reduce the likelihood of corals persistence.

\section{METHODS}

Study sites

Our research was conducted in the summer of 2015 along shallow ( 5 to $8 \mathrm{~m}$ ) fore reefs located approximately $10 \mathrm{~km}$ off the upper section of the Florida Keys, USA (Fig. 4.1A). Our sites encompassed low to high-relief spur and groove reef formations spanning a gradient of benthic assemblages and structural complexity from almost flat, gorgonian-dominated plains to more complex spur tops communities, and encompassed the steep ( $>45$ degrees) sides of spurs and hard-bottom patches within sandy spurs (Fig. $4.1 \mathrm{~B} \& \mathrm{C})$. 


\section{Benthic community composition}

We first described the benthic community composition, where corals are likely to settle and develop, and its relationship with physical habitat characteristics (e.g., substrate slope, sediment depth, and rugosity). We surveyed the benthos in $25(50 \times 50 \mathrm{~cm})$ quadrats placed every two meters along eight fixed $(50 \mathrm{~m})$ transects per site $(\mathrm{n}=200$ plots/site). We photographed each $50 \times 50 \mathrm{~cm}$ quadrat to analyze the benthic composition in the lab using Coral Point Count with Excel extensions version 4.1 (CPCe, Kohler and Gill 2006) with a modified code. Turf algae were classified as a multi-species (e.g. Polysiphonia spp, Ceramium spp.) algal assemblage forming a layer $<1 \mathrm{~cm}$ tall. We binned all species of crustose coralline algae into a single group (CCA). Species from the genus Peyssonnelia, a non-coralline crustose alga, were classified as a single group (Peyssonnelia). Percent cover from each plot was calculated from 25 points generated following a stratified-random distribution within each photo-quadrat. For each coral colony within a plot, we measured the size as the maximum colony diameter of corals larger than $4 \mathrm{~cm}$ in diameter. We surveyed coral juveniles (colonies $\leq 4 \mathrm{~cm}$ in diameter) in situ within the southwest quarter $(25 \times 25 \mathrm{~cm})$ of each plot. Each juvenile was measured and identified to genus level. We divided the number of coral juveniles by 0.0625 (area surveyed in $\mathrm{m}^{2}$ ) to estimate the density of a square meter (no. juveniles $\mathrm{m}^{-2}$ ).

Since physical characteristics can determine benthic composition, such as abundance of CCA (e.g., sediment load and slope of the substrate, see Fabricius and De'ath 2001) including coral recruitment facilitators (Arnold et al. 2010), we collected information on abiotic reef characteristics in each plot, including rugosity, sediment layer depth, and substrate slope. Rugosity index (RI) was used as a proxy of structural complexity 
(Risk 1972). We estimated RI using a $50 \mathrm{~cm}$ chain (link $\sim 1 \mathrm{~cm}$ length) laid within each $50 \times 50 \mathrm{~cm}$ quadrat, parallel to the transect line and measured the linear length. We calculated RI by dividing the linear length covered by the chain within the plot by the total length $(50 \mathrm{~cm})$ of the chain. Sediment depth $(\mathrm{mm})$ was measured using a pencil calibrated with $1 \mathrm{~mm}$ increments. The pencil was inserted vertically into the sediment layer until it reached hard substrate. We recorded the slope of the substrate (i.e., the angle from horizontal) using a protractor with a string connected to a small foam float. Small angles correspond to relatively flat (horizontal) substrate, where higher degree angles (up to $90^{\circ}$ ) were associated with vertical substrates.

Sediment was usually trapped within turf algae, forming a sediment-turf matrix. In order to quantify the sediment-turf matrix, we first measured the depth of the sediment layer of the matrix in five plots at $1 \mathrm{~m}, 11 \mathrm{~m}, 21 \mathrm{~m}, 31 \mathrm{~m}$, and $41 \mathrm{~m}$ along each transect ( $n=40 /$ site). Then, we removed sediment by perturbing the water with a manual bilge pump until we fully exposed the turf algae that was entangled within the sediment-turf matrix. Finally, we used a calibrated pencil to record the length of the exposed turf algae. Grazing rate of herbivorous fishes

To assess potential intra-habitat variability in herbivory, we videotaped $50 \times 50$ $\mathrm{cm}$ plots covering the range of reef habitats [i.e., plain $(\mathrm{n}=24)$, spur wall $(\mathrm{n}=23)$, flat spur top $(n=23)$, rugose spur top $(n=23)$ and groove $(m=21)]$. We chose plots located close to our transects that represent specific reef habitats as shown in Fig. 4.1B. We videotaped each plot for approximately 3 hours (during peak feeding time between 1000 and 1400) using GoPro cameras. We analyzed one hour of video (beginning approximately 1 hour after the camera was set up) from each plot and recorded the size, species, and entry and 
exit time of each fish observed within the plot. We recorded the number of bites taken by each herbivorous fish while identifying the species and estimate its size (TL). We estimated the weight of each herbivore using the length-weight equation following Bohnsack and Harper (1988) and Claro and Parenti (2001). Given that larger fishes often take larger bites and have a larger impact on algal communities (Lokrantz et al. 2008) we obtained a biomass-weighted metric of herbivory. We multiplied the total number of bites taken by each fish by the fish weight to account for the different impacts of bites by differently-sized fishes.

\section{Statistical analysis}

We averaged abiotic and biotic variables by habitat, transect, and site. The data were used in a nonmetric-multidimensional scaling analysis (NMDS) followed by permutational analysis of variance (PERMANOVA) to compare benthic community composition across sites and habitats (R package vegan, Oksanen et al. 2017). The relationship among abiotic variables (slope, rugosity, and sediment depth) was analyzed using a linear mixed model (R package lme4, Bates et al. 2015) where "habitat" and "transect" were nested within "site" and all were random variables. Except for the abundance of CCA, that was log transformed, all data met the assumptions for linear models. To test for the relationship between abiotic variables (fixed factors) and abundance (\% cover) of benthic groups we ran four linear mixed models with "habitat" and "transect" nested within "site" as random variables. Model selection was based on Akaike Information Criterion (AIC). The model explaining most variation (lowest AIC) was used to estimate the influence of predictive variables using R Package car (Fox and Weisberg 2011). We log-transformed the biomass-weighted metric of herbivory to 
achieve a normal distribution, then compared data among habitats and sites using a linear model.

Predicting drivers of coral communities

Because of low coral abundance across all habitats and sites, we tested for the influence of biotic and abiotic variables using presence and absence data of juvenile and adult corals using a logistic error structure (binomial distribution). We combined benthic community composition data with grazing pressure and used a Boosted regression tree $(\mathrm{BRT})$ model (tree complexity $=5$, learning rate $=0.005)$ following Elith et al. (2008) using the gbm package in R (Ridgeway 2008). We choose BRT over conventional models (e.g., general linear models) because, among other advantages, BRT is better equipped to handle interactions between predictors and are less sensitive to outliers (Elith et al. 2008). The deviance plots as well as total and residual deviance resulting from each BRT model can be found in appendix C (Fig. C4-C8). We ran all descriptive analysis, graphs, and models with R version, 3.2.2 (R Development Core Team 2016).

\section{RESUlts}

Benthic community composition

Our study sites displayed a gradient of reefs that ranged from almost complete horizontal substrates covered by sediment (plain) to more diversified algal communities (e.g., CCA, Turf and Dictyota spp.) in habitats with steeper and more physically complex substrates such as spur top and wall of the spurs (Fig. 4.2). Sediment, turf, CCA and Dictyota spp. dominated benthic communities across all habitats and study sites (Table C1, Fig. 4.2). Differences in community composition 
among habitats explained almost double the variation explained by reef site (PERMANOVA, habitat, $\mathrm{R}^{2}=0.37, \mathrm{~F}_{4,141}=28.1, \mathrm{p}=0.010$, site, $\mathrm{R}^{2}=0.21, \mathrm{~F}_{5,141}=$ $13.0, \mathrm{p}=0.010)$

Slope of the substrate was positively related to rugosity (Fig. C1A, LMM, $\chi^{2}=$ $5.8, p=0.015$ ) but only slope significantly decreased depth of the sediment layer (Fig. C1A, LMM, slope, $\chi^{2}=10.6, p=0.001$, rugosity, $\left.\chi^{2}=1.00, p=0.317\right)$. Percent cover of sediment decreased with both slope (Fig. C1A, LMM, $\left.\chi^{2}=17.2, p<0.001\right)$ and rugosity (Fig. C2B, LMM, $\left.\chi^{2}=23.2, p<0.001\right)$ of the substrate reaching the highest value $(>70 \%)$ at the least complex and more horizontal habitats, groove and plain (Table C1).

Slope and sediment depth displayed significant interactions (LMM, slope:site, $\chi^{2}=23.5, \mathrm{p}<0.001$, sediment depth:site, $\chi^{2}=21.6, \mathrm{p}=0.001$, slope:sediment, $\chi^{2}=$ $17.0, \mathrm{p}=0.004)$. The abundance of Dictyota spp. averaged $33 \pm 3 \%$ and $30 \pm 1 \%$ at rugose spur top and spur wall habitats which comprised approximately double the abundance found at lower rugosity habitats, groove $(16 \pm 1 \%)$ and plain $(18 \pm 1 \%)$ (Fig. 4.2). The abundance of Dictyota spp. and turf increased with rugosity and was highest at the two reef habitats with greatest substrate rugosity, spur wall and rugose spur top (Table C1, Fig. C2D\&H, turf, $\chi^{2}=17.1, \mathrm{p}<0.001$, Dictyota spp., $\chi^{2}=4.5, \mathrm{p}=0.034$ ). Other species of macroalgae such as Lobophora variegata were practically absent (> $1 \%$ cover).

Surprisingly, abundance of CCA was neither related to rugosity nor to slope of the substrate (Fig. C2E\&F, rugosity, $\chi^{2}=0.5, p=0.463$, slope, $\chi^{2}=2.0, p=0.158$ ). 
However, the abundance of CCA decreased rapidly with sediment depth at some sites where CCA became almost undetectable in areas with more than $1 \mathrm{~mm}$ depth sediment (Fig. 4.3A, sediment depth: site, $\chi^{2}=30.1, \mathrm{p}<0.001$ ). Similarly, percent cover of turf algae decreased with sediment depth (Fig. 4.3B, $\chi^{2}=51.5, \mathrm{p}<0.001$ ). Our sediment removal plots showed that sediment depth was tightly coupled with turf length (Fig. 4.3C, $\chi^{2}=491.6, \mathrm{p}<0.001$ ) which form commonly found sediment-turf matrix. Fish abundance and grazing activity of herbivorous fishes

We found that the number of herbivorous fishes visiting plots in both rugose habitats and flat spur tops $\left(\sim 50\right.$ ind. $\left.\mathrm{hr}^{-1}\right)$ was approximately double the number in plain $\left(27 \pm 3\right.$ ind. $\left.\mathrm{hr}^{-1}\right)$ and spur wall $\left(17 \pm 5\right.$ ind. $\left.\mathrm{hr}^{-1}\right)$ plots, regardless of site (LMM, habitat, $\mathrm{F}_{4,99}=10.03, \mathrm{p}<0.001$, site, $\left.\mathrm{F}_{4,99}=0.73, \mathrm{p}=0.576\right)$. Herbivorous fish showed lower grazing pressure on plain $\left(96 \pm 20\right.$ bite plot hr $\left.^{-1}\right)$ and spur wall habitats $(31 \pm 23$ bite plot $\mathrm{hr}^{-1}$ ) compared to the other three habitats that ranged from $195 \pm 28$ bites plot $\mathrm{hr}^{-1}$ (flat spur top) to $230 \pm 40 \mathrm{bite}^{\mathrm{plot}} \mathrm{hr}^{-1}$ (rugose spur top), irrespective of site (LMM, habitat, $\mathrm{F}_{4,99}=7.46, \mathrm{p}<0.001$, site, $\mathrm{F}_{4,99}=1.19, \mathrm{p}=0.320$ ). Similarly, herbivory pressure, the product of number of bites taken by fish weight, was lowest at spur wall habitats $\left(4063 \pm 2927\right.$ bite $\mathrm{g}$ plot $\left.\mathrm{Hr}^{-1}\right)$ while the groove and rugose spur topranked the highest with $22299 \pm 6362$ bite g plot $\mathrm{Hr}^{-1}$ and $22416 \pm 5065$ bite g plot $\mathrm{Hr}^{-1}$, respectively (LMM, habitat, $\left.\mathrm{F}_{4,99}=18.24, \mathrm{p}<0.001\right)$.

Predicting drivers of coral communities

Coral cover was very low $(1.0 \pm 0.1 \%)$ across all sites $\left(\mathrm{LMM}, \chi^{2}=9.0, \mathrm{p}=\right.$ 0.108 ) and rugosity of the substrate was the only abiotic or biotic variable that was 
individually significant (LMM, rugosity, $\chi^{2}=4.2, p=0.040$ ). The density of juvenile $(\leq 4 \mathrm{~cm})$ corals averaged $13.1 \pm 0.6$ coral $\mathrm{m}^{2}$ with communities dominated by Agaricia (35\% of juvenile corals), Siderastrea (29\% of juvenile corals) and Porites (28\% of juvenile corals) (Fig. C3A\&B). We found more than $50 \%(n=604)$ of the total number of plots $(n=1086)$ did not contain juvenile corals, thus we used analyses of presence/absence for this zero-inflated data set. The boosted regression tree model revealed that presence/absence of juvenile corals was primarily driven by the depth of sediment layer ( $\sim 20 \%$ relative influence), the slope of the substrate ( $\sim 18 \%$ relative influence) and abundance of Dictyota spp. ( $16 \%$ relative influence) (Fig. 4.4A\&B). Presence of juvenile corals of both Siderastrea ( $\sim 40 \%$ relative influence) and Porites ( $\sim 20 \%$ relative influence) was positively related to the density of all adult corals Fig. 4.5A\&C). Abundance and depth of sediment were the best predictors of juvenile corals of Agaricia ( $\sim 40 \%$ relative influence both combined) the second best predictor (after density of adult corals) of Siderastrea (Fig. 4.5A\&B). In contrast, the abundance of Dictyota spp. ( $14 \%$ relative influence) was the second-best predictor of juveniles of Porites followed by the abundance of sediment with approximately $13 \%$ relative influence (Fig. 4.5C).

The density of adult corals $(>4 \mathrm{~cm})$ was low across all habitats $\left(0.8 \pm 0.1\right.$ coral m$^{-}$ ${ }^{2}$ ), which represents approximately $90 \%$ fewer adult corals compared to the density of juveniles (Fig. C3C). Approximately $60 \%$ of all $(n=214)$ adult colonies belonged to Siderastrea (Fig. C3D). The abundance of turf was the best positive predictor related to the presence of adult corals while the abundance of sediment (sediment cover) was the best negative predictor (Fig. 4.6A\&B). Abundance of CCA was the weakest predictor of presence/absence of both juvenile and adult corals. Noticeably, juvenile and adult 
colonies of large reef-building corals such as Orbicella and Acropora represented approximately $3 \%$ of both juvenile $(\mathrm{n}=25)$ and adult $(\mathrm{n}=8)$ coral communities (Fig. C3 $\mathrm{B} \& \mathrm{D})$.

DISCUSSION

Overfishing has depleted abundance of herbivorous fish in the western Atlantic leading to reduced top-down control on macroalgal communities with negative implication for coral reef resilience (Jackson et al. 2014). South Florida coral reefs represent a special case where there is still high a abundance of large herbivorous fish species. The low resilience of Florida Keys reefs despite a significant supply of coral larvae (van Woesik et al. 2014) and high abundance of herbivorous fish suggest that suitable habitat conditions for coral to settle and grow might be the limiting recovery factor. Our results showed that abundance and depth of the sediment layer are major factors affecting both juveniles and adult corals, particularly if the substrate is flat (steeper slopes have reduced sediment build up). We found extremely low coral cover and communities of juveniles dominated by so-called weedy species (Knowlton 2001) of genera, Porites, Agaricia, and Siderastrea. The density of adult colonies was very low and primarily dominated by Siderastrea.

There is substantial evidence that sediment has deleterious effects on juvenile and adult corals (Rogers 1990, Jones et al. 2015). Negative effects of sedimentation include reduction of fertilization rates (Jones et al. 2015), recruitment (Birrell et al. 2005), coral growth (Rogers 1990), and complete or partial coral colony mortality (Flores et al. 2012). Reef habitats with a high percent cover of sediment were ubiquitous across our study 
sites, suggesting that sediment might be creating unsuitable conditions for the settlement and growth of coral recruits. In support of this hypothesis, we found that Siderastrea was the dominant genus of the fewer (approximately $10 \%$ of the number of juveniles) adult corals. Siderastrea is temperature and sediment tolerant coral genus (Lirman and Manzello 2009) and thus the most likely to thrive under high sediment conditions.

In addition to the negative effect of sediment, parrotfish predation on corals can have a substantial impact on coral colonies (Roff et al. 2011, Mumby 2009). For instance, Rotjan et al. (2006) showed that chronic coral predation can delay the process of coral recovery after disturbances. In places with low coral cover and high abundance of corallivore parrotfish such as South Florida, coral predation often increases leading to overall detrimental effects on coral communities.

The second detractor of coral communities, in order of relative influence, was the abundance of Dictyota spp. Species within the genus (e.g., Dictyota pulchella) have been shown to reduce the growth of newly settled corals, specifically via physical abrasion, shading, or other physical mechanisms (Box and Mumby 2007). We did not specifically identify the species of Dictyota found in our study, but morphology and size of commonly found specimens suggest that species of Dictyota differ in abundance across habitats. In exposed habitats such as plain and flat spur top, upright species resemble those of D. pulchella, D. caribbea, and D. menstrualis (author's personal observations). Similar morphology of fleshy algae (e.g. Liagora sp.) has also shown to physically inhibit settlement and develop of corals (Box and Mumby 2007, Doropoulos et al. 2014). Macroalgae such as Lobophora variegata with similar prostrate morphology can decrease survival and growth of coral, likely via abrasion (Box and Mumby 2007). This suggests 
that Dictyota found in our surveys might impact coral juvenile physically (e.g. abrasion), via allelopathic interactions (Rasher et al. 2011), or simply via pre-emption of the substrate and thus reduction in available space for recruits (Kuffner et al. 2006). Other commonly seeing algae in Caribbean coral reefs such as Lobophora variegata were practically absent.

Turf and CCA displayed low abundance, yet they might still influence corals, particularly at rugose spur top and spur wall. Turf algae either associated with sediment or not have been shown to reduce coral settlement (Birrell et al. 2005, Arnold et al. 2010). In the case of CCA, only a few species (e.g., Titanoderma prototypum) facilitate coral recruitment (Arnold et al. 2010, Ritson-Williams et al. 2010). Furthermore, we did not find evidence that CCA influenced the density of juvenile or adult corals, suggesting that the most common species in our sites might not facilitate coral settlement. In support of this hypothesis, the most common crustose algae, at least on rugose spur tops, was a thick crustose alga with a smooth surface likely belonging to genus Porolithon.

Benthic composition, substrate texture and color, the abundance of micro-refuges, and orientation are among the many factors that can influence coral settlement (Nozawa 2008, Davies et al. 2013, Strader et al. 2015, Webster et al. 2015). Our findings show that across the five identified reef habitats, the conditions are likely unsuitable for newly settled corals to grow. Pooling the abundance of sediment and Dictyota spp., major predictors with a negative influence on juvenile corals (CCA is still unclear since a higher taxonomic resolution is needed), they cover $>50 \%$ of the benthos. This suggests that coral larvae have a low likelihood of finding favorable conditions to settle on these reefs. Our results support the hypothesis proposed by van Woesik et al. (2014), that larval supply 
does not seem to be the main cause of low coral recruitment in the Florida Keys reefs, but rather, the lack of substrate with suitable habitat quality for settlement and survival of recruits. Further studies are needed to evaluate the effect of sedimented-turf on settlement and survival of new settle corals.

The Florida Keys Reefs have experienced severe ( $>75 \%)$ loss of corals in the last 50 years caused by several disturbances including cold-water stress events (Burns 1985, Lirman et al. 2011), coral diseases (Porter and Meier 1992, Kuta and Richardson 1996), and bleaching events (Manzello 2015), resulting in a dramatic decline in coral cover (Lewis et al. 2017). As a result, the current coral cover is less than $5 \%$ across the outer reefs (spur and groove reefs) Florida Keys-wide (Rutten et al. 2008, McClenachan et al. 2017). Unlike other Caribbean reefs (e.g., Discovery Bay, Jamaica), protection of herbivorous fishes has kept high herbivory pressure in the Florida Keys with the potential to maintain low macroalgal states. However, the positive result of protecting herbivorous fishes on coral communities might be obscured by the current high abundance of sediment that creates unfavorable habitat conditions for settlement, survival, and growth of corals. Our results suggest that along with protection of herbivores further strategies are needed to save the Florida Keys reefs.

\section{ACKNOWLEDGEMENTS}

This work was supported in part by a grant from a State Wildlife Grant from the Florida Fish and Wildlife Conservation Commission. We thank all volunteers that assisted us during our field and lab work. This work was conducted under a permit from the Florida Keys National Marine Sanctuary \#2014-083-A1. This is contribution \#x from 
the Center for Coastal Oceans Research in the Institute for Water and Environment at

Florida International University.

\section{REFERENCES}

Adam TC, Burkepile DE, Ruttenberg BI, Paddack MJ (2015a) Herbivory and the resilience of Caribbean coral reefs: knowledge gaps and implications for management. Mar Ecol Prog Ser 520:1-20

Adam TC, Kelley M, Ruttenberg BI, Burkepile DE (2015b). Resource partitioning along multiple niche axes drives functional diversity in parrotfishes on Caribbean coral reefs. Oecologia 179:1173-1185

Arnold SN, Steneck RS (2011) Settling into an increasingly hostile world: The rapidly closing "recruitment window" for corals. PloS ONE 6(12): e28681.

Doi:10.1371/journal.pone.0028681

Arnold SN, Steneck RS, Mumby PJ (2010) Running the gauntlet: inhibitory effects of algal turfs on the processes of coral recruitment. Mar Ecol Prog Ser 414:91-105

Aronson RB, Precht WF (2001) White-band disease and the changing face of Caribbean coral reefs. Hydrobiologia 460:25-38

Baker AC, Glynn PW, Riegl B (2008) Climate change and coral reef bleaching: A ecological assessment of long-term impacts, recovery trends and future outlook. Estuar Coast Shelf Sci 80:435-471

Bates D, Maechler M, Bolher B, Walker S (2015) Fitting linear mixed-effects models using lme4. J Stat Softw 67:1-48

Begin C, Schelten CK, Nugues MM, Hawkins J, Roberts Callum, Cote IM (2015) Effects of protection and sediment stress on coral reefs in Saint Lucia. PloS ONE 11:e0146855.Doi.10.1371/journal.pone.0146855

Birrell CL, McCook LJ, Willis BL (2005) Effects of algal turfs and sediment on coral settlement. Mar Poll Bull 51:408-414

Birrell Cl, McCook LJ, Willis BL, Diaz-Pulido GA (2008) Effects of benthic algae on the replenishment of corals and the implications for the resilience of coral reefs. Oceanogr Mar Biol Annu Rev 46:25-63 
Bohnsack JA, Harper DE (1988) Length-weight relationships of selected marine reef fishes from southeastern United States and the Caribbean. NOAA Tech. Mem. NMFS-SEFC-215

Box SJ, Mumby PJ (2007) Effect of macroalgal competition on growth and survival of juvenile Caribbean corals. Mar Ecol Prog Ser 342:139-149

Bozec Y-M, Alvarez-Filip L, Mumby PJ (2015) The dynamics of architectural complexity on coral reefs under climate change. Glob Change Biol 21:223-235

Brandl SJ, Hoey AS, Bellwood DR (2013) Micro-topography mediates interactions between corals, algae, and herbivorous fishes on coral reefs. Coral Reefs.Doi.10.1007/s00338-013-1110-5

Burkepile DE, Allgeier JE, Shantz AA, Pritchard CE, Lemoine NP, Bhatti LH, Layman CA (2013) Nutrient supply from fishes facilitates macroalgae and suppresses corals in a Caribbean coral reef ecosystem. Sci Rep 3:1493.Doi.10.1038/srep1493

Burns TP (1985) Hard-coral distribution and cold-water disturbances in South Florida: variation with depth and location. Coral Reefs 4:117-124

Claro R, Parenti L (2001) The marine ichthyofauna of Cuba. In: R. Claro, K. C. Lindeman and L. R. Parenti (eds) Ecology of the marine fishes of Cuba. Smithsonian Institution Press, Washington and London: pp 21-57

Davies SW, Matz MV, Vize PD (2013) Ecological complexity of coral recruitment processes: Effects of invertebrate herbivores on coral recruitment and growth depends upon substratum properties and coral species. PloS ONE 8(9): e72830. Doi:10.1371/journal.pone.0072830

D'Angelo C, Wieddenmann J (2014) Impacts of nutrient enrichment on coral reefs: new perspectives and implications for coastal management and reef survival. Curr Opin Environ Sustain 7:82-93

Done TJ, Ogden JC, Wiebe WJ, Rosen BR (1996) Biodiversity and ecosystem function of coral reefs. In: Moonet HA, Cushman JH, Medina E, Sala OE, Schulze ED (eds) Functional roles of biodiversity: A Global Perspective. SCOPE 1996, John Wiley and Sons

Doropoulos C, Roff G, Zupan M, Nestor V, Isechal AL, Mumby PJ (2014) Reef-scale failure of coral settlement following typhoon disturbance and macroalgal bloom in Palau, Western Pacific. Coral Reefs 33:613-623 
Doropoulos C, Roff G, Bozec Y-M, Zupan M, Werminghausen, Mumby PJ (2016) Characterizing the ecological trade-offs throughout the early ontogeny of coral recruitment. Ecol Monogr 86:20-44

Dustan P (1977) Vitality of reef coral populations off Key Largo, Florida: Recruitment and mortality. Environ Geol 2:51-58

Elith J, Leathwick JR, Hastie T (2008) A working guide to boosted regression trees. J Anim Ecol 77:802-813

Engle VD, Summers JK (1999) Latitudinal gradients in benthic community composition in western Atlantic Estuaries. J Biogeogr 26:1007-1023

Fabricius K, De'ath G (2001) Environmental factors associated with the spatial distribution of crustose coralline algae on the Great Barrier Reef. Coral Reefs 19:303-309

Flores F, Hoogenboom MO, Smith LD, Cooper TF, Abrego D, Negri AP (2012) Chronic exposure of corals to fine sediments: lethal and sub-lethal impacts. PloS ONE e37795.Doi:10.1371/journal.pone.0037795

Fox J, Weisberg S (2011) Companion to apllied regression, second edition. Thousand Oaks: Sage. URL: http://socserv.socsci.mcmaster.ca/jfox/Books/Companion

Harborne AR, Rogers A, Bozec Y-M, Mumby PJ (2016) Multiple stressors and the functioning of coral reefs. Annu Rev Mar Sci 9:445-468

Hoey AS, Pratchett MS, Cvitanovic C (2011) High macroalgal cover and low coral recruitment undermine the potential resilience of the world's southernmost coral reef assemblages. PloS ONE 6:e25824.Doi:10.1371/journal.pone.0025824

Hughes TP, Graham NAJ, Jackson JBC, Mumby PJ, Steneck RS (2010) Rising to the challenge of sustaining coral reef resilience. Trends Ecol Evol 25:633-642

Jaap WC (1984) The ecology of the south Florida coral reefs: a community profile. US Fish Wild FWS/OBS-82/08.138 pp

Jackson JBC, Donovan MK, Cramer KL, Lam VV (2014). Status and Trends of Caribbean Coral Reefs: 1970-2012. Global Coral Reef Monitoring Network, IUCN, Gland, Switzerland

Jones R, Ricardo GF, Negri AP (2015) Effects of sediment on the reproductive cycle of corals. Mar Pollut Bull 100:13-33

Knowlton N (2001) The future of coral reefs. Proc Natl Acad Sci USA 98:5419-5425 
Kohler KE, Gill SM (2006) Coral point count with Excel extensions (CPCe): A visual basic program for the determination of coral and substrate coverage using random point count methodology. Computers and Geosciences 32:1259-1269

Kuffner IB, Walters LJ, Becerro MA, Paul VJ, Ritson-Williams R, Beach KS (2006) Inhibition of coral recruitment by macroalgae and cyanobacteria. Mar Ecol Prog Ser 323:107-117

Kuta KG, Richardson LL (1996) Abundance and distribution of black band disease on coral reefs in the northern Florida Keys. Coral Reefs 15:219-223

Lapointe BE, Thacker K, Hanson C, Getten L (2011) Sewage pollution in Negril, Jamaica: effects on nutrition and ecology of coral reef macroalgae. Chin $\mathrm{J}$ Oceanology Limnol 29:775-789

Lewis CL, Neely KL, Richardson LL, Rodriguez-Lanetty M (2017) Temporal dynamics of black band disease affecting pillar coral (Dendrogyra cilindricus) following two consecutive hyperthermal events on the Florida Reef Tract. Coral Reefs $36: 427-431$

Lirman D, Manzello D (2009) Patterns of resistance and resilience of the stress-tolerant coral Siderastrea radians (Pallas) to sub-optimal salinity and sediment burial. J Exp Mar Biol Ecol 369:72-77

Lirman D, Schopmeyer S, Manzello D, Gramer LJ, Precht WF, et al. (2011) Severe 2010 Cold-Water Event Caused Unprecedented Mortality to Corals of the Florida Reef Tract and Reversed Previous Survivorship Patterns. PLoS ONE 6(8): e23047. Doi:10.1371/journal.pone.0023047

Lokrantz J, Nystrom M, Thyresson M, Johansson C (2008) The non-linear relationship between body size and function in parrotfishes. Coral Reefs 27:967-974

Manzello DP (2015) Rapid recent warming of coral reefs in the Florida Keys Sci Rep 5:16762.Doi.10.1038/srep16762

McClenachan L, O’Connor G, Neal BP, Pandolfi JM, Jackson JBC (2017) Ghost reefs: Nautical charts document large spatial scale of coral reef loss over 240 years. Sci Adv 3:e1603155.Doi: 10.1126/sciadv.1603155

Mumby PJ (2006) The impact of exploiting grazers (Scaridae) on the dynamics of Caribbean coral reefs. Ecol Appl 16:747-769

Mumby PJ, Hasting A, Edwards HJ (2007) Thresholds and the resilience of Caribbean coral reefs. Nature 450:98-101 
Mumby PJ (2009) Phase shifts and the stability of macroalgal communities on Caribbean coral reefs. 28:761-773

Nozawa Y (2008) Micro-crevice structure enhances coral spat survivorship. J Exp Mar Biol Ecol 367:127-130

Oksanen J, Blanchet FG, Friendly M, Kindt R, Legendre P, McGlinn D, Minchin PR, O'Hara RB, Simpson GL, Solymos P, et al. 2017. Community ecology package. https://cran.r-project.org, https://github.com/vegandevs/vegan

Paddack MJ, Cowen RK, Sponaugle S (2006) Grazing pressure of herbivorous coral reef fishes on low coral-cover reefs. Coral Reefs 25:461-472

Porter JW, Meier OW (1992) Quantification of loss and change in Floridian Reef Coral Populations. Amer Zool 32:625-640

R Development Core Team (2016) R: A language and environment for statistical computing. R Foundation for Statistical Computing, Vienna, Austria. ISBN 3900051-07-0, URL http://R-project.org/

Rasher DB, Stout EP, Engel S, Kubanek J, Hay ME (2011) Macroalgal terpenes function as allelopathic agents against reef corals. Proc Natl Acad Sci 108:17726-17731

Ridgeway, G. (2008) Generalized boosted regression models. Documentation on the $R$ Package 'gbm', version 1.5-7. http://www.i-pensieri.com/gregr/gbm.shtml

Risk MJ (1972) Fish diversity on a coral reef in the Virgin Islands. Atoll Res Bull 153:16

Ritson-Williams R, Paul VJ, Arnold SN, Steneck RS (2010) Larval settlement preferences and post-settlement survival of the threatened Caribbean corals $A$. palmata and A. cervicornis. Coral Reefs 29:71-81

Roff G, Ledlie MH, Ortiz JC, Mumby PJ (2011) Spatial patterns of parrotfish corallivory in the Caribbean: The importance of coral taxa, density and size. PloS ONE 6:e29133.Doi.org/10.1371/journal.pone.0029133

Rogers CS (1990) Responses of coral reefs and reef organisms to sedimentation. Mar Ecol Prog Ser 62:185-202

Rotjan RD, Dimond JL, Thornill DJ, Leichter JJ, Helmuth B, Kemp DW, Lewis SM (2006) Chronic parrotfish grazing impedes coral recovery after bleaching. Coral Reefs.Doi10.1007/s00338-006-0120-y 
Rutten LM, Chiappone M, Swanson DW, Miller SL (2008) Stony coral species diversity and cover in the Florida Keys using design-based sampling. Proc $11^{\text {th }}$ Int Coral Reef Symp 18:800-804

Ruzicka RR, Colella MA, Porter JW, Morrison JM, Kidney JA, Brinkhuis V, Lunz KS, Macaulay KA, Bartlett LA, Meyers MK, Colee J (2013) Temporal changes in benthic assemblages on Florida Keys reefs 11 years after the 1997/1998 El niño. Mar Ecol Prog Ser 489:125-141

Suchley A, McField MD, Alvarez-Filip L (2016) Rapidly increasing macroalgal cover not related to herbivorous fishes on Mesoamerican reefs. PeerJ 4:e2084. Doi.10.7717/peerj.2084

Schutte VGW, Selig ER, Bruno JF (2010) Regional spatio-temporal trends in Caribbean coral reef benthic communities. Mar Ecol Prog Ser 402:115-122

Toth LT, van Woesik R, Murdoch TJT, Smith SR, Ogden JC, Precht WF, Aronson RB (2014) Do no-take reserves benefit Florida's corals? 14 years of changes and stasis in the Florida Keys National Marine Sanctuary. Coral Reefs 33:565-577

van Woesik R, Scott WJ, Aronson RB (2014) Lost opportunities: coral recruitment does not translate to reef recovery in the Florida Keys. Mar Pollut Bull 88:110-117

Walker BK (2012) Spatial analyses of benthic habitats to define coral reef ecosystem regions and potential biogeographic boundaries along a latitudinal gradient. PloS ONE 7: e30466. https://doi.org/10.1371/journal.pone.0030466

Walker BK, Gilliam DS (2013) Determining the extent and characterising coral reef habits of the northern latitudes of the Florida Reef Tract (Martin County) PloS ONE 8: e80439. Doi:10.1371/journal.pone.0080439

Webster FJ, Babcock RC, Keulen MV, Loneragan NR (2015) Macroalgae inhibits larval settlement and increases recruit mortality at Ningaloo Reef, Western Australia. PloS ONE 10(4): e0124162. Doi:10.1371/journal.pone.0124162

Zaneveld JR, Burkepile DE, Shantz AA, Pritchard CE, McMinds R, Payet JP, Welsh R, Correa AMS, Lemoine NP, Rosales S, Fuchs C, Maynard J, Vega-Thurber R (2016) Overfishing and nutrient pollution interact with temperature to disrupt coral reefs down to microbial scales. Nat Commun 7:11833.Doi:10.1038/ncomms11833 
Figure 4.1 Study sites (A), graphical representation of the reef habitat within spur and groove formation, and (C) proportion of habitats by study sites.
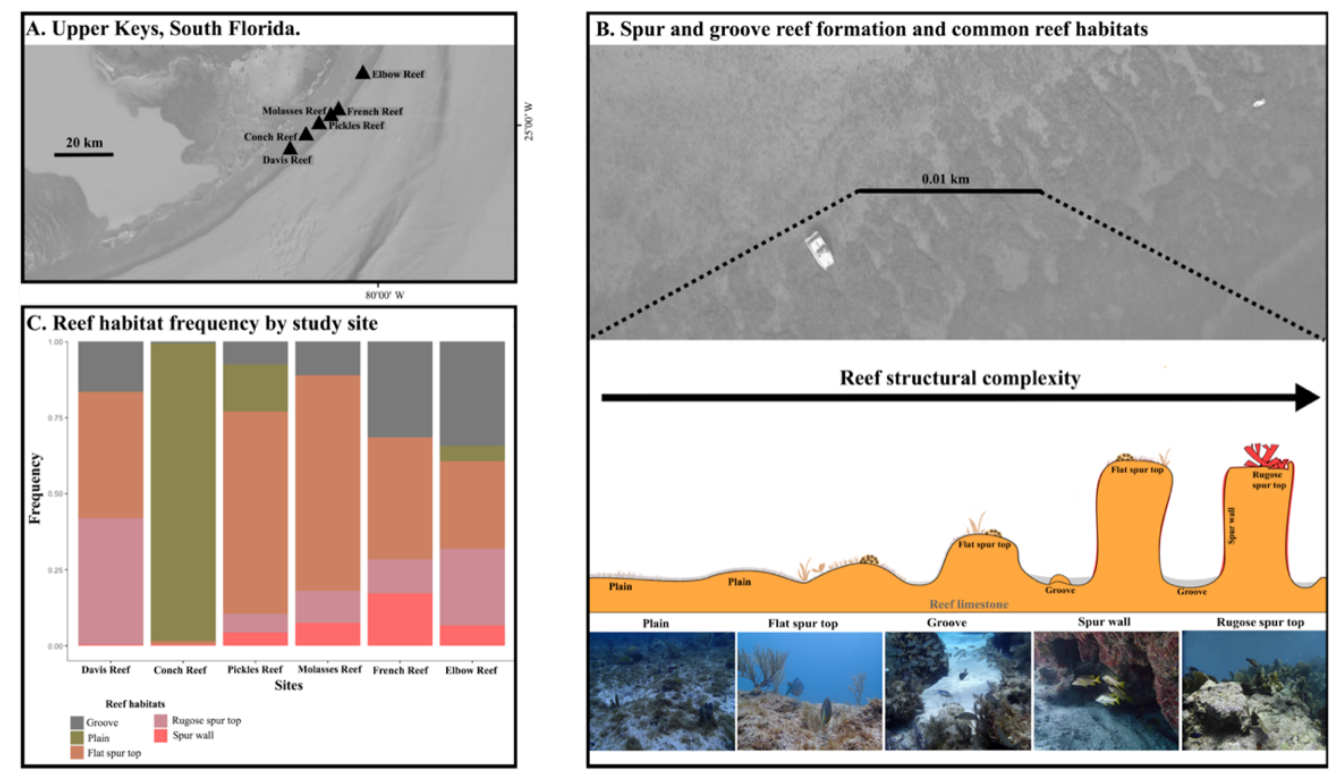
Figure 4.2 Abundance of major taxa by reef habitat, groove (A), plain (B), flat spur top $(C)$, rugose spur top (D) and spur wall (E). The bars indicate average $( \pm S E)$. NonMultidimensional Scaling Analysis (NMDS) contrasting reef habitats and sites (F). Statistics resulted from permutational analysis of variance (PERMANOVA).
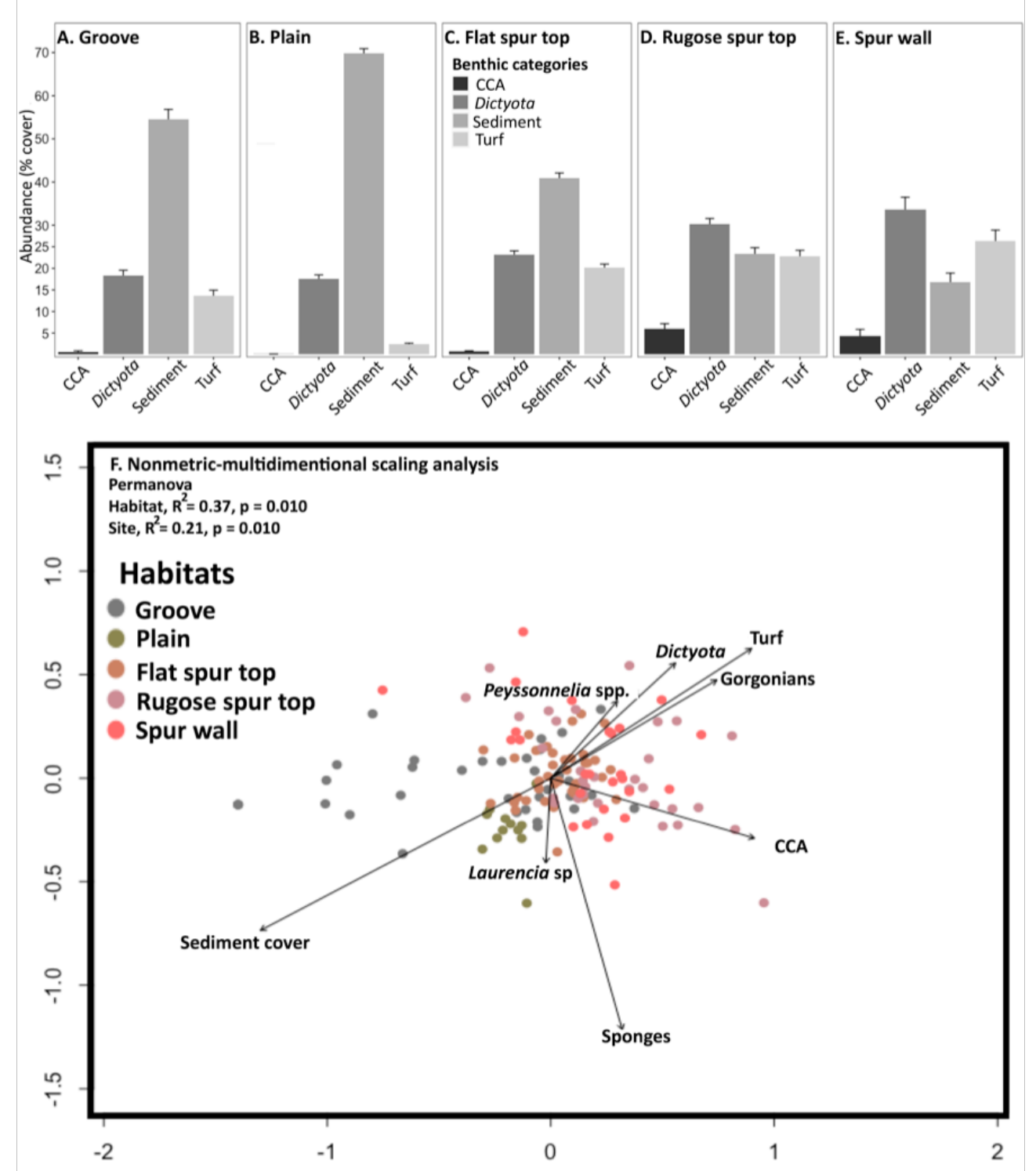
Figure 4.3 Relationship between abundance of CCA (A) and turf (B) in relation to sediment depth. Panel C illustrates the relationship between the sediment depth and the length of turf algae found after removing the sediment layer. Points represent the average cover, the line indicates the linear relationship and shaded area the standard error. Statistics resulted from the Linear Mixed Model (LMM).
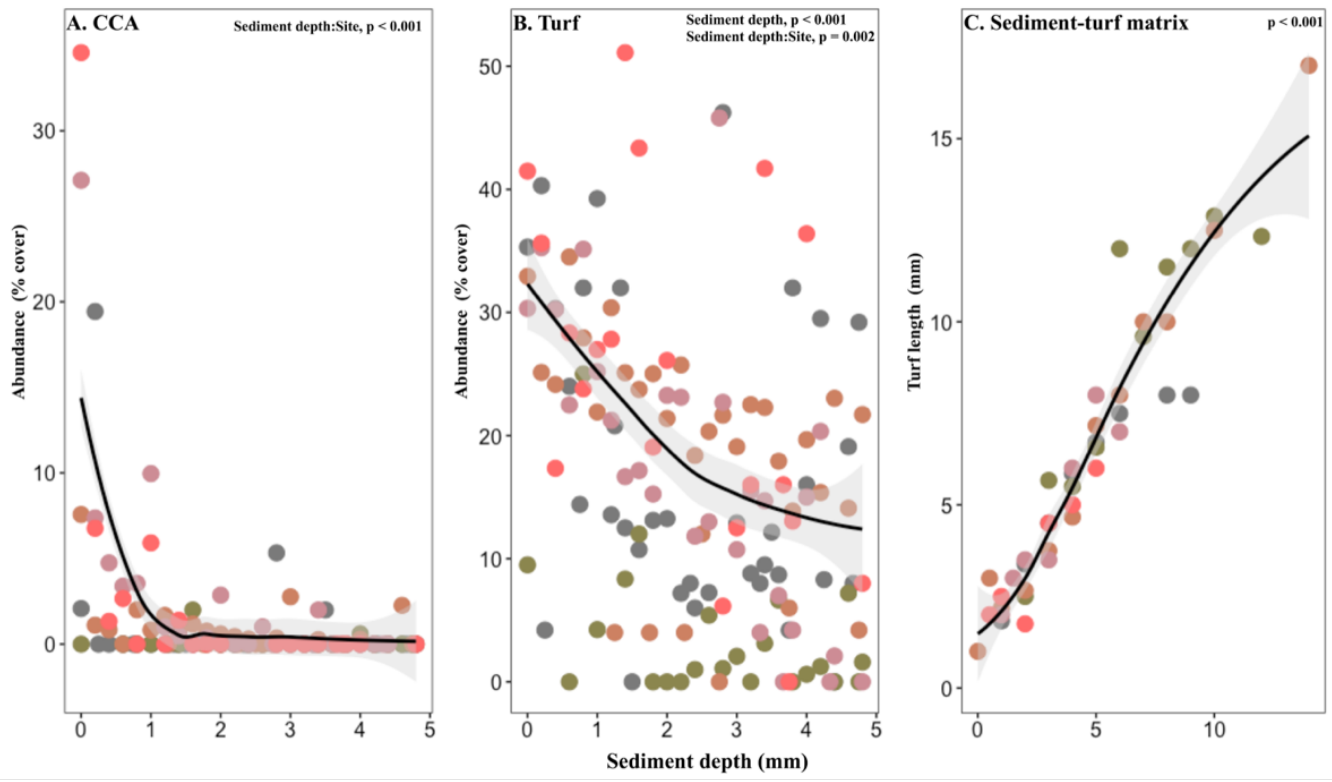
Figure 4.4 Relative influence of factors driving presence of juvenile $(\leq 4 \mathrm{~cm})$ (A) corals. Average $( \pm \mathrm{SE})$ density of juvenile corals as a function of sediment depth.
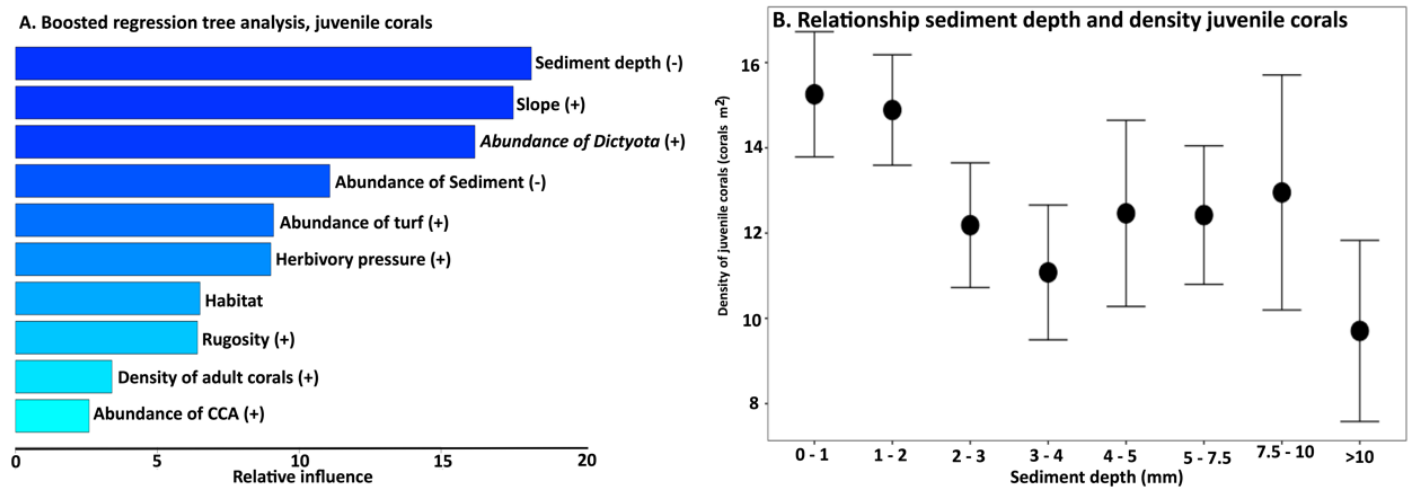
Figure 4.5 Relative influence of factors driving presence of juvenile $(\leq 4 \mathrm{~cm})$ corals of the most abundant genera, Siderastrea (A), Agaricia (B) and Porites (C).

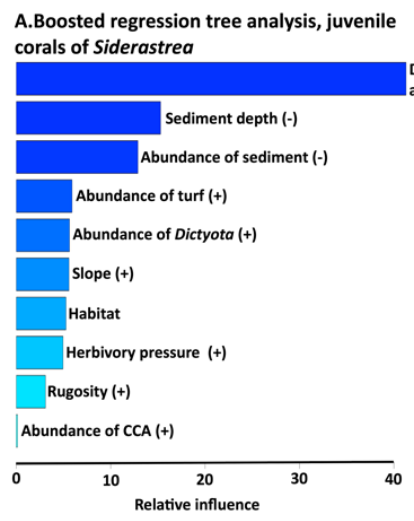

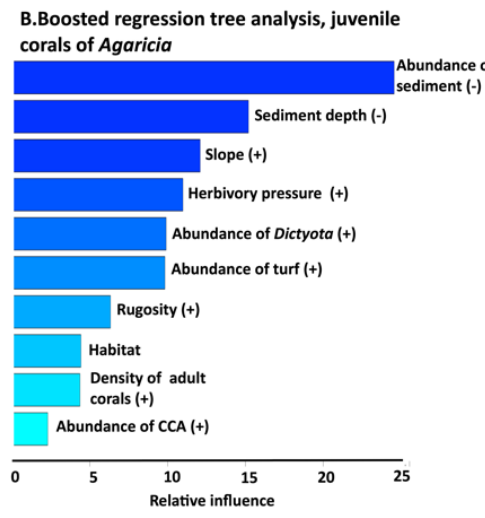

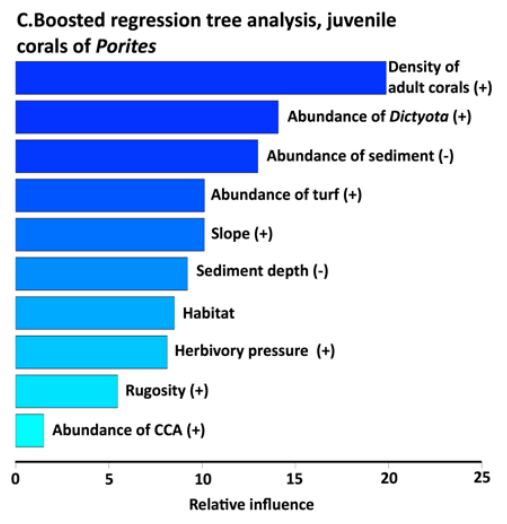


Figure 4.6 Relative influence of factors driving presence of adult $(>4 \mathrm{~cm})(\mathrm{A})$ corals. Average $( \pm \mathrm{SE})$ density of adult corals as a function of sediment abundance.
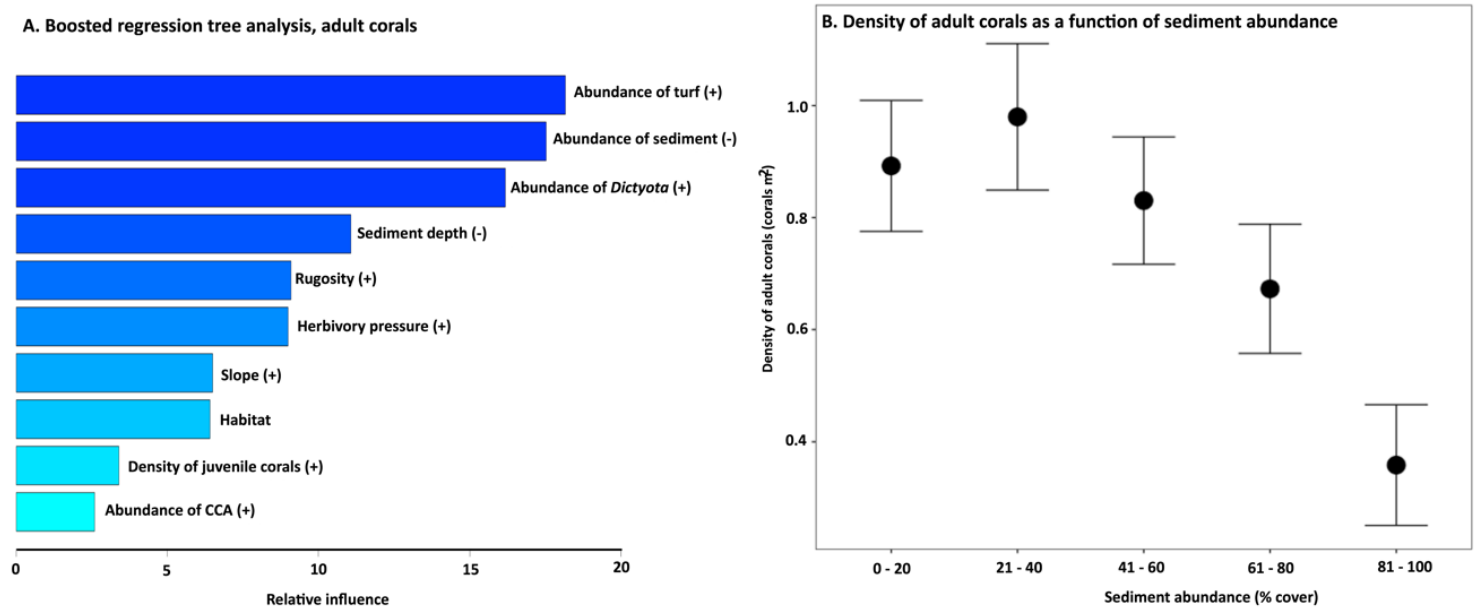
CHAPTER V

FISHING, POLLUTION, CLIMATE CHANGE, AND THE LONG-TERM DECLINE OF CORAL REEFS OFF HAVANA, CUBA 


\section{ABSTRACT}

Understanding temporal and spatial variation of coral reef communities allows us to analyze the relative effects of local stressors, such as fishing and eutrophication, and global stressors, such as ocean warming. To test for spatial and temporal changes in coral reef communities, we combined recent benthic and fish surveys from 2016 with long-term data, dating back to the late 1990s, from four zones located at different distances from Central Havana, largest Cuban population center. These changes may indicate the shifting importance of local versus global stressors affecting reef communities. Regardless of the distance from Havana, we found that coral cover was uniformly low $(\sim 10 \%)$, whereas macroalgal abundance was often high ( $65 \%)$. Similarly, fish biomass was low across zones, particularly for herbivorous fishes $\left(\sim 12 \mathrm{~g} \mathrm{~m}^{-2}\right)$ that are critical ecological drivers of reef structure and coral resilience. Analyses of longer-term trends showed that coral cover near Havana has been below $\sim 10 \%$ since at least 1995 , potentially because of local stressors. In contrast, reefs further from Havana maintained relatively high coral cover ( $\sim 30 \%$ ) until the early 2000 s but declined more recently to $\sim 15 \%$, putting them near the Caribbean-wide average. These distinct spatial and temporal trajectories of reef communities may be the result of the expansion of local stressors away from Havana as the human population increased or fishers ventured farther away to exploit new resources. Alternatively, the more recent decline of reefs farther from population centers may have resulted from increasingly frequent global stressors, such as bleaching events and hurricanes. 


\section{INTRODUCTION}

The impact of global and local stressors including climate change, ocean acidification, overfishing, and coastal pollution have caused a dramatic decline in coral reefs world-wide (De'ath et al. 2012, Roff and Mumby 2012, Fabricius et al. 2014). Some studies suggest that global stressors (e.g., climate change) exert the strongest control over coral reef health (e.g., Spalding and Brown 2015, Bruno and Valdivia 2016, Hughes et al. 2017), while others emphasize that human activities at a local scale might be the determinant factor of coral reef resilience (e.g., Jackson et al. 2014, Cinner et al. 2016). It is likely that both global and local stressors act concurrently with additive or synergistic effects (Harborne et al. 2017). For instance, localized nutrient enrichment can interact with regional thermal stress events to increase the susceptibility of corals to diseases and bleaching (Vega-Thurber et al. 2014). Consequently, the interaction of multiple stressors may determine the function of coral reefs (Ban et al. 2014), and thus explain site-specific variation in the condition of coral reefs.

The frequency and intensity of coral bleaching driven by thermal stress events, one of the most prevalent global and regional stressors, have increased dramatically since the 1980s (Hoegh-Guldberg 1999). Accordingly, the number of coral reefs affected by bleaching events tripled between 1985-2012 (Heron et al. 2016), contributing to the accelerating loss of coral cover world-wide (Roff and Mumby 2012). For example, the Caribbean Sea has been warming by roughly $0.29{ }^{\circ} \mathrm{C}$ per decade (Chollett et al. 2012), causing multiple severe bleaching events (Oxenford et al. 2008, Jackson et al. 2014). The conspicuous loss of coral throughout the Caribbean ( $\sim 50 \%$ since 1970 s) has been largely attributed to coral diseases, bleaching events, storms, and the subsequent failure of corals 
to recover (Aronson and Precht 2006, Bruno and Valdivia 2016). Losses are often particularly pronounced in areas where overfishing has reduced herbivory and macroalgae are abundant (Jackson et al. 2014). Today's Caribbean coral reefs are the result of current and past impacts of global, regional and local stressors. Yet disentangling the primary drivers of reef decline is challenging because of the paucity of long-term data and the many potential factors that can influence reef health.

The Cuban mainland is the largest island in the Caribbean and exhibits significant variation of coastal geomorphology (e.g., wide and shallow shelf with patch reefs to narrow shelf with a series of terrace reefs) bordered by coral reefs with varying levels of human impact (Claro et al. 2001, Pina-Amargos et al. 2013). The less impacted reefs are typically fully protected and distant from major cities (e.g., Gardens of the Queen) whereas others, such as the reefs in northwestern Cuba near Havana, are heavily impacted by anthropogenic activities (Gonzalez-Diaz et al. 2003, Gonzalez-Sanson et al. 2009, Pina-Amargos et al. 2013). Yet temporal analyses of the trajectory of Cuban coral reefs are surprisingly rare (but see Jackson et al. 2014).

The northern reefs of Havana (from Cabañas to Bacunayagua) exhibit spatial variation in fish and benthic community structure in relation to local anthropogenic drivers (Herrera and Alcolado 1983, Gonzalez-Diaz et al. 2003, Gonzalez-Sanson et al. 2009). In 2012, the City of Havana had a population of more than two million individuals, with 20,019 Ind. $\mathrm{km}^{-2}$ and 40,984.2 Ind. $\mathrm{km}^{-2}$ in Habana Vieja and Centro Habana respectively, the two closest municipalities to Havana Bay (Cuban office of Statistics, 2016). In addition to heavy artisanal fishing pressure, reefs of Havana are also exposed to pollutants that include heavy metals, fertilizers, and other inorganic and 
organic compounds released into the coastal area through two main sources, Havana Bay (Armenteros et al. 2009) and the Almendares River (Graham et al. 2011), as well as other less conspicuous sources such as street drainage and smaller rivers. As a result, the coral reefs in northwest Cuba have suffered from long-term impacts of localized anthropogenic activities such as overfishing and pollution that likely decrease in impact with increasing distance from the city (Herrera and Alcolado 1983, Gonzalez-Diaz et al. 2003, GonzalezSanson et al. 2009).

This gradient of anthropogenic effects, along with the availability of long-term data of coral and algal abundance from published and unpublished reports, allowed us to analyze the spatial and temporal changes in benthic and fish communities in northwest Cuba as potential indicators of the shifting importance of local versus global drivers of reef communities. Specifically, we aimed to answer the following questions: (1) How does the reef benthic community and fish community change with increasing distance from Havana? and (2) How has the benthic community changed through time across this distance gradient? To address these questions, we assessed nutrient availability, reef structural complexity, and benthic and fish community composition of coral reefs at increasing distances from Havana in 2016. We also compiled existing data on benthic communities to look for temporal changes in coral and macroalgal abundance within the region as well as examine the frequency of coral bleaching events and hurricanes. We anticipated that the historically high fishing pressure and poor water quality near Havana have led to a gradient in declining reef condition (e.g., lower coral cover, higher algal abundance, and lower fish biomass) with proximity to the city. At more distant sites, we expected to see a gradual decline in coral cover and rise in macroalgae over time as local 
stressors expanded from the human population center and global stressors such as coral bleaching events became more prevalent.

\section{METHODS}

Study site

The northwest coast of Cuba is a narrow shelf characterized by a flat submarine terrace that drops smoothly to an edge $(8-10 \mathrm{~m})$ approximately 150 to $300 \mathrm{~m}$ from the shoreline. From the terrace edge, the shelf drops vertically to a deeper terrace $(>12 \mathrm{~m})$ followed by spur and groove formations with distinct levels of development. Our study region included seven reef sites located at the terrace edge distributed along a $120 \mathrm{~km}$ stretch of the Havana shelf (from Bacunayagua to Cabañas following the old administration division). Each reef was located at different distances from Havana, with the center of Havana Bay used as the reference point for the city (henceforth "Zone 0"; see Fig. 5.1). Zone 0 is characterized by the highest human density in the country (> 20,000 Ind. $\mathrm{km}^{-2}$ ) and proximity to two major pollutant sources (Havana Bay and Rio Almendares) that release large amounts of organic matter, hydrocarbons and heavy metals (Armenteros et al. 2009, Graham et al. 2011). Pollutants discharged to the ocean by Havana Bay and Rio Almendares are carried to the west and east by ocean currents (Alcolado and Herrera 1987, Aguilar et al. 2004), creating a gradient of pollution in both directions.

We surveyed a total of seven sites varying in distance both east and west from Havana. Previous studies in the region have identified zones that experience distinct effects of local stressors on communities of fish, corals, and other invertebrates (Alcolado 
and Herrera 1987, Aguilar and Gonzalez-Sanson 2007, Alcolado-Prieto et al. 2012).

Therefore, we classified our study sites by these previously defined zones to assess whether these patterns in anthropogenic impacts have changed. Our sites and zones were defined as follows. Zone 1 covered the area from Miramar to Santa Fe (approximately 7$20 \mathrm{~km}$ west from Havana Bay) where we included three study sites (Fig. 5.1, Calle 16, Calle 30 and Santa Fe). Zone 2 extended approximately 21 to $35 \mathrm{~km}$ from Havana Bay and included two sites, Calderas toward the east and Baracoa toward the west (Fig. 5.1). Zone 3 was located the farthest from Havana Bay (more than $35 \mathrm{~km}$ ) and included two sites, Henequen to the west and Bacunayagua to the east (Fig. 5.1). Analysis of present-day nutrient content, rugosity, and benthic and fish community composition

Present-day status of these reefs (except those located in Zone 0) was studied in situ between May 17 and 31, 2016. Zone 0 was not sampled due to previously reported high levels of harmful toxins and the need for a special permit to access sites close to the entry of Havana Bay (Armenteros et al. 2009). Nutrient availability at each site was estimated from nutrient content in the tissue of Sargassum hystrix J.Agardh, a common brown macroalga that was present at all study sites. Because macroalgae are frequently used as a proxy for nutrient availability (e.g., Diaz-Pulido and McCook 2005, Reef et al. 2012), we collected four samples (10-15 g) of S. hystrix from each site. Samples were immediately transported on ice and kept frozen in the lab until processed. After cleaning off epiphytes, we dried the samples at $65^{\circ} \mathrm{C}$ for $72 \mathrm{hrs}$, ground them to a fine powder and sent them to the Analytical Lab of the Marine Science Institute, University of California, Santa Barbara, to obtain levels of $\delta \mathrm{N}^{15}$ and percent of nitrogen content (dry weight, $\mathrm{DW}$ ). 
$\delta \mathrm{N}^{15}$ is particularly useful to distinguish anthropogenic nitrogen sources (Heaton 1986, Swart et al. 2013).

To assess structural complexity of the reef, we laid out four, $50 \mathrm{~m}$ transects running parallel to the reef ledge at each site. Along each transect, a $5 \mathrm{~m}$ chain was laid out every ten meters, ensuring that the chain followed the contours of the reef (Risk 1972). We calculated a rugosity index as the ratio between the actual length of the chain $(5 \mathrm{~m})$ divided by the measured linear length. Higher values of the rugosity index indicate greater reef complexity.

Benthic communities were assessed using the point intercept technique within a $50 \times 50 \mathrm{~cm}$ gridded plot ( 25 points per plot). Plots were laid out every $5 \mathrm{~m}$ along the same transects described above for a total of 40 plots per site. Specimens found at each point were visually identified to the lowest possible taxonomic level to obtain a percent cover value per plot. We also quantified percent cover of turf algae which is an assemblage of short $(<1 \mathrm{~cm})$ filamentous species (e.g., Polysiphonia spp., Ceramiun spp.). We surveyed the density of juvenile corals $(<4 \mathrm{~cm}$ in diameter) within a $25 \times 25 \mathrm{~cm}$ subsection of each plot. Finally, we quantified the number of sea urchins (Echinometra spp. and Diadema antillarum) in $1 \mathrm{~m}$ wide swaths along each of our $50 \mathrm{~m}$ transects.

Fish communities were characterized and quantified via visual surveys along 12 (30 $2 \mathrm{~m})$, belt transects at each site. Transects were haphazardly placed to run parallel to the reef ledge and separated by at least five meters. On each transect, we identified each fish encountered and estimated its size to the nearest $\mathrm{cm}$. This information was used to calculate density and biomass per species using published weight-length relationships 
(Bohnsack and Harper 1998). We further classified fishes as herbivores, invertivores, and piscivores following Sierra et al. (2001).

Analysis of temporal changes of benthic community structure

We compiled data on reefs in this area from published and gray literature including graduate student theses and technical reports (Table D1) to analyze temporal trends in coral and algal abundance. We collated benthic data from 85 sites within the previously defined zones $(0,1,2$, and 3) sampled between 1995 and 2015. From the 85 sites, we found 46 sites that had information regarding algal cover and 78 sites that included coral cover. From these studies, we used the average cover of macroalgae and coral at each site as a single data point to assess temporal changes within each zone.

\section{Statistical analysis}

We tested for differences across zones in algal tissue nutrient content, reef rugosity, percent cover of benthic groups, juvenile coral density, sea urchin density, and fish biomass using ANOVA with site nested within zone. When response variables differed among zones, we used the Tukey's honest significant test (Tukey's HSD) as post-hoc analysis to determine which zones were different. Within each zone, we analyzed temporal changes in macroalgal and coral cover using linear mixed effect models that included sites as random factors to test for changes in cover through time. Data are presented as means \pm standard errors and all analyses were carried out using the following packages in R V.3.2.2 (R Development Core Team 2012): doBy (Soren 2016) and nlme (Pinheiro et al. 2017) for ANOVA and linear and non-linear mixed effect models. 


\section{RESULTS}

Analysis of present-day nutrient content, rugosity, and benthic and fish community composition

Current $\delta \mathrm{N}^{15}$ levels in Sargassum hystrix tissue ranged from 1.8\%o to $6.2 \%$ and decreased with distance from Havana. Zone 1, closest to Havana, exhibited values twice as high as those recorded at sites in Zones 2 and 3 (Fig. 5.2A, ANOVA, F $2,21=102.46, \mathrm{P}$ $<0.001)$. Similarly, nitrogen content in S. hystrix was the highest in Zone 1 while Zone 2 had the lowest values with Zone 3 being intermediate in nitrogen content (Fig. 5.2B, ANOVA, $\left.F_{2,21}=25.09, \mathrm{P}<0.001\right)$. Reef structural complexity, estimated as the rugosity index, averaged $1.24 \pm 0.1$ with no differences among zones (appendix D, ANOVA, $F_{2}$, $122=1.09, \mathrm{P}=0.338)$.

Benthic communities were dominated by algae ( $>60 \%$ cover of all algal groups) across all zones (Fig. 5.3A, ANOVA, $\mathrm{F}_{2,21}=0.98, \mathrm{P}=0.393$ ). Zone 2 was dominated by cyanobacteria and turf which covered more than $20 \%$ of the benthos, particularly at the Calderas site (Fig. 5.3B\&C, ANOVA, Cyanobacteria, $\mathrm{F}_{2,21}=4.46, \mathrm{P}=0.024$, Turf, $\mathrm{F}_{2,21}$ $=11.19, \mathrm{P}<0.001)$. Dictyota spp. and Lobophora variegata were up to twice as abundant in Zones 1 and 3 compared to Zone 2 (Fig. 5.3D\&E, ANOVA, Dictyota, $\mathrm{F}_{2,21}=5.38, \mathrm{P}=$ 0.014 , Lobophora variegata, $\left.\mathrm{F}_{2,21}=8.19, \mathrm{P}=0.002\right)$. Sargassum spp. were most abundant in Zone $1(23.5 \pm 1.2 \%)$ compared to Zones 2 and 3 (Fig. 5.3F, ANOVA, F2, 21 $=27.84, \mathrm{P}<0.001)$. Amphiroa spp. $(2.48 \pm 0.40 \%)$, Jania spp. $(2.78 \pm 0.50 \%)$, and Halimeda spp. $(3.98 \pm 0.42 \%)$ covered approximately $9 \%$ of the benthos combined but only Amphiroa spp. showed differences among zones (Fig. 5.3 G, H \& I).

Across all sites, the percent cover of coral averaged $9.7 \pm 0.8 \%$ with Zone 2 
having the lowest coral cover with approximately $5 \%$ (Fig. 5.4A, ANOVA, $\mathrm{F}_{2,21}=13.77$, $\mathrm{P}<0.001)$. Siderastrea was the dominant coral genus region-wide, and cover was highest in Zone 1, covering $7.6 \pm 1.1 \%$ of the benthos (ANOVA, $\mathrm{F}_{2,21}=6.76, \mathrm{P}=0.005$ ). Porites, Orbicella and Agaricia had the next highest percent cover with Porites having the highest cover in Zone 1 (ANOVA, Porites, $\mathrm{F}_{2,21}=10.39, \mathrm{P}<0.001$, Orbicella, $\mathrm{F}_{2,21}$ $=3.62, \mathrm{P}=0.067$, Agaricia, $\left.\mathrm{F}_{2,21}=0.90, \mathrm{P}=0.422\right)$.

Total density of juvenile corals averaged $20.9 \pm 1.8$ juveniles $\mathrm{m}^{-2}$ in Zone 1 and decreased with distance from Havana. Bacunayagua, the farthest site from the city, had the lowest juvenile coral density, with just $5.6 \pm 2.0$ juveniles $\mathrm{m}^{-2}$ (Fig. 5.4B, ANOVA, $\left.\mathrm{F}_{2,21}=4.49, \mathrm{P}=0.024\right)$. Approximately $50 \%\left(8.1 \pm 1.2\right.$ juveniles $\left.\mathrm{m}^{-2}\right)$ of the juvenile corals region-wide belonged to the genus Porites, which were most abundant in Zone 1 with $11.5 \pm 1.9$ juveniles $\mathrm{m}^{-2}$ (ANOVA, $\mathrm{F}_{2,21}=7.18, \mathrm{P}=0.004$ ). In contrast, Siderastrea averaged $2.7 \pm 0.5$ juveniles $\mathrm{m}^{-2}$ region-wide with Zone $3\left(4.8 \pm 1.5\right.$ juveniles $\left.\mathrm{m}^{-2}\right)$ having twice as many juveniles as Zone $1\left(2.05 \pm 0.30\right.$ juveniles $\left.\mathrm{m}^{-2}\right)\left(\right.$ ANOVA, $\mathrm{F}_{2,21}=0.91, \mathrm{P}=$ 0.419). Agaricia, the coral genus with the second highest density of juveniles in the region $\left(4.3 \pm 0.8\right.$ juveniles $\mathrm{m}^{-2}$ ), showed no variation with distance or among zones (ANOVA, $\left.F_{2,21}=0.43, P=0.657\right)$.

The total fish biomass averaged $26.1 \pm 5.0 \mathrm{~g} \mathrm{~m}^{-2}$ across all zones (Fig. 5.5A, ANOVA, $F_{2,77}=1.23, \mathrm{P}=0.299$ ). Herbivorous fishes (parrotfishes and surgeonfishes) were approximately $50 \%$ of the total fish biomass $\left(11.9 \pm 1.3 \mathrm{~g} \mathrm{~m}^{-2}\right)$ with no change in biomass relative to zone (Fig. 5.5A, ANOVA, $\mathrm{F}_{2,77}=1.08, \mathrm{P}=0.344$ ). Similarly, the biomass of invertivores (e.g., fam. Labridae) averaged $7.9 \pm 0.9 \mathrm{~g} \mathrm{~m}^{-2}$ and did not differ 
across zones (Fig. 5.5B, ANOVA, invertivores, $\mathrm{F}_{2,77}=1.59, \mathrm{P}=0.211$ ). In contrast, the biomass of piscivores (e.g., fam. Serranidae and Sphyraenidae) was the highest in Zone 3 with $13.3 \pm 4.4 \mathrm{~g} \mathrm{~m}^{-2}$ (Fig. 5.5C, ANOVA, piscivores, $\mathrm{F}_{2,77}=4.41, \mathrm{P}=0.015$ ). In addition to low herbivorous fish biomass region-wide, we recorded low densities $(0.02$ Ind. $\mathrm{m}^{-2}$ ) of the herbivorous sea urchins Echinometra spp. and Diadema antillarum, with Zone 3 having the highest density with 0.24 Ind. $\mathrm{m}^{-2}$ (Fig. 5.5D, ANOVA, $\mathrm{F}_{2,21}=6.89, \mathrm{P}$ $=0.005)$.

Analysis of temporal changes of benthic community structure

Macroalgal abundance in northwest Cuba showed both temporal and spatial variation between 2000 and 2016 (lme, Year:Zone, $\chi_{1}^{2}=14.05, \mathrm{R}^{2}=0.24, \mathrm{P}<0.001$ ). Zone 0 (Havana) exhibited a reduction in algal cover from $\sim 85 \%$ in 2008 to $\sim 40 \%$ in 2012 (Fig. 5.6A, lme, Year, $\chi_{1}^{2}=7.70, \mathrm{R}^{2}=0.46, \mathrm{P}=0.006$ ). However, since survey data only goes back to 2008, it is difficult to tell if this is indicative of anomalously high algal cover in 2008 or a true, long term trend in declining algal cover. Zone 1 averaged 55\% and Zone $245 \%$ cover of macroalgae, without significant changes through time (Fig. 5.6B\&C, Year, Zone 1 , lme, $\chi^{2}{ }_{1}=2.70, \mathrm{R}^{2}=0.16, \mathrm{P}=0.101$, Zone $2, \chi^{2}{ }_{1}=0.03, \mathrm{R}^{2}=$ $0.01, \mathrm{P}=0.856)$. In contrast, Zone 3 displayed a three-fold increase in macroalgae from $\sim 23 \%$ in 2000 to $67 \%$ in 2016 (Fig. 5.6D, lme, Year, $\chi_{1}^{2}=11.09, \mathrm{R}^{2}=0.60, \mathrm{P}<0.001$ ).

Coral cover also showed zone specific variations through time (Fig. 5.6E-H, lme, Zone:Year, $\left.\chi_{1}^{2}=5.86, \mathrm{R}^{2}=0.52, \mathrm{P}=0.015\right)$. Both Zone 0 and Zone 1 were characterized by low coral cover $(3.8 \pm 0.8 \%$ and $9.8 \pm 0.6 \%$, respectively $)$ with little change since 1997 (Fig. 5.6E\&F, lme, Year, Zone $0, \chi^{2}{ }_{1}=2.63, \mathrm{R}^{2}=0.24, \mathrm{P}=0.105$, Zone $1, \chi^{2}{ }_{1}=$ $\left.0.04, \mathrm{R}^{2}=0.01, \mathrm{P}=0.843\right)$. In contrast, coral cover in Zone 2 and Zone 3 declined by 
more than $50 \%$ over the same time period (Fig. $5.6 \mathrm{G} \& \mathrm{H}, 1 \mathrm{~m}$, Zone $2, \chi^{2}{ }_{1}=5.07, \mathrm{R}^{2}=$ $0.21, \mathrm{P}=0.024$, Zone $\left.3, \chi^{2}{ }_{1}=5.73, \mathrm{R}^{2}=0.39, \mathrm{P}=0.017\right)$.

\section{DISCUSSION}

We found that coral reefs near Havana are in poor condition, even at significant distances from the city. Nitrogen content (Nitrogen DW\% and $\delta \mathrm{N}^{15}$ ) in algal tissue increased with proximity to Havana (Zone 0), suggesting both an increase in $\mathrm{N}$ availability and increasing contribution of anthropogenic $\mathrm{N}$ sources to reefs. Regardless of distance from the Havana, fish biomass was low and the benthic communities were dominated by macroalgae ( $>60 \%$ cover) with low coral cover. In contrast, the highest densities of juvenile corals were at sites closest to the Havana. Our analyses of long-term benthic trends revealed that coral cover has remained low and macroalgal cover high on the reefs nearest to Havana since the 1990s. Yet, at sites farthest from Havana, coral cover has declined by $\sim 50 \%$ and macroalgae increased by over $100 \%$ during the same time period.

Havana is home to more than two million people concentrated in approximately $730 \mathrm{~km}^{2}$ (Cuban Office of Statistics, 2016). The metropolitan area includes several rivers, such as Almendares and Quibu, which carry high levels of pollutants that are delivered to coastal areas (Armenteros et al. 2009, Graham et al. 2011). One would expect to find higher $\delta \mathrm{N}^{15}$ (an indicator of human waste $\mathrm{N}$ sources) and nitrogen content in algal tissue samples from areas adjacent to the city. While this was the case, we also found high nitrogen content at the farthest site from Havana (Bacunayagua, Zone 3), suggesting sitespecific $\mathrm{N}$ delivery unrelated to population density. Based on low $\delta \mathrm{N}^{15}$ values, nutrients 
could be coming from sources other than human waste, such as fertilizers from agricultural runoff. Along the north coast of Havana there are many small rivers, some of which are close to our study sites (e.g., Rio Jaimanitas, Rio El Mosquito, Rio Jaruco) that could be significant sources of nutrients. Unfortunately, information regarding the water quality and drainage from these rivers is scarce. High levels of nutrient availability can promote algal abundance on coral reefs (Lapointe 1997, Littler et al. 2006), which may at least partially explain the increase in macroalgae since the early 2000 s at sites distant from Havana. In addition, these distant sites suffered a reduction of coral cover over the past decade, leaving more suitable space to be colonized by macroalgae.

Low levels of herbivory have likely contributed to the ubiquitously high cover of macroalgae. Herbivorous fish biomass averaged just under $12 \mathrm{~g} \mathrm{~m}^{-2}$ across the region, compared to $\sim 30 \mathrm{~g} \mathrm{~m}^{-2}$ on unfished Caribbean reefs (Edwards et al. 2014). During our surveys we did not record any herbivores over $20 \mathrm{~cm}$ total length, suggesting fishing pressure is high across all three zones. In contrast, Gonzalez-Sanson et al. (2009) reported that in 2004 there were differences in fish communities between Zones 1, 2, and 3, with average fish size declining and shifts in species composition occurring at sites closer to Havana Bay. The presence of zone-specific fish communities just a decade ago suggests a fairly recent expansion of fishing pressure across the region. Moreover, herbivorous urchin abundance was low at all of our sites (Fig. 5.5D). Consequently, algal communities were dominated by palatable species such as Sargassum spp. and red articulated calcareous algae (e.g., Jania spp. and Amphiroa spp.) that are often preferentially consumed by herbivorous fishes (Burkepile and Hay 2008, Adam et al. 2015). It is likely that the low biomass of herbivorous fishes and sea urchins resulted in 
reduced herbivore control over macroalgae across all of the zones. Similar results have been reported in other overfished Caribbean reefs after the massive sea urchin (Diadema antillarum) die-offs at the beginning of the 1980's (Jackson et al. 2014).

Surprisingly, despite the elevated cover of macroalgae, we found that the abundance of juvenile corals in our study region $\left(21\right.$ juveniles $\left.\mathrm{m}^{-2}\right)$ was high when compared to other regions such as the Florida Keys ( 7 juveniles $\mathrm{m}^{-2}$, Moulding 2005, Burkepile et al. 2013) and Curacao (7 juveniles $\mathrm{m}^{-2}$, Vermeij et al. 2011). The high abundance of macroalgae might not be inhibiting recruitment, as is often observed (Vermeij et al. 2009), but it could be limiting the growth of juvenile corals via competition. Unexpectedly, Zone 1, which was predicted to be the most heavily impacted, contained the highest density of juvenile corals. The greater number of juveniles in Zone 1 may be due to the high prevalence of brooding species in this region (appendix D), which have short planktonic durations and low dispersal distances that promote larval retention (Ritson-Williams et al. 2009). Interestingly, brooding species are often associated with unstable or degraded habitats (Szmant 1986), perhaps reflecting a longer history of human impacts in Zone 1. Additionally, other biophysical drivers, such as larval supply, oceanic currents, and temperature regimes likely contribute to the observed distribution of juvenile corals (Ritson-Williams et al. 2009, Green and Edmunds 2011). In the future, reefs in these zones may provide an interesting setting to study propagule supply and the population genetics of the coral community.

Although there is very little information on current or historical fishing pressure in the region, parrotfishes have been targeted by local fishers since at least the 1970 s when large individuals of midnight parrotfish (Scarus coelestinus) and rainbow parrotfish 
(Scarus guacamaia) were still present (Aguilar and Gonzalez-Sanson 2007). However, the dense low-income population in and around Havana combined with easy access to the reefs facilitated by the narrow shelf has created a large artisanal fishery (AD, personal observation), and we frequently encountered spear fishers during our surveys, even at sites more than $40 \mathrm{~km}$ from Havana. It is likely that the high artisanal fishing pressure has not only increased near Havana but also has expanded further away as fish have become less abundant and human population increases. This high fishing pressure could explain the low fish biomass region-wide.

The current coral cover at our study sites $(10 \%)$ is lower than the current Caribbean-wide average (16\%) reported by Jackson et al. (2014). However, the decline in coral cover in the region appears to have happened in at least two different time periods that may be associated with distinct types of stressors. Closer to Havana (Zones 0 and 1), the coral cover was already low in the 1990s $(<10 \%)$, whereas reefs farther from the city (Zones 2 and 3) still maintained more than 30\% coral cover. Prior to the 1990s, Havana Bay was considered one of the 10 most polluted bays on Earth, containing high concentrations of lead, zinc, selenium, and mercury along with heavy loads of organic sediment (Armenteros et al. 2009, Diaz-Asencio et al. 2011). Exposure to high sedimentation and high concentrations of nutrients and heavy metals can negatively affect growth, photosynthesis, fertilization, larval survival, and the microbiome of corals (Gilmour 1999, Jessen et al. 2013, Tout et al. 2015) resulting in reduced coral abundance in polluted areas (De'Ath and Fabricius 2010). Prior to the 1990s, reduction of coral cover close to Havana may have been related to high levels of pollution released onto the reefs from Havana Bay. 
In contrast, coral cover in the two zones more distant from Havana (Zones 2 and 3 ) remained high $(25-30 \%)$ into the early 2000 s but suffered a $\sim 50 \%$ reduction in the last 15 years. Declining coral cover at these more distant sites may indicate the expansion of local stressors, increasing impacts of global stressors, or a combination of both. It is possible that the effects of local stressors that were concentrated around Havana before the 2000s have expanded outward as a result of economic pressure in a growing metropolitan population. The nitrogen content in algae showed high values in areas farther away from the city suggesting region-wide increases in nutrient concentrations. Similarly, fish biomass is now low region-wide, suggesting that fishing pressure has expanded since the initial classification of the reef zones around Havana. According to the Cuban Office of Statistics, the population of Havana has increased from 1,954,413 in 1980 to 2,200,000 individuals between 1995 and 2000 with a recent (2014) count of $2,121,871$ individuals. A rapidly increasing population in the late 1990 s might have increased the impact of local stressors.

Over the past 15 years there have also been increases in global stressors in the region. During at least five summers between 2003 and 2015, corals in Havana reefs experienced large-scale bleaching events (51 to 75\% corals bleached), with 2009 being the worst with more than $75 \%$ of corals bleached (Table D2, Alcolado 2006, Alcolado and Iglesias 2010). In the Caribbean, similar thermal stress events have led to widespread coral mortality, particularly in areas with high coral cover (Oxenford et al. 2008, Eakin et al. 2010, Alemu and Clement 2014). The frequency of coral bleaching events has increased since the first event was described in 1980; the first documented world-wide bleaching event occurred in 1998 (Hoegh-Guldberg 1999). Coral reefs located in 
Caribbean regions including South Florida, the Bahamas, and Cuba have suffered an average of seven thermal stress events between 1985 to 2012 (Heron et al. 2016). It is likely that the recent increase in frequency and severity of bleaching events has contributed to coral loss in those sites farther from the Havana. Coral cover in Zone 0 and Zone 1 was already low before 2000, however, it is possible that bleaching had less of an impact on the remaining corals. In support of this idea, Siderastrea and Porites were both very abundant closer to Havana, and these taxa tend to be some of the most resistant species to bleaching (Okazaki et al. 2016). In contrast, Orbicella and Agaricia showed higher cover away from the city, although they were low in overall cover. These taxa are more susceptible to bleaching than Siderastrea and Porites (Fournie et al. 2012, Okazaki et al. 2016) and may have declined the most during recent coral losses at sites distant from Havana.

Hurricanes can also cause substantial losses of coral cover (Gardner et al. 2005). The occurrence of five hurricanes in 2005 , two of which were category 5 , presumably had strong impacts on these reefs. Unfortunately, we did not find information directly related to these hurricanes. But, given the narrow reef shelf around Cuba, it is likely that their effect was widespread across multiple sites in the region. For instance, Hurricane Wilma (2005) occurred more than $80 \mathrm{~km}$ from Havana, and Jones et al. (2008) described damage to gorgonians, sponges, and corals as deep as $15 \mathrm{~m}$ on Havana's coral reefs. Corals in areas near Havana (Zone 0 and 1 ) have not been affected directly by hurricanes for more than 50 years (Table D3); this relative calm could make them more vulnerable to major storms as it has been proposed that the larger the lapse between hurricanes, the slower the recovery (Mumby et al. 2011). In contrast, at least two hurricanes affected 
zones 2 and 3 at western sites (Hurricane Charley, 2004) and eastern sites (Hurricane Dennis, 2005). It is possible that these hurricanes facilitated the downward trajectory of corals in sites farther from Havana.

Understanding the drivers of coral reef decline is critical for management and conservation strategies (Keller et al. 2009). The current status of reefs around Havana is likely the result of combined global and local stressors that have both reduced coral cover and limited their ability to recover. The coral reefs near Havana have experienced different spatial and temporal trajectories of coral decline and a rise in macroalgae in the last 20 years. The temporal decline in coral abundance can be likely attributed to both global stressors (e.g., bleaching events followed by increase of diseases) and local stressors such as, high nutrient levels, and overfishing. Yet, the failure of corals to recover is probably influenced by local impacts to these reefs, particularly overfishing, which has led to very low herbivorous fish biomass and a rise in macroalgae. Our results suggest that despite the wide-spread decline, coral recruitment is still occurring and there is there is a robust population of juvenile corals, even at sites near Havana. Decreasing nutrient influx and implementing artisanal fishery regulations may help reduce macroalgae and provide these reefs with an opportunity to recover after stress events such as bleaching. Ultimately, however, global-scale efforts are required to decelerate the current rate of carbon emissions that drive climate change, the major driver of future coral mortality. 
AUTHOR'S CONTRIBUTION

A.D. conceived and designed the research. A.D., L.C-V., V.C.M., L.P., A.R. and A.A.S. conducted field work. A.D., and A.A.S. analyzed the data. A.D., D.E.B., L.C-V., V.C.M., L.P., A.R. and A.A.S. contributed to writing the manuscript and participated in the scientific discussion.

\section{ACKNOWLEDGEMENTS}

We thank the two Florida International University funding sources of this project: The Kimberly Green Latin American and Caribbean Center and the International Center for Tropical Botany. We also thank the faculty and staff of the Center for Marine Research from University of Havana, Cuba, especially the diving center led by Ivan Rodriguez. In addition, we are grateful for the advice and data contribution of Pedro Alcolado-Prieto and Hector Salvat. This is contribution \#75 of the Marine Education and Research Center in the Institute for Water and Environment at Florida International University.

\section{REFERENCES}

Adam TC, Kelly M, Ruttenberg BI, Burkepile DE. 2015. Resource partitioning along multiple niche axes drives functional diversity in parrotfishes on Caribbean coral reefs. Oecologia. 179:1173-85

Aguilar C, Gonzalez-Sanson G, Munkittrick KR, MacLatchy DL. 2004. Fish assemblages on fringe coral reefs of the northern coast of Cuba near Habana Harbor.

Ecotoxicol. Environm. Saf. 58:126-138

Aguilar C, Gonzalez-Sanson G. 2007. Composición de la ictifauna costera de Ciudad de la Habana y evaluación de los factores que la determinan. Rev. Invest. Mar. 28:43-56. 
Alcolado PM, Herrera A. 1987. Efectos de la contaminación sobre las comunidades de esponjas en el litoral de La Habana, Cuba. Reporte de Investigaciones del Instituto de Oceanologia, Academia Ciencias de Cuba 68:1-17.

Alcolado PM, Iglesias SC. 2010. Reporte de blanqueamiento de corales del año 2009 en Cuba. Red de monitoreo voluntario de alerta temprana de arrecifes coralinos. Projecto PNUD/GEF Sabana-Camaguey. 6pp

Alcolado PM. 2006. Reporte de blanqueamiento de corales del año 2003 en Cuba. Red de monitoreo voluntario de alerta temprana de arrecifes coralinos. Projecto PNUD/GEF Sabana-Camaguey. 5pp

Alcolado-Prieto P, Caballero H, Alcolado PM, Lopeztegui A. 2012. Reclutamiento de corales petreos en arrecifes coralinos a diferentes distancias de fuentes contaminantes. Int. J. Trop. Biol. 60:981-994.

Alemu JB, Clement Y. 2014. Mass coral bleaching in 2010 in the Southern Caribbean PLoS ONE 9(1): e83829. https://doi.org/10.1371/journal.pone.0083829

Armenteros M, Perez-Angulo A, Regadera AR, Beltran J, Vincx M, Decraemer W. 2009. Effects of chronic and heavy pollution on macro- and microbenthos of Havana Bay, Cuba. Rev. Invest. Mar. 30:203-214.

Aronson RB, Precht WF. 2006. Conservation, precaution, and Caribbean reefs. Coral Reefs. 25:441-450.

Ban SS, Graham NAJ, Connolly SR. 2014. Evidence for multiple stressor interactions and effects on coral reefs. Glob. Change Biol. 20:681-697.

Bohnsack JA, Harper DE. 1988. Length-weight relationships of selected marine reef fishes from southeastern United States and the Caribbean. NOAA Tech. Mem. NMFS-SEFC-215. $31 \mathrm{p}$.

Bruno JF, Valdivia A. 2016. Coral reef degradation is not correlated with local human population density. Sci. Rep. 6:1-8.

Burkepile DE, Allgeier JE, Shantz AA, Pritchard CE, Lemoine NP, Bhatii LH, Layman CA. 2013. Nutrient supply from fishes facilitates macroalgae and suppresses coral in a Caribbean coral reef ecosystem. Sci. Rep. 3, 1493.

https://doi.org/10.1038/srep01493

Burkepile DE, Hay ME. 2008. Herbivore species richness and feeding complementary affect community structure and function on a coral reef. Proc. Natl. Acad. Sci. 105:16201-16206. 
Chollett I, Muller-Karger FE, Heron SF, Skirving W, Mumby P. 2012. Seasonal and spatial heterogeneity of recent sea surface temperature trends in the Caribbean Sea and southeast Gulf of Mexico. Mar. Poll. Bull. 64:956-965.

Cinner JE, Hunchery C, MacNeil MA, Graham AJ, McClanahan TR, Maina J, Maire E, Kittinger JN, Christina CH, Mora C, et al. 2016. Bright spots among the world's coral reefs. Nature. 535:416-419.

Claro R, Reshetnikov YS, Alcolado PM. 2001. Physical attributes of coastal Cuba. In: Claro R, Lindeman KC and Parenti LR, editors. Ecology of the marine fishes of Cuba. Smithsonian Institution Press, Washington and London.

Cuban Office of Statistics [Internet]. La Habana, Cuba. Available from: http://www.one.cu

De'ath G, Fabricius KE. 2010. Water quality as a regional driver of coral diversity and macroalgae on the Great Barrier Reef. Ecol. Appl. 20:840-850.

De'ath G, Fabricius KE, Sweatman H, Puotinen M. 2012. The 27-year decline of coral cover on the Great Barrier Reef and its causes. Proc. Natl. Acad. Sci. 109:1799517999.

Diaz-Asencio M, Corcho-Alvarado JA, Alonso-Hernandez C, Quejido-Cabezas A, RuizFernandez AC, Sanchez-Sanchez M, Gomez-Mancebo MB, Froideaux P, Sanchez-Cabezas JA. 2011. Reconstruction of metal pollution and recent sedimentation processes in Habana Bay (Cuba): A tool for coastal ecosystem management. J. Hazard. Mater. 196:402-411.

Diaz-Pulido G, McCook LJ. 2005. Effects of nutrient enhancement on the fecundity of a coral reef macroalga. J. Exp. Mar. Bio. Ecol. 317:13-24.

Eakin CM, Morgan JA, Heron SF, Smith TB, Liu G, Alvarez-Filip L, Baca B, Bartels CB, Bouchon C, Brandt M, et al. 2010. Caribbean corals in crisis: Record thermal stress, bleaching, and mortality in 2005. PLoS ONE, 5:e13969.

Https://doi.org/10.1371/journal.pone.0013969

Edwards CB, Freindlander AM, Green AG, Hardt MJ, Sala E, Sweatman HP, Williams ID, Zgliczynski B, Sandin SA, Smith JE. 2014. Global assessment of the status of coral reef herbivorous fishes: evidences for fishing effects. Proc. R. Soc. B. 281:20131835. https://doi.org/rspb.2013.1835

Fabricius KE, Logan M, Weeks S, Brodie J. 2014. The effects of river run-off on water clarity across the central Great Barrier Reef. Mar. Poll. Bull. 84:191-200. 
Fournie JW, Vivian DN, Yee SH, Courtney LA, Barron MG. 2012. Comparative sensitivity of six scleractinian corals to temperature and solar radiation. Dis. Aquat. Organ. 99:85-93.

Gardner TA, Cote IM, Gill JA, Alastair G, Watkinson AR. 2005. Hurricanes and Caribbean coral reefs: Impacts, recovery patterns and role in long term decline. Ecology 86:174-184.

Gilmour J. 1999. Experimental investigation into the effects of suspended sediment on fertilization, larval survival and settlement in a scleractinian coral. Mar. Biol. 135:451-462.

Gonzalez-Diaz P, De la Guardia E, Gonzalez-Sanson G. 2003. Efecto de efluentes terrestres sobre las comunidades bentónicas de arrecifes coralinos de Ciudad de la Habana, Cuba. Rev. Invest. Mar. 24:193-204.

Gonzalez-Sanson G, Aguilar C, Hernandez I, Cabrera Y, Suarez-Montes N, Bretos F, Guggenheim D. 2009. Natural and human-induced variability in the composition of fish assemblages in the Northwestern Cuban shelf. Rev. Biol. Trop. 57:721740 .

Graham DW, Olivares-Riemont S, Knapp CW, Lima L, Werner D, Bowen E. 2011. Antibiotic resistance gene abundance associated with waste discharges to the Almendares River near Havana, Cuba. Environ. Sci. Technol. 45:418-424.

Green DH, Edmunds PJ. 2011. Spatio-temporal variability of coral recruitment on shallow reefs in St. John US Virgin Islands. J. Exp. Mar. Biol. 327:220-229.

Harborne AR, Rogers A, Bozec Y-M, Mumby PJ. 2017. Multiple stressors and the functioning of coral reefs. Annu. Rev. Mar. Sci. 9:445-68.

Heaton THE. 1986. Isotopic studies of nitrogen pollution in the hydrosphere and atmosphere: a review. Isot. Geosc. Sect. 59:87-102.

Heron SF, Maynard JA, van Hooidonk R, Eakin CM. 2016. Warming trends and bleaching stress of the world's coral reefs 1985-2012. Sci. Rep. 6:38402. https://doi 10:1038/srep38402.

Herrera A, Alcolado PM .1983. Efectos de la contaminación sobre las comunidades de gorgonaceos al oeste de la Bahia de la Habana. Ciencias Biologicas. 10:69-85.

Hoegh-Guldberg O. 1999. Climate change, coral bleaching and the future of the world's coral reefs. Mar. Freshw. Res. 50:839-866. 
Hughes TP, Kerry JT, Alvarez-Noriega M, Alvarez-Romero JG, Anderson KD, Baird AH, Badcock RC, Beger M, Bellwood DR, Berkelmans R, et al. 2017. Global warming and recurrent mass bleaching of corals. Nature. 543:373-377. https://doi.org/10.1038/nature21707

Jackson JBC, Donovan MK, Cramer KL, Lam VV. 2014. Status and Trends of Caribbean Coral Reefs: 1970-2012. Global Coral Reef Monitoring Network, IUCN, Gland, Switzerland.

Jessen C,.Lizcano JFV, Lizcano T, Bayer T, Roder C, Aranda M, Wild C, Voolstra CR. 2013. In-situ effects of eutrophication and overfishing on physiology and bacterial diversity of the Red Sea coral Acropora hemprichii. PLoS ONE 8, e62091. https://doi.org/10.1371/journal.pone.0062091

Jones L, Alcolado PM, Cala Y, Cobian D, Coelho V, Hernandez A, Jones R, Mallela J, Manfrino C. 2008. The effect of coral bleaching in the Northern Caribbean and Western Atlantic. In: Wilkinson C, Souter D, (editors). Status of Caribbean coral reefs after bleaching and hurricanes in 2005, Global Coral Reef Monitoring Network, and Reef and Rainforest Research Centre, Townsville, 152 p.

Keller BD, Gleason DF, McLeod E, Woodley CH, Airame S, Causey BD, Freindlander AM, Grober-Dunsmore R, Jonson JE, Miller SL and Steneck RS. 2009. Climate change, coral reef ecosystems and management options for marine protected areas. Environ. Manage. 44:1069-1088.

Lapointe BE. 1997. Nutrient thresholds for bottom-up control of macroalgal blooms on coral reefs in Jamaica and southeast Florida. Limnol. Oceanogr. 42:1119-1131.

Littler MM, Littler DS, Brooks BL. 2006. The effects of nitrogen and phosphorus enrichment on algal community development: Artificial mini-reefs on the Belize Barrier Reef sedimentary lagoon. Harmful Algae. 9:255-263.

Moulding AL. 2005. Coral recruitment patterns in the Florida Keys. Rev. Biol. Trop. 53:75-82.

Mumby PJ, Vitolo R, Stepheson DB. 2011. Temporal clustering of tropical cyclones and its ecosystem impacts. Proc. Nat. Acad. Sci. 108:17626-17630.

Okasaki RR, Towle EK, van Hooidonk R, Mor C, Winter RN, Piggot AM, Cunning R, Baker AC, Klaus JS, Swart PK, Langdon C. 2016. Species-specific responses to climate change and community composition determine future calcification rates of the Florida Keys reefs. Glob. Change Biol. 23:1023-1035. 
Oxenford HA, Roach R, Brathwaite A, Nurse L, Goodridge R, Hinds F, Baldwin K, Finney C. 2008. Quantitative observations of a major coral bleaching events in Barbados, Southeastern Caribbean. Clim. Change. 87:435-449.

Pina-Amargos F, Gonzalez-Sanson G, Martin-Blanco F, Valdivia A. 2013. Evidence for protection of targeted reef fish on the largest marine reserve in the Caribbean. PeerJ. 2:e274. https://doi.org/10.7717/peerj.274

Pinheiro J, Bates D, DebRoy S, Sarkar D, R Core Team. 2017. nlme: Linear and Nonlinear Mixed Effects Models. R package version 3.1-131. https://CRAN.Rproject.org/package $=$ nlme.

R Core Team. 2012. R: A language and environment for statistical computing. $\mathrm{R}$ Foundation for Statistical Computing, Vienna, Austria. ISBN 3-900051-07-0, URL http://www.R-project.org/

Reef R, Pandolfi JM, Lovelock CE. 2012. The effect of nutrient enrichment on the growth, nucleic acid concentrations, and elemental stoichiometry of coral reef macroalgae. Ecol. Evol. 2:1985-1995.

Risk ML. 1972. Fish diversity on coral reef in the Virgin Islands. Atoll. Res. Bull. 153:16.

Ritson-Williams R. Arnold SN, Fogarty ND, Steneck RS, Vermeij MJA, Paul VJ. 2009. New perspectives on ecological mechanisms affecting coral recruitment on reefs. Smithson. Contrib. Mar. Sci. 38:437-457.

Roff G, Mumby PJ. 2012. Global disparity in the resilience of coral reefs. Trends in Ecol. Evol. 27:404-413.

Sierra LM, Claro R, Popova OA. 2001. Trophic biology of the marine fishes of Cuba. In: Claro R, Lindema KC, Parenti LR (editors) ecology of the Marine fishes of Cuba. Smithsonian Institution Press, Washington and London.

Soren H. 2016. Grouping statistics, LS means, Linear contrasts, utilities. http://people.math.aau.dk/ sorenh/software/doBy/

Spalding MD, Brown BE. 2015. Warm-water coral reefs and climate change. Science. 350 p. https://doi.org/10.1126/science.aad0349

Swart P, Anderson WT, Altabet MA, Drayer C, Bellmund S. 2013. Sources of dissolved inorganic nitrogen in a coastal lagoon adjacent to a major metropolitan area, Miami Florida (USA). Appl. Geochem. 38:134-146.

Szmant AM. 1986. Reproductive ecology of Caribbean reef corals. Coral Reefs 5:43-54. 
Tout J, Siboni N, Messer LF, Garren M, Stocker R, Webster NS, Ralph PJ, Seymour JR. 2015. Increased seawater temperature increases the abundance and alters the structure of natural Vibrio populations associated with the coral Pocillopora damicornis. Front. Microbiol. 6:432. Https://doi.org/10.3389/fmicb.2015.00432

Vega-Thurber R, Burkepile DE, Fuchs C, Shantz AA, McMinds R, Zaneveld JR. 2014. Chronic nutrient enrichment increases prevalence and severity of coral disease and bleaching. Glob. Change Biol. 20:544-554.

Vermeij MJA, Smith JE, Smith CM, Vega Thurber R, Sandin SA. 2009. Survival and settlement success of coral planulae: independent and synergistic effects of macroalgae and microbes. Oecologia. 159:325-336.

Vermeij MJA, Bakker J, Hal NVD, Bak RPM. 2011. Juvenile coral abundance has decreased by more than $50 \%$ in the only three decades on a small Caribbean Island. Diversity. 3:296-307. 
Figure 5.1 Study sites within each zone located at different distances from Havana, Cuba: Zone 0 (Havana) indicated by the circle, Zone 1, the closest to the city includes three study sites (Calle 16, Calle 30 and Santa Fe), Zone 2 includes sites at intermediate distances (21-35km; Baracoa and Calderas) and Zone 3 the farthest away from the city with two sites (Henequen west and Bacuanayagua east).

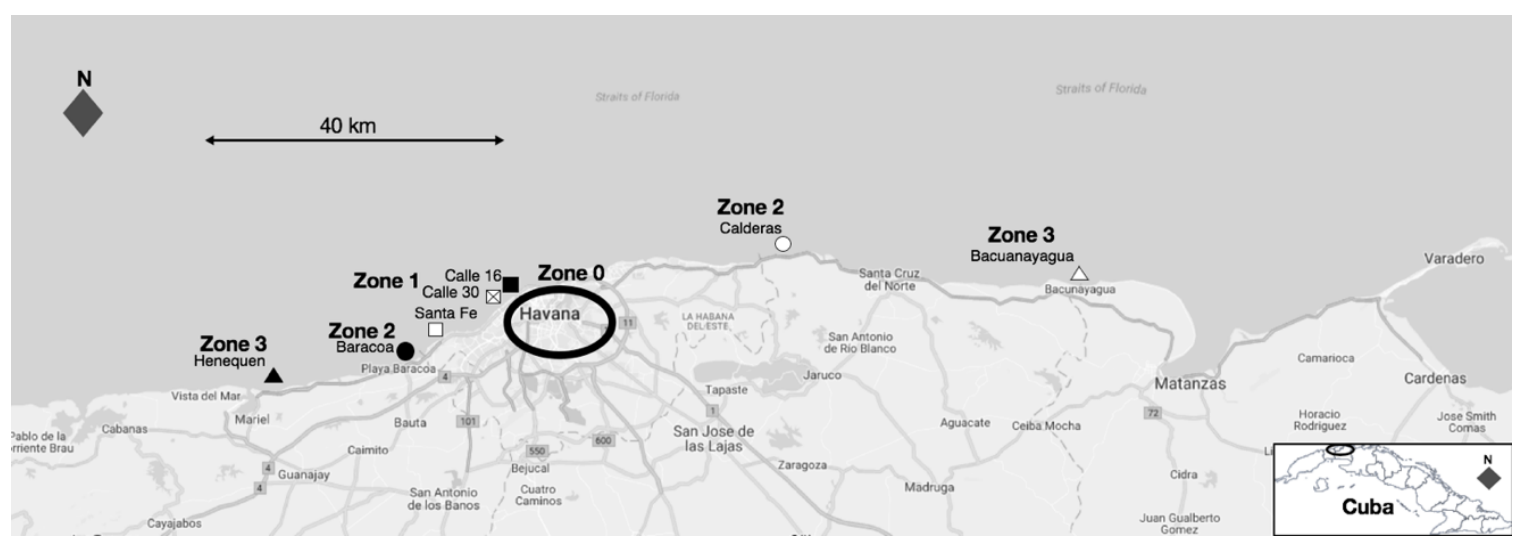


Figure 5.2 Delta $\mathrm{N}^{15}$ (A) and nitrogen concentration (B) in Sargassum tissue samples by sites within each zone. Data are mean \pm SE. Probability values comes from ANOVA analysis among zones with bolded results distinguishing statistically significant values ( $\mathrm{P}$ $<0.05)$. Letters along the bottom indicate differences between zones based on Tukey HSD. Error bars of Delta $\mathrm{N}^{15}$ of Baracoa and Henequen are difficult to see because of small values.

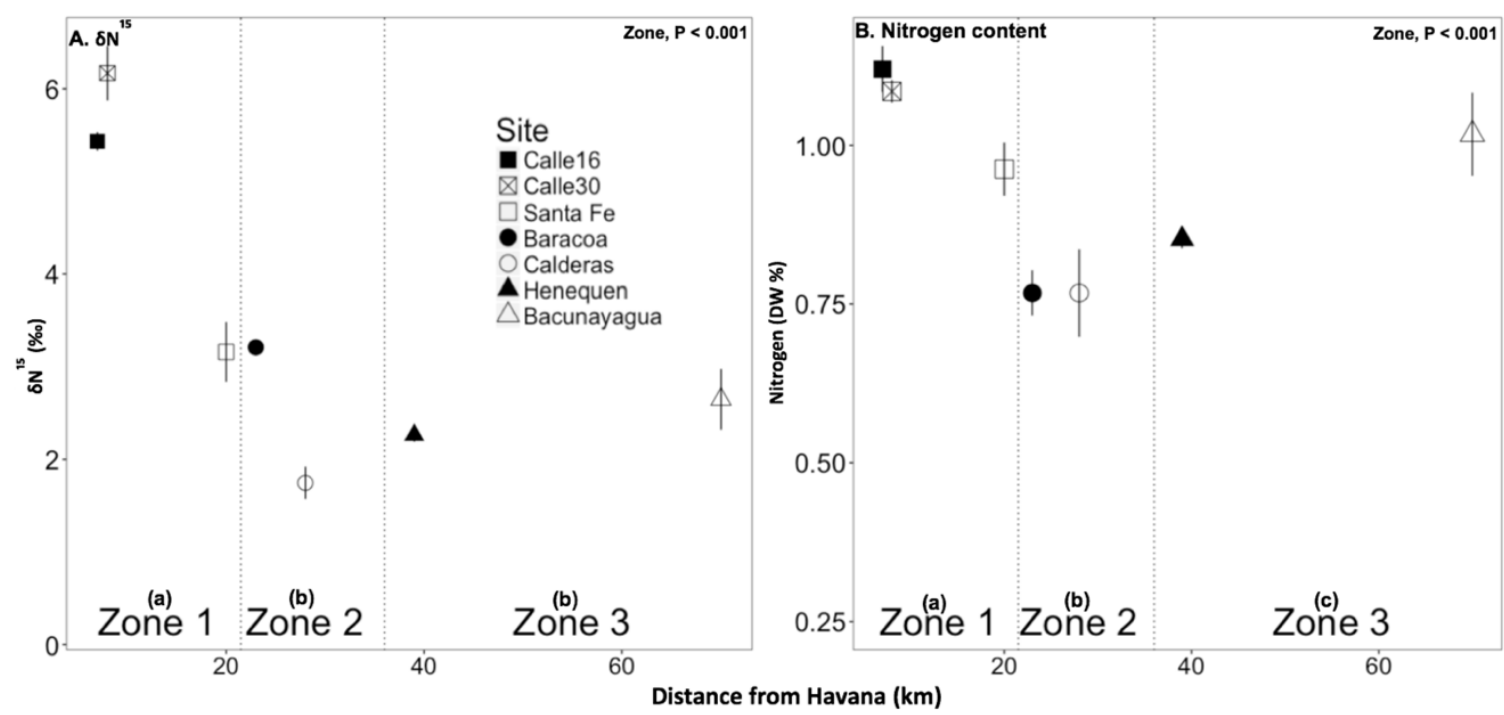


Figure 5.3 Average abundance of total and common algal taxa by site within each zone: (A) total algal (all species of algae), (B) Cyanobacteria, (C) Turf, (D) Dictyota spp., (E) Lobophora variegata, (F) Sargassum spp., (G) Jania spp., (H) Amphiroa spp. and (I) Halimeda spp. Data are mean \pm SE. Probability values comes from ANOVA with bold font indicating statistically significant values $(\mathrm{P}<0.05)$. Letters along the bottom indicate differences between zones based on Tukey HSD.
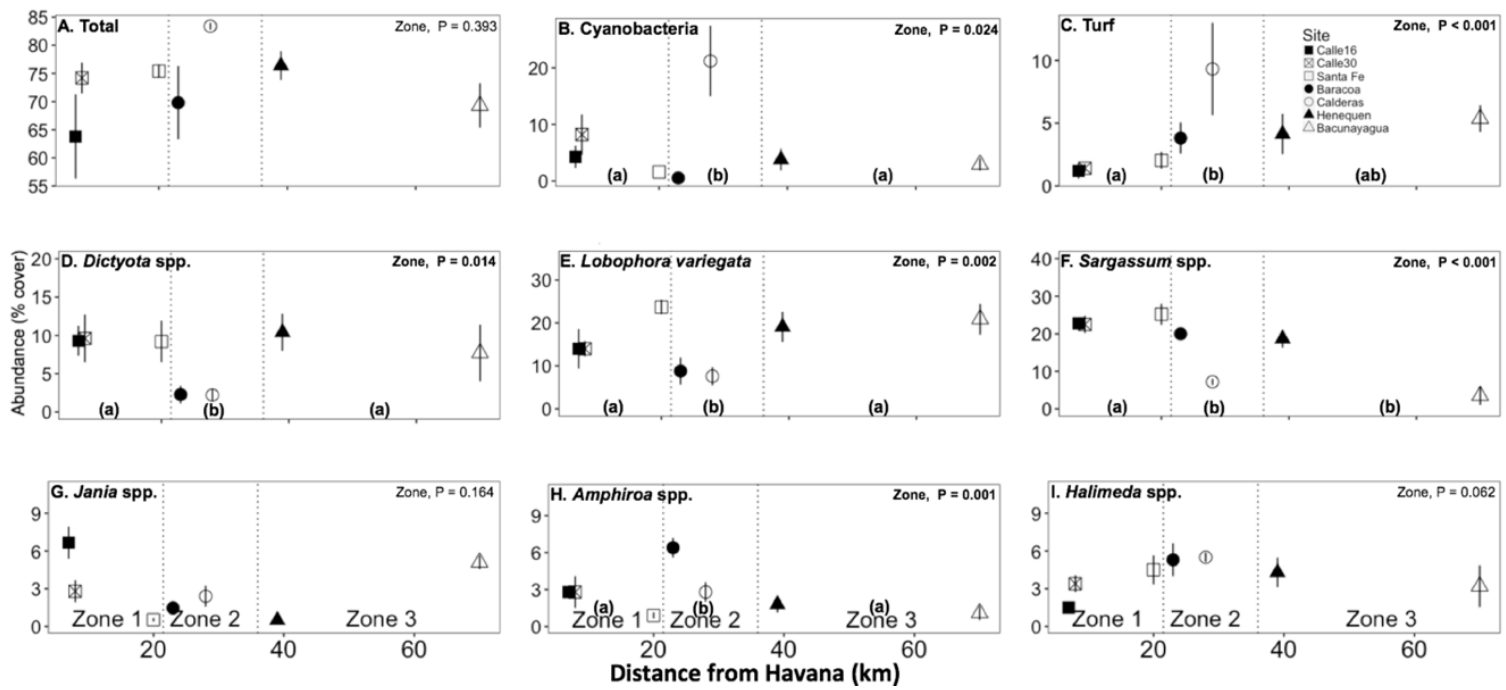
Figure 5.4 Total abundance of corals (A) and density of juveniles $(<4 \mathrm{~cm}$ diameter) (B) by site within each zone. Data are mean \pm SE. Probability values comes from ANOVA with bold font indicating statistically significant values $(\mathrm{P}<0.05)$. Letters along the bottom indicate differences between zones based on Tukey HSD.

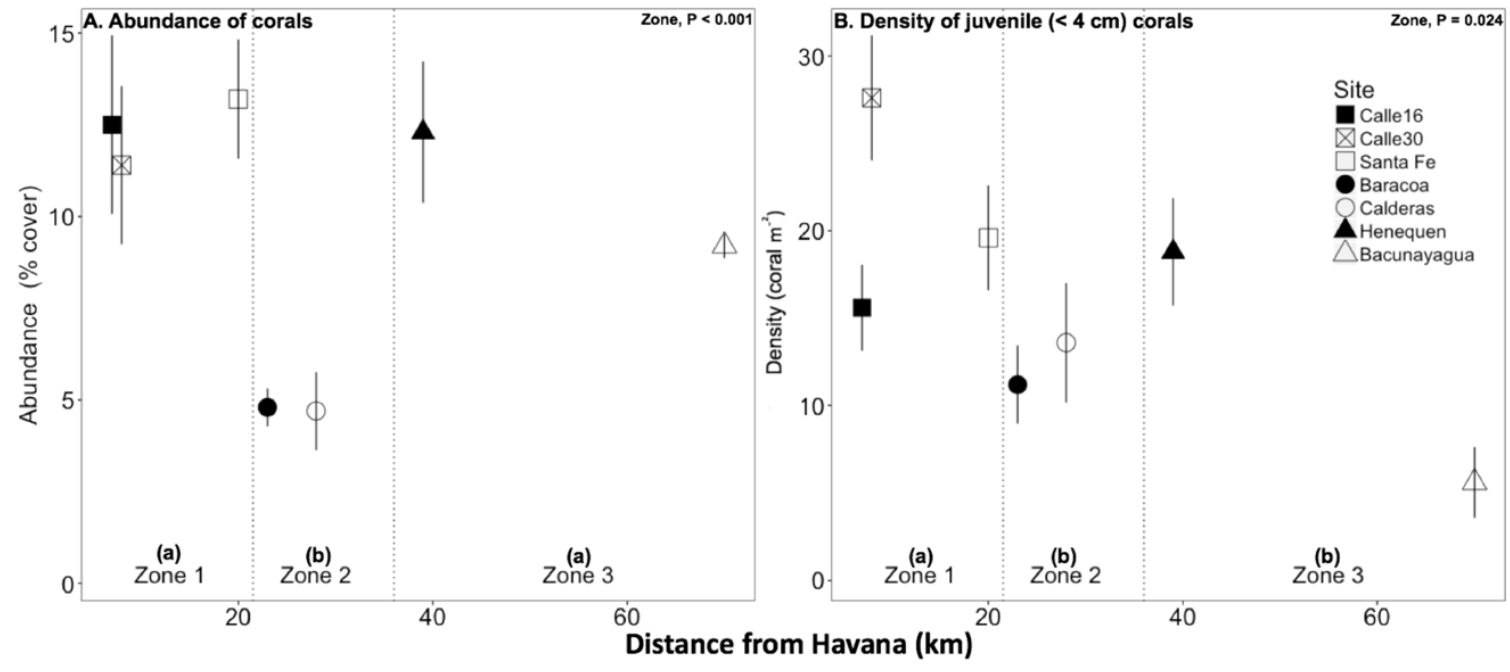


Figure 5.5 Biomass of fishes by trophic group by site within each zone: (A) Herbivores (e.g., parrotfish and surgeonfish); (B) Invertivores (e.g., grunts and wrasses); and (C) Piscivores (e.g., groupers, snappers and barracudas). Data are mean \pm SE. Probability values comes from ANOVA with bold font indicating statistically significant values $(\mathrm{P}<$ 0.05). Letters along the bottom indicate differences between zones based on Tukey HSD.

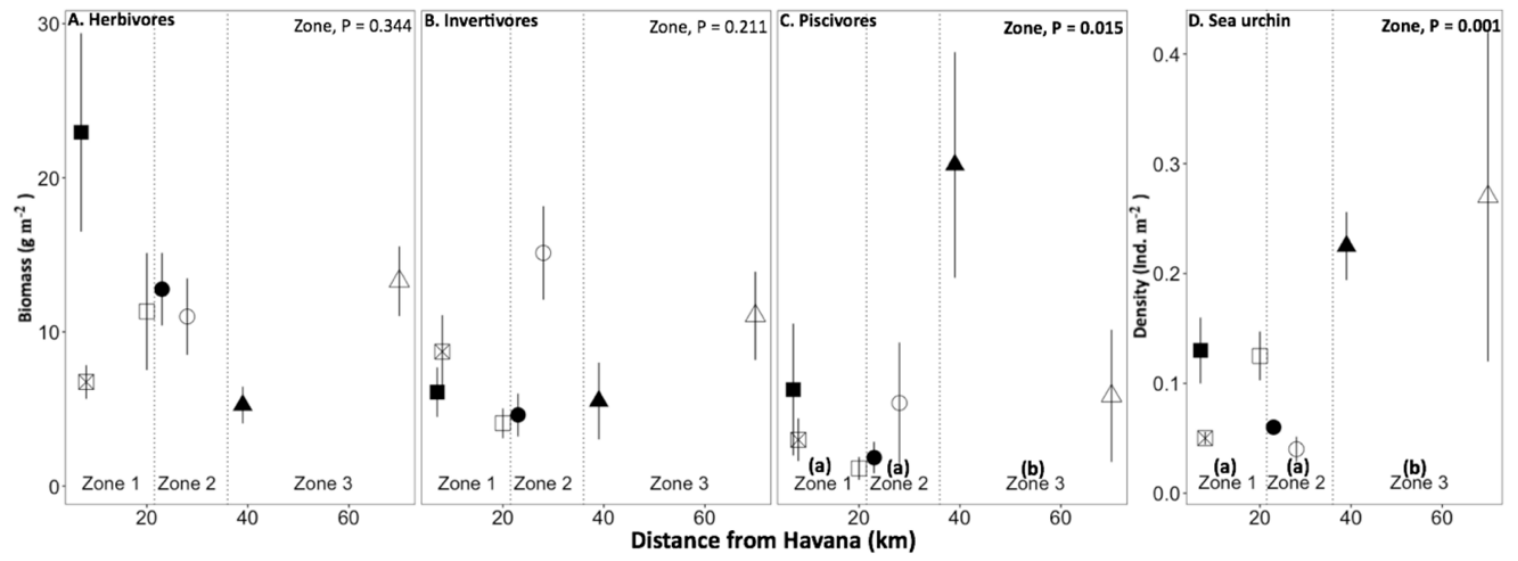


Figure 5.6 Macroalgal (A-D) and coral cover (E-H) by zone over time. Points represent average percent cover from individual sites taken from the literature and authors' unpublished data. Probability values indicates results of linear mixed effect model.
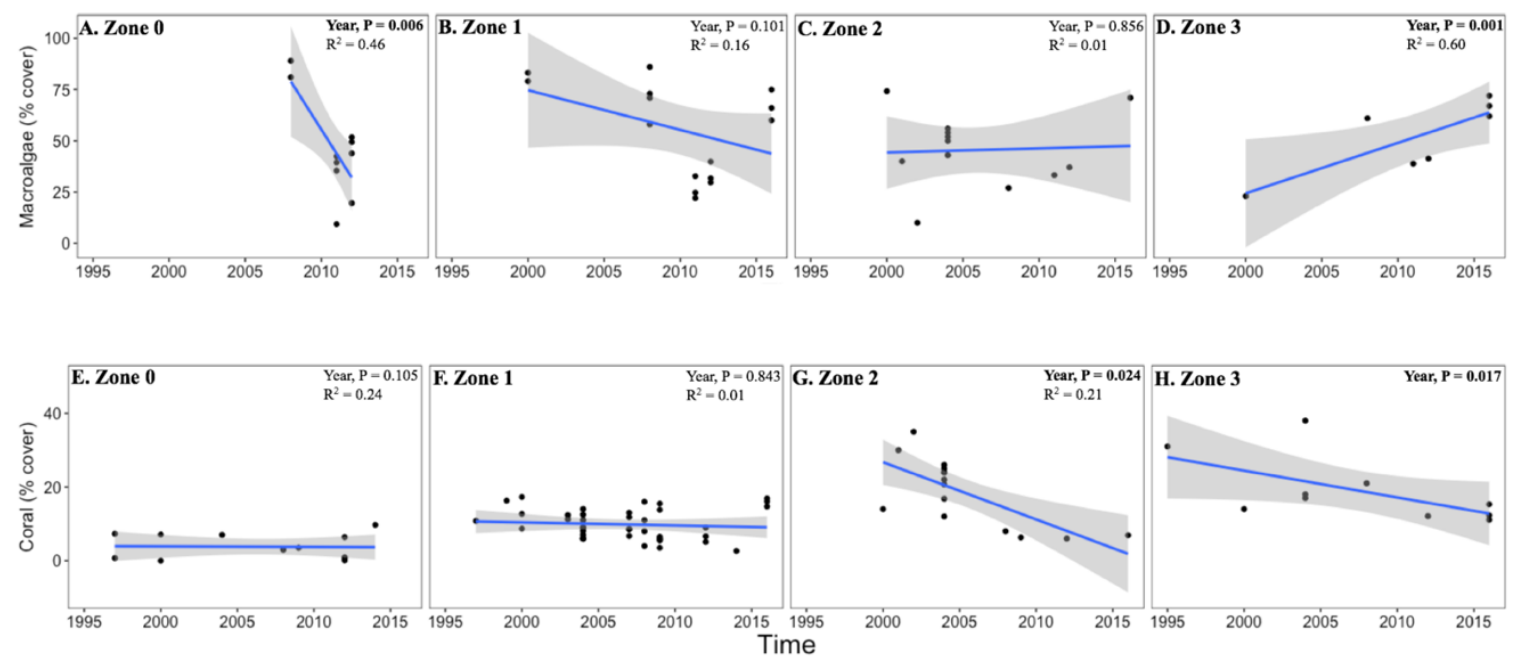
CHAPTER VI

CONCLUSIONS 


\section{CONCLUSIONS}

Predicting the response of coral reefs to global and regional stressors requires the best possible understanding of factors and processes determining community dynamics. The most relevant indicator of the Anthropocene coral reef crisis is the loss of coral cover as a consequence of increased frequency of global bleaching events (Logan et al. 2014), region-wide outbreaks of coral diseases (e.g., white band and black band, see Goreau et al. 1998) and outbreaks of coral-eating organisms such as the crown of thorns starfish (De'ath et al. 2012). The Caribbean region, compared to Pacific reefs, not only seems to be more frequently affected by bleaching events (Hughes et al. 2018) but reefs also display lower resilience as a consequence of lower diversity and grazing of herbivores, higher algal recruitment, and nutrient availability, among other factors (Roff and Mumby 2012). The grazing activity of herbivores over macroalgae, free space and facilitate recruitment and growth of corals enhancing reef resilience (Hughes et al. 2007, Steneck et al. 2017). Other factors such as reduced coral larvae supply (Hughes and Tanner 2000) and structural complexity (Newman et al. 2015) resulting from the dramatic loss of coral cover (over the last 50 year) in the Caribbean (Alvarez-Filip et al. 2009), might be compromising coral recovery. Given the current predictions of the continued increase of stress events, there is an urgent need to fully understand how, individually and combined, some of these factors and processes can influence coral reef resilience.

In Chapter II, we addressed a fundamental knowledge gap in one of the most important processes involved in coral reef resilience, herbivory (Steneck et al. 2017). We showed that the two most abundant surgeonfish species, Acanthurus tractus and $A$. coeruleus in the Caribbean, feed on turf algae but avoid it when it is mixed with 
sediment. We also found evidence that $A$. tractus preferably consumed macroalgae (e.g., Dictyota spp) than turf algae. Despite the ontogenetic shift in the diet of surgeonfishes, our results indicated that while both species can impede algal community development towards further successional stages, $A$. tractus can also help to recover reefs in advanced successional stages commonly dominated by macroalgae (e.g., Dictyota spp.). Our results are a fundamental contribution to predict the differential species impact of herbivory on Caribbean coral reefs highlighting the importance of niche diversification when considering species protection strategies.

Our small-scale field experiment in Chapter III demonstrated that besides herbivory other factors, in this case structural complexity, can influence the structure of coral reef benthic communities. The impact of herbivory on macroalgal communities of horizontal substrates coincided with previous works (Duran et al. 2016). Our findings add to the body of knowledge by showing that regardless of herbivory, the vertical substrate were quickly covered and remained dominated by crustose algae. Interestingly, vertical substrates with and without herbivores were the only that show coral recruits $(n=4)$ after the year-long experiment. Our results suggest that flattening of Caribbean coral reefs can negatively influence coral reef dynamics as more horizontal area colonized by upright macroalgae need to be controlled by herbivores. Our work raises further questions such as, how much herbivory is needed to promote resilience of Caribbean coral communities? And how does the loss of structural complexity is essential to be considered when designing strategies to enhance coral reef resilience.

In chapter IV we performed a detailed study of biological and physical characteristics of several reefs located in the upper section of the Florida Keys reefs. Our 
surveys of multiple reef habitats displaying a gradient of benthic communities and physical characteristics provided new insights to the question, why South Florida coral reefs do not follow the conservation paradigm in which high abundance of herbivores results in high coral abundance (promoting coral recovery and subsequently reef resilience). We found that abundance of sediment (percent cover) and depth of sediment layer are likely the primary factors impeding recovery of corals in this region. Our work offers a mechanistic explanation for previous findings indicating that marine protected areas are not enough to enhance the resilience of coral reefs in Florida Keys (Toth et al. 2014). Given our results, it is highly probable that the settlement and development of a fair amount of coral larvae in the Florida Keys reefs (van Woesik et al. 2014) is limited by the high abundance of a thick sediment layer and the species of the macroalga Dictyota spp. Results of this study highlights that while the negative impact of Dictyota spp. on corals has been shown, further work is needed to elucidate the effect of sediment (e.g., different sediment depths) and other commonly found benthic groups (e.g, CCA diversity) on settlement and post-settlement development of corals. Furthermore, analysis of accretion/erosion rate as well as sources of sediment need to be considered when developing conservation strategies including restoration programs. In addition, novel ideas (e.g., engineering techniques, genetic modification, the creation of artificial reefs) to improve coral reef resilience in the Florida Keys are also needed.

In contrast to South Florida, overfishing of reef herbivorous fishes are widely spread across the Caribbean leading to region-wide low herbivore abundance and consequent deleterious impact of coral reefs (Jackson et al. 2014). In chapter V we carried the first ever integrative, temporal and spatial, study in the North Havana coral 
reef region, historically characterized by an increased influence of anthropogenic stressors (e.g., nutrient enrichment and fishing pressure) close to Havana, Cuba. We reported two main findings in our study: 1) a current overall low coral cover and high abundance of macroalgae likely as a result of practical absence of herbivorous fishes (particularly larger than $15 \mathrm{~cm} \mathrm{TL})$, and 2) a major temporal decline ( $\sim 50 \%$ loss) of coral and increase of algal cover in the last 20 years. Bleaching events and storms seem to be the major coral decline factors. However, we observed a fair amount of corals, in which growth and development was probably limited by the increased abundance of macroalgae. In this case, protection of herbivorous fishes is imperative to promote the control of macroalgae which in turn favors growth of reef corals.

In conclusion, my dissertation provides a framework of results that builds on specific factors and processes (herbivory, structural complexity, and sediment) that shape structure and dynamics of Caribbean coral reefs. It also offers insight on spatial and temporal scales in which some factors can be more influential. For instance, while herbivory can be a major driver of benthic communities across coral reefs (meter to kilometers long), within few centimeters, the microhabitat conditions (structural complexity) might be a strong driver of algal and coral communities. Similarly, results from our chapter V showed that increased frequency and intensity of climate-change related stressors (e.g., thermal stress events and tropical storms) might be the current major factors leading to recent massive die-offs of corals across the globe (Hughes et al. 2018). Therefore, in order to develop management strategies that enhances coral reef resilience to global and regional stressors, we need to include multiple spatial and temporal scales in our studies. 


\section{REFERENCES}

Alvares-Filip L, Dulvy NK, Gill JA, Cote IM, Watkinson AR (2009) Flattening of Caribbean coral reefs: region-wide declines in architectural complexity. Proc $\mathrm{R}$ Soc B:1-7.Doi:10.1098/rspb.2009.0339

De'ath G, Fabricious KE, Sweatman H, Puotinen M (2014) The 27-year decline of coral cover on the Great Barrier Reefs and its causes. Proc Natl Acad Sci 109:1799517999

Duran A, Collado-Vides L, Burkepile DE (2016) Seasonal regulation of herbivory and nutrient effects on macroalgal recruitment and succession in a Florida coral reefs. PeerJ 4:e2643.Doi.107717/peerj.2643

Goreau TJ, Cervino J, Goreau M, Hayes R, Hayes M, Richardson L, Smith G, DeMeyer K, Nagelkerken I, Garzon-Ferrera J, Gil D, Garrison G, Williams EH, BunkleyWilliams L, Quirolo C, Patterson K, Porter JW, Porter K (1998) Rapid spread of diseases in Caribbean coral reefs. Rev Bio Trop 46:157-171

Hughes TP et al. (2018) Spatial and temporal patterns of mass bleachin of corals in the Anthropocene. Science 359:80-83

Hughes TP, Rodrigues MJ, Bellwood DR, Ceccarelli D, Hoegh-Guldberg O, McCook L, Moltschaniwskyj N, Pratchett MS, Steneck RS, Willis B (2007) Phase shift, herbivory, and the resilience of coral reefs to climate change. Curr Biol 17:360365

Hughes TP, Tnner JE (2000) Recruitment failure, life histories, and long-term decline of Caribbean corals. Ecology 81:2250-2263

Jackson JBC, Donovan MK, Cramer KL, Lam VV (2014) Status and Trends of Caribbean Coral Reefs: 1970-2012. Global Coral Reef Monitoring Network, IUCN, Gland, Switzerland

Logan CA, Dunne JP, Eakin CM, Donner SD (2014) Incorporating adaptive response into future projections of coral bleaching. Glob Change Biol 20:125-139

Newman SP, Meesters EH, Dryden CS, Williams SM, Sanchez C, Mumby PJ, Polunin NVC (2015) Reef flattening effects on total richness and species responses in the Carbbean. J Anim Ecol.Doi10.1111/1365-2656.12429

Roff G, Mumby PJ (2012) Global disparity in the resilience of coral reefs. Trend Ecol Evol 27:404-413 
Steneck RS, Bellwood DR, Hay ME (2017) Herbivory in the marine realm. Curr Biol 27:R431-R510

Toth LT, van Woesik R, Murdoch TJT, Smith SR, Ogden JC, Precht WF, Aronson RB (2014) Do no-take reserves benefit Florida's corals? 14 years of changes and stasis in the Florida Keys National Marine Sanctuary. Coral Reefs 33-565-577

van Woesik R, Scott WJ, Aronson RB (2014) Lost opportunities: coral recruitment does not translate to reef recovery in the Florida Keys. Mar Pollut Bull 88:110-117 
Appendix A: Supplementary tables and figures for chapter II

Table A1. Number of individuals by size class observed during the grazing rate surveys

$\begin{array}{cccccc}\text { Species } & \begin{array}{c}\text { Size class } \\ \text { (cm TL) }\end{array} & \begin{array}{c}\text { Conch } \\ \text { Reef }\end{array} & \begin{array}{c}\text { Pickles } \\ \text { Reef }\end{array} & \begin{array}{c}\text { Molasses } \\ \text { Reef }\end{array} & \begin{array}{c}\text { French } \\ \text { Reef }\end{array} \\ \text { A. coeruleus } & 1-5 & 1 & 4 & 8 & 6 \\ \text { A. coeruleus } & 6-10 & 3 & 5 & 3 & 4 \\ \text { A. coeruleus } & 11-15 & 1 & 1 & 1 & 1 \\ \text { A. coeruleus } & 16-20 & 7 & 5 & 10 & 14 \\ \text { A. coeruleus } & \text { Over } 20 & 3 & 4 & 2 & 0 \\ \text { A. tractus } & 1-5 & 0 & 0 & 2 & 0 \\ \text { A. tractus } & 6-10 & 1 & 5 & 7 & 2 \\ \text { A. tractus } & 11-15 & 4 & 6 & 6 & 10 \\ \text { A. tractus } & 16-20 & 8 & 4 & 5 & 8 \\ \text { A. tractus } & \text { Over } 20 & 2 & 0 & 2 & 0\end{array}$


Table A2. Number of individuals by size class surveyed during the fish feeding observations

\begin{tabular}{|cccccc} 
Species & $\begin{array}{c}\text { Size class } \\
\text { (cm TL) }\end{array}$ & $\begin{array}{c}\text { Conch } \\
\text { Reef }\end{array}$ & $\begin{array}{c}\text { Pickles } \\
\text { Reef }\end{array}$ & $\begin{array}{c}\text { Molasses } \\
\text { Reef }\end{array}$ & $\begin{array}{c}\text { French } \\
\text { Reef }\end{array}$ \\
\hline A. coeruleus & $1-5$ & 27 & 24 & 16 & 4 \\
A. coeruleus & $6-10$ & 16 & 16 & 14 & 4 \\
A. coeruleus & $11-15$ & 11 & 11 & 26 & 10 \\
A. coeruleus & $16-20$ & 21 & 31 & 30 & 9 \\
A. coeruleus & Over 20 & 34 & 10 & 25 & 20 \\
A. tractus & $1-5$ & 12 & 9 & 7 & 2 \\
A. tractus & $6-10$ & 40 & 20 & 23 & 4 \\
A. tractus & $11-15$ & 19 & 34 & 33 & 11 \\
A. tractus & $16-20$ & 27 & 29 & 44 & 16 \\
A. tractus & Over 20 & 12 & 0 & 15 & 13
\end{tabular}


Figure A1. Photographic representation ( $5 \times 5 \mathrm{~cm}$ frame) of some common benthic groups quantified during surveys of benthic communities and fish feeding activities. A) crustose algae with arrows pointing to the turf algae growing on it (turf on crustose algae), B) different types of turf-forming algae (turf), C) turf algae associated with sediment (TAS), D) Dictyota spp., E) species of articulated calcareous algae, from left to right there is Galaxaura sp., Halimeda sp., Jania sp. and Amphiroa sp., and F) thallus of (likely old individual) of Stypopodium zonale with arrows indicating turf forming algae as epiphytes

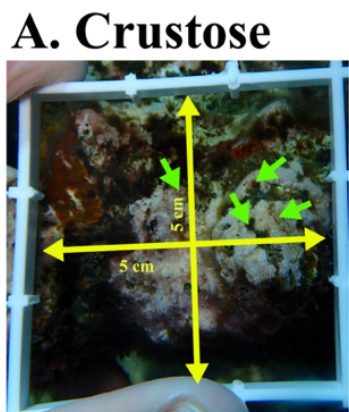

\section{Dictyota}

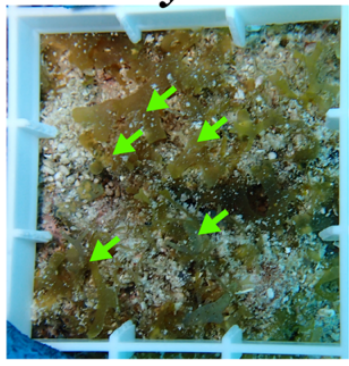

\section{B. Turf}

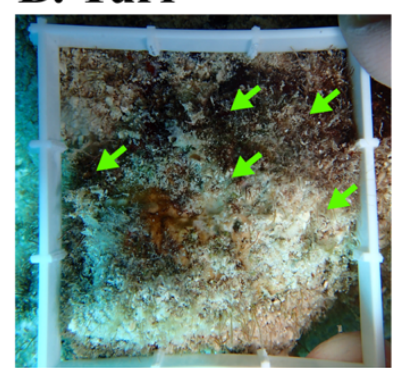

E. Articulated

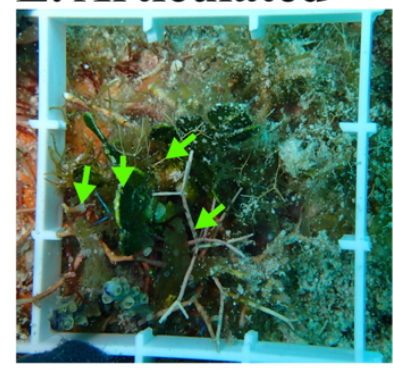

C. TAS

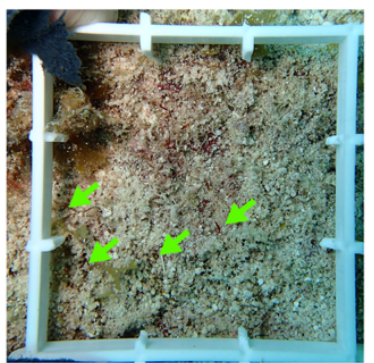

F. Stypopodium

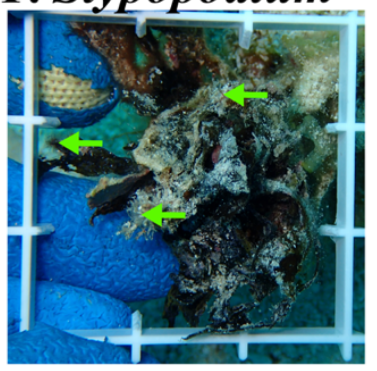


Figure A2. Average sediment depth at each reef site. Mean $( \pm \mathrm{SE})$. An analysis of variance $\left(\right.$ ANOVA) showed differences among all sites $\left(\mathrm{F}_{3,28}=6.60, p=0.002\right)$

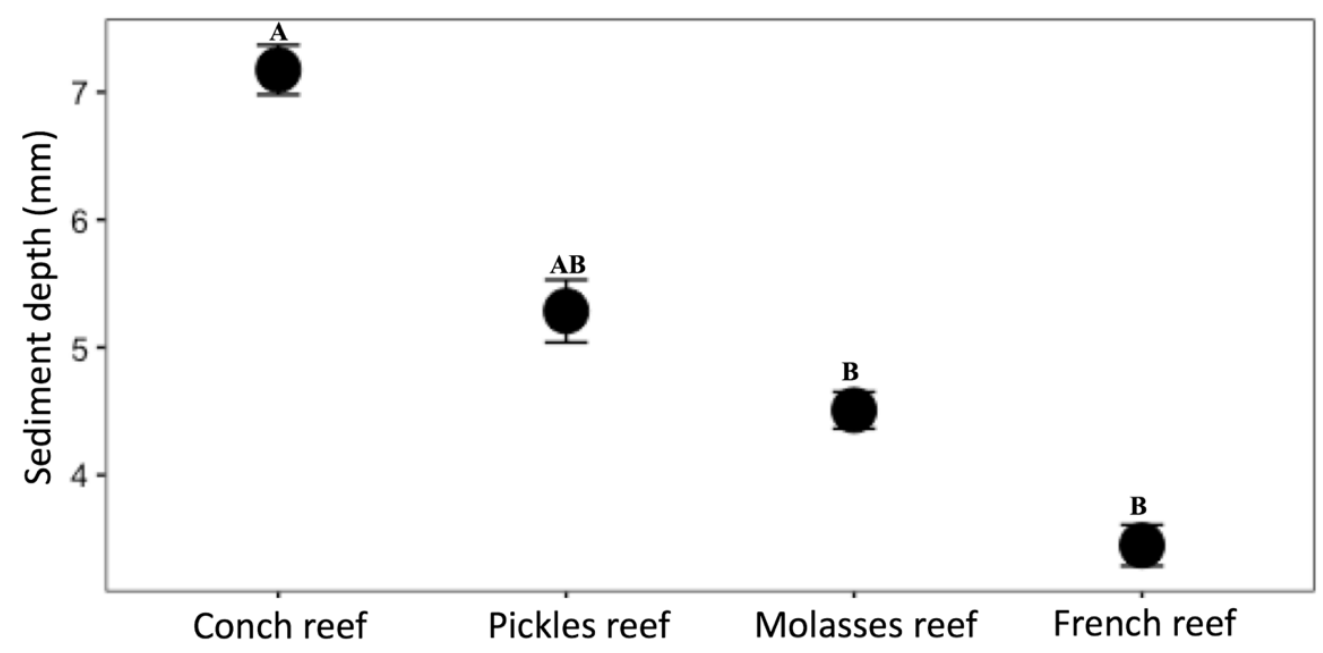


Figure A3. Boxplot distribution of sediment depth targeted (from fish bite) by surgeonfish species among among studied sites

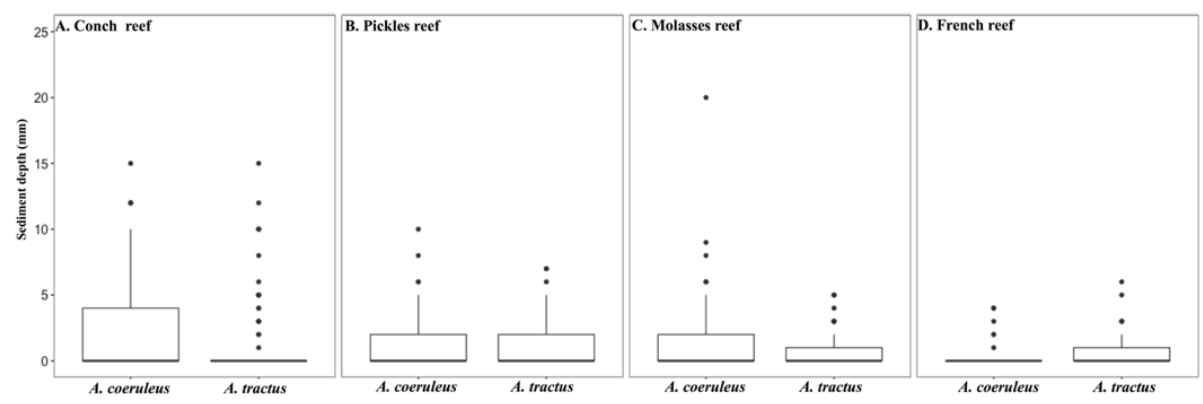


Figure A4. Boxplot distribution of turf height targeted (from fish bite) by surgeonfish species among studied sites

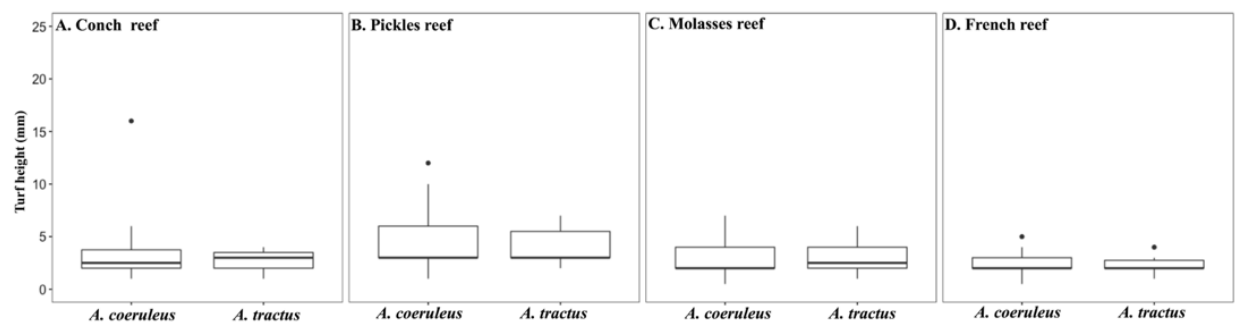


Appendix B: Supplementary tables and figures for chapter III

Figure B1. Photographs of the two juvenile Porites spp. coral recruits found on vertical substrates. We found no recruits on horizontal substrates

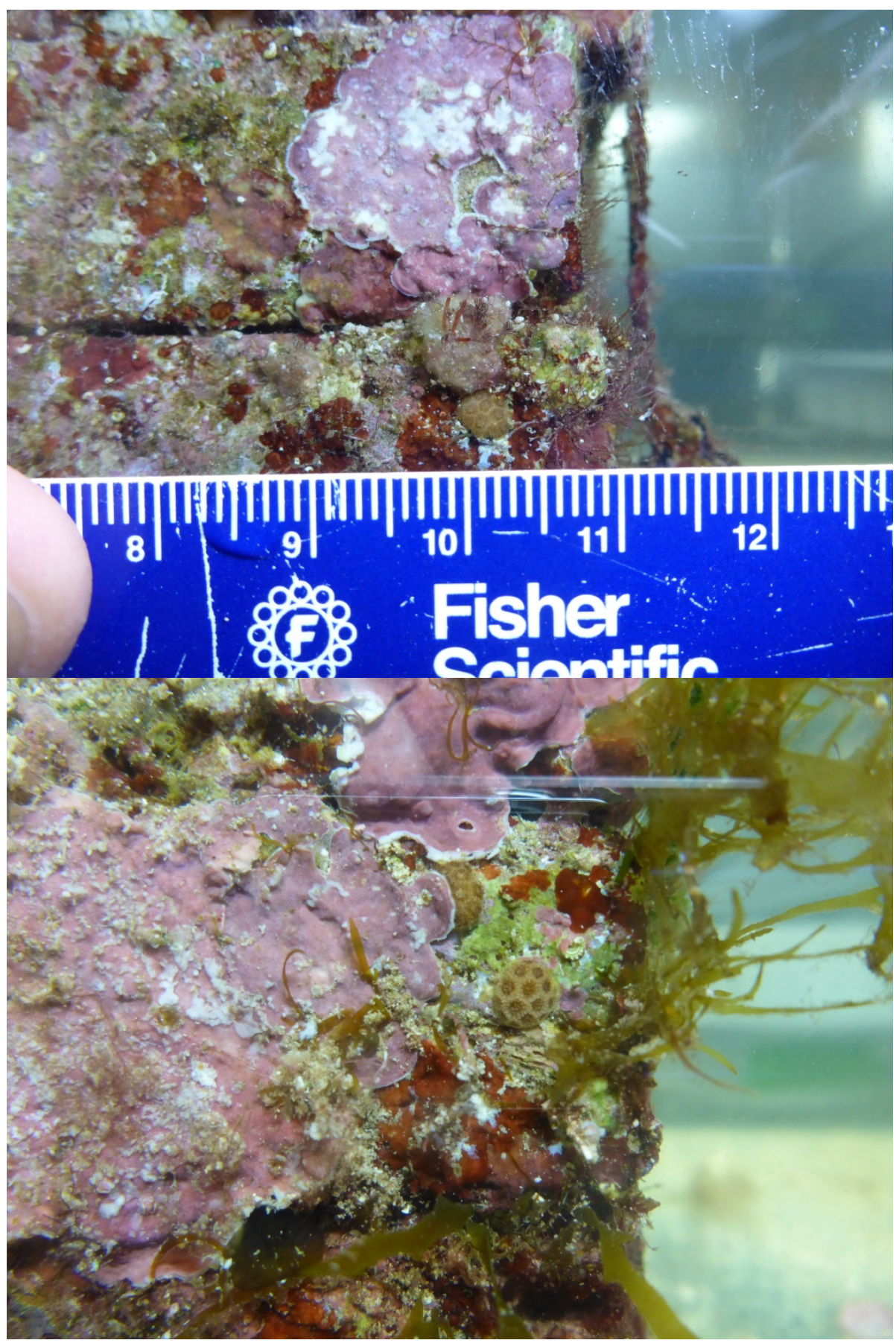


Appendix C: Supplementary tables and figures for chapter IV

Table $\mathrm{C}$ 1. Average $( \pm \mathrm{SE})$ values of abiotic variables (slope, rugosity and sediment depth) and major benthic groups (sediment, turf, crustose coralline algae) by reef habitat.

\begin{tabular}{|c|c|c|c|c|c|}
\hline Habitat & Groove & Plain & $\begin{array}{l}\text { Flat spur } \\
\text { top }\end{array}$ & $\begin{array}{l}\text { Rugose } \\
\text { spur top }\end{array}$ & $\begin{array}{l}\text { Spur } \\
\text { wall }\end{array}$ \\
\hline $\begin{array}{c}\text { Slope } \\
\text { (degree) }\end{array}$ & $\begin{array}{c}14.7 \\
( \pm 1.1)\end{array}$ & $\begin{array}{c}6.9 \\
( \pm 0.4)\end{array}$ & $\begin{array}{c}13.3 \\
( \pm 0.5)\end{array}$ & $\begin{array}{c}15.6 \\
( \pm 1.2)\end{array}$ & $\begin{array}{c}40.1 \\
( \pm 2.7)\end{array}$ \\
\hline Rugosity & $\begin{array}{c}1.2 \\
( \pm 0.1)\end{array}$ & $\begin{array}{c}1.2 \\
( \pm 0.1)\end{array}$ & $\begin{array}{c}1.2 \\
( \pm 0.1)\end{array}$ & $\begin{array}{c}1.4 \\
( \pm 0.1)\end{array}$ & $\begin{array}{c}1.4 \\
( \pm 0.1)\end{array}$ \\
\hline $\begin{array}{c}\text { Sediment } \\
\text { depth }(\mathrm{mm})\end{array}$ & $\begin{array}{c}9.0 \\
( \pm 0.7)\end{array}$ & $\begin{array}{c}6.4 \\
( \pm 0.2)\end{array}$ & $\begin{array}{c}3.4 \\
( \pm 0.1)\end{array}$ & $\begin{array}{c}1.8 \\
( \pm 0.2)\end{array}$ & $\begin{array}{c}2.0 \\
( \pm 0.3)\end{array}$ \\
\hline $\begin{array}{c}\text { Percent } \\
\text { cover of Turf }\end{array}$ & $\begin{array}{c}11.6 \\
( \pm 1.2)\end{array}$ & $\begin{array}{c}2.4 \\
( \pm 0.3)\end{array}$ & $\begin{array}{c}20.3 \\
( \pm 0.8)\end{array}$ & $\begin{array}{c}22.7 \\
( \pm 1.5)\end{array}$ & $\begin{array}{c}26.4 \\
( \pm 2.4)\end{array}$ \\
\hline $\begin{array}{l}\text { Percent } \\
\text { cover of } \\
\text { Sediment }\end{array}$ & $\begin{array}{c}56.2 \\
( \pm 2.4)\end{array}$ & $\begin{array}{c}69.5 \\
( \pm 1.2)\end{array}$ & $\begin{array}{c}41.0 \\
( \pm 1.1)\end{array}$ & $\begin{array}{c}23.3 \\
( \pm 1.5)\end{array}$ & $\begin{array}{c}16.9 \\
( \pm 2.1)\end{array}$ \\
\hline $\begin{array}{l}\text { Percent } \\
\text { cover of } \\
\text { CCA }\end{array}$ & $\begin{array}{c}0.5 \\
( \pm 0.2)\end{array}$ & $\begin{array}{c}0.1 \\
( \pm 0.1)\end{array}$ & $\begin{array}{c}0.7 \\
( \pm 0.2)\end{array}$ & $\begin{array}{c}6.0 \\
( \pm 1.1)\end{array}$ & $\begin{array}{c}4.4 \\
( \pm 1.5)\end{array}$ \\
\hline $\begin{array}{l}\text { Percent } \\
\text { cover of } \\
\text { Dictyota }\end{array}$ & $\begin{array}{c}15.6 \\
( \pm 1.2)\end{array}$ & $\begin{array}{c}17.5 \\
( \pm 0.9)\end{array}$ & $\begin{array}{c}23.2 \\
( \pm 0.8)\end{array}$ & $\begin{array}{c}30.2 \\
( \pm 1.3)\end{array}$ & $\begin{array}{l}33.6 \\
( \pm 2.9)\end{array}$ \\
\hline
\end{tabular}


Figure C1. Relationship between abiotic variables. (A) Slope and rugosity, (B) slope and sediment depth, and (C) rugosity and sediment depth. Statistics indicates results of the linear mixed model.
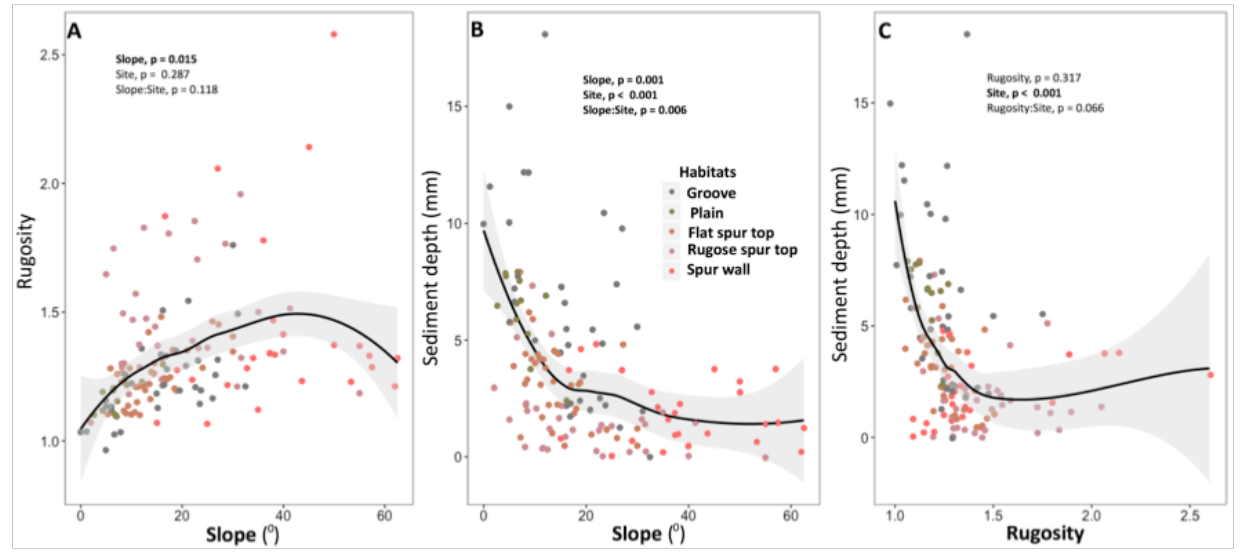
Figure C2. Relationship between abundance sediment, turf, crustose coralline algae (CCA) and Dictyota with slope and rugosity of the substrate. Points represent the average cover, the line indicates the linear relationship and shaded area the standard error. Statistics resulted from the Linear Mixed Model (LMM).
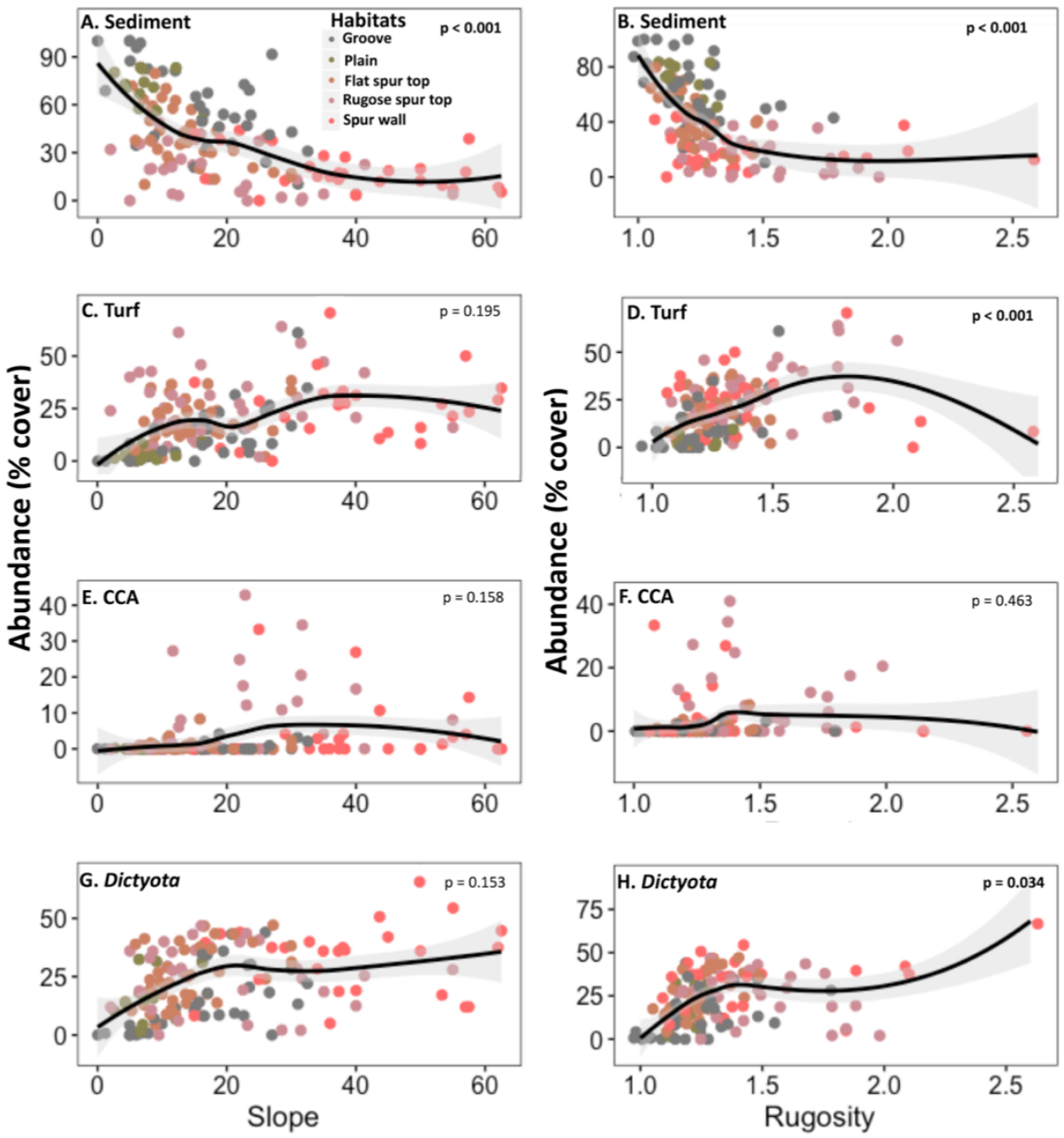
Figure C3. Density and community composition of of juvenile (A\&B) and adult corals $(\mathrm{C} \& D)$. Points represent average $( \pm \mathrm{SE})$.
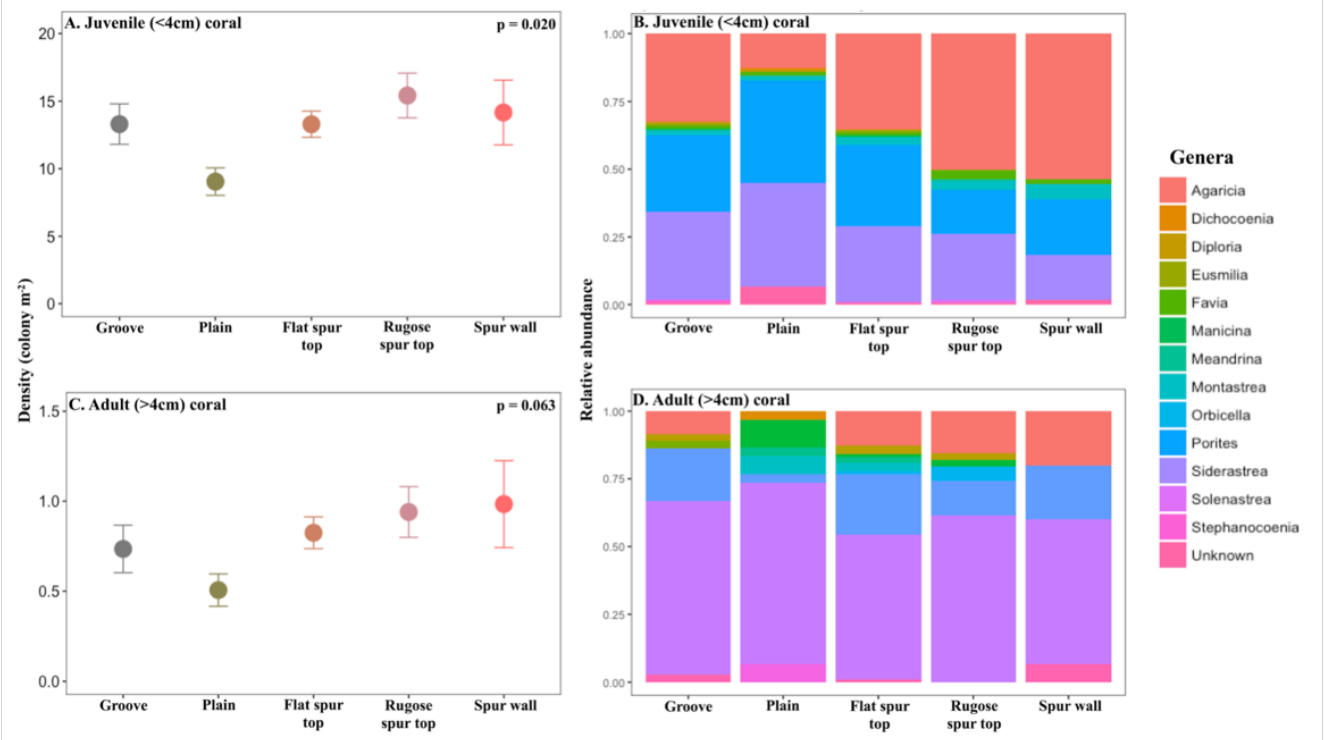
Figure C4. Deviance plot resulted from boosted regression tree predicting relative influence of all studied factors on presence/absence of all juvenile corals. Mean total deviance $=1.373$, mean residual deviance $=1.31$.

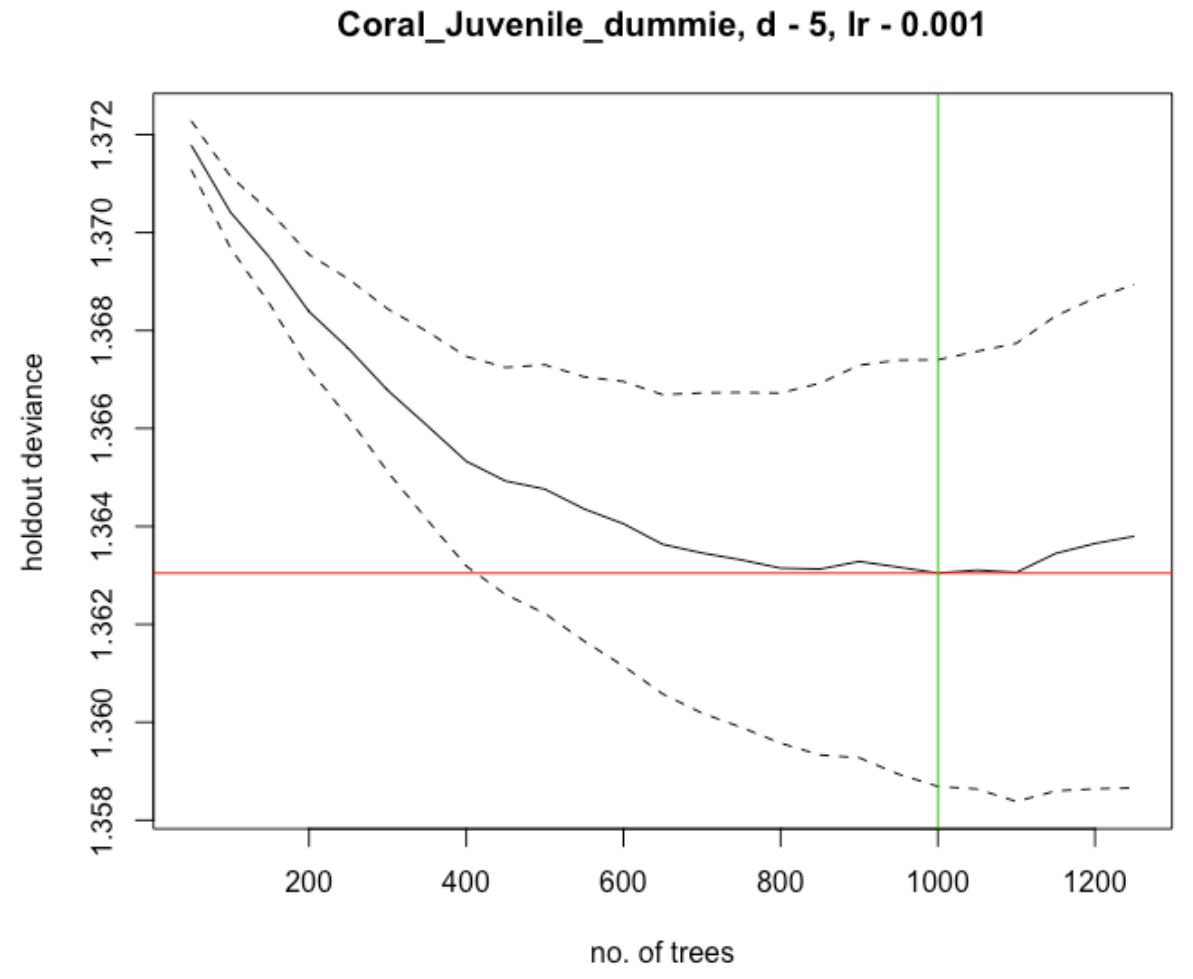


Figure C5. Deviance plot resulted from boosted regression tree predicting relative influence of all studied factors on presence/absence of Siderastrea juvenile corals. Mean total deviance $=1.089$, mean residual deviance $=0.834$.

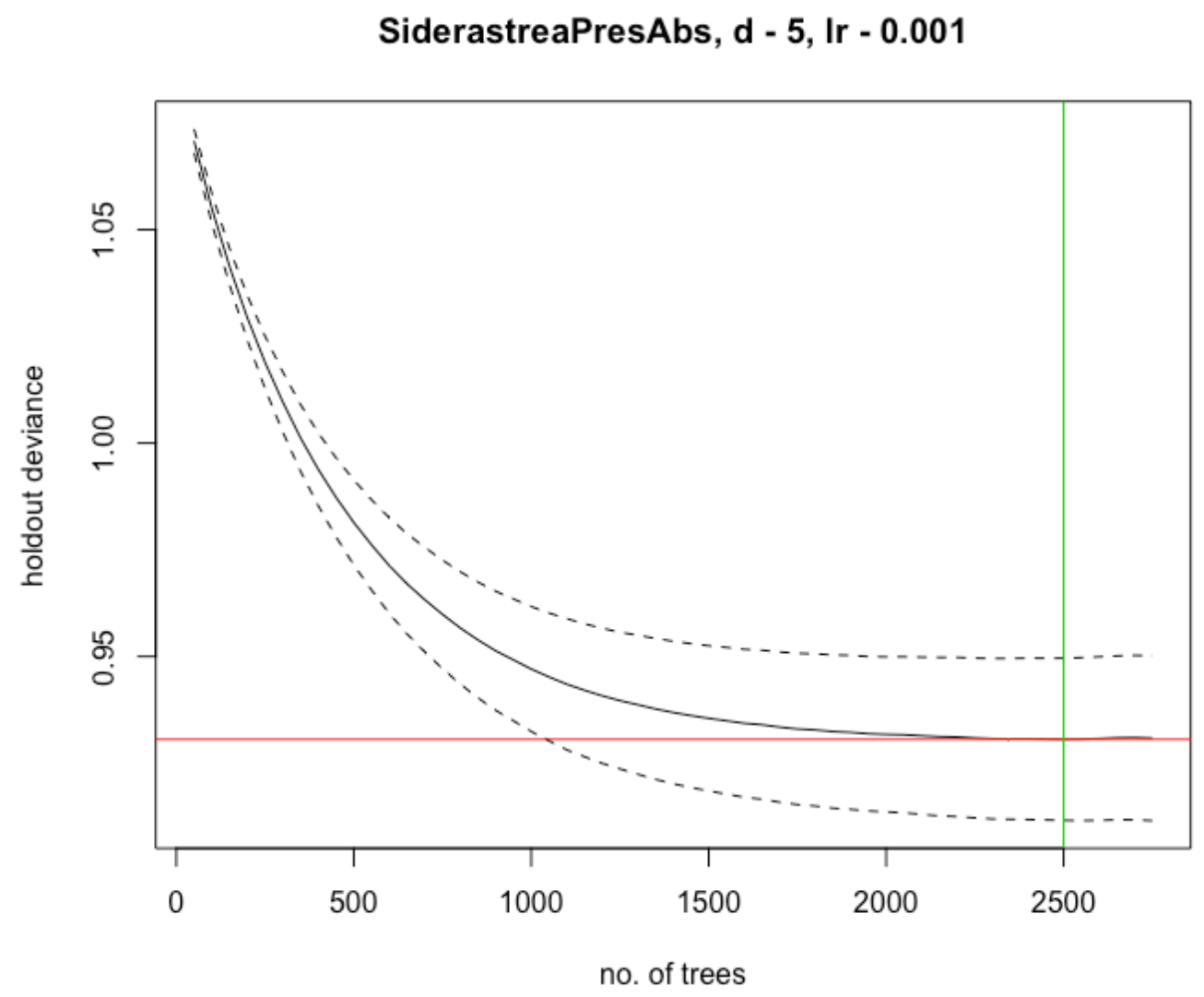


Figure C6. Deviance plot resulted from boosted regression tree predicting relative influence of all studied factors on presence/absence of Agaricia juvenile corals. Mean total deviance $=1.024$, mean residual deviance $=0.778$.

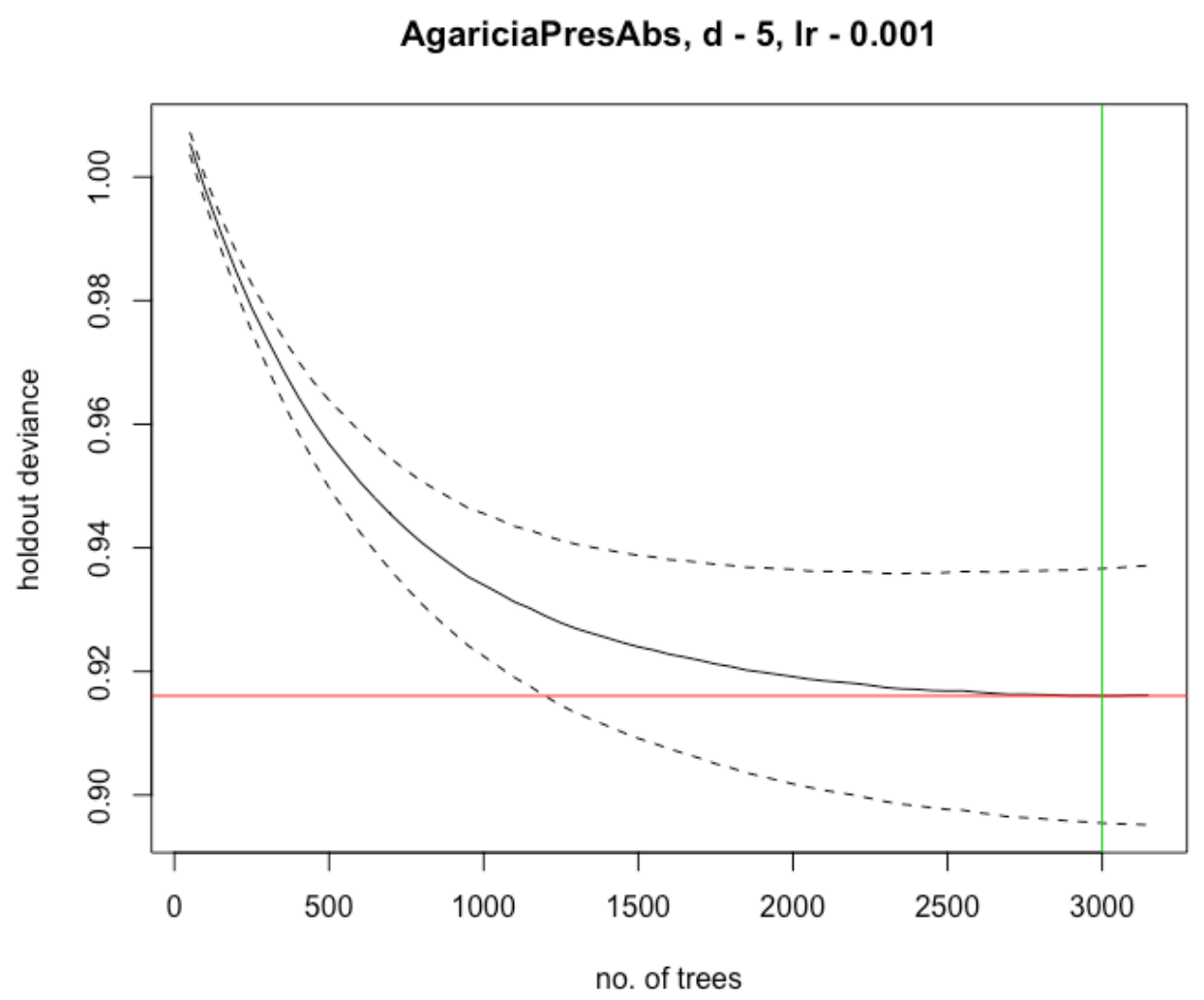


Figure C7. Deviance plot resulted from boosted regression tree predicting relative influence of all studied factors on presence/absence of Porites juvenile corals. Mean total deviance $=1.001$, mean residual deviance $=0.908$.

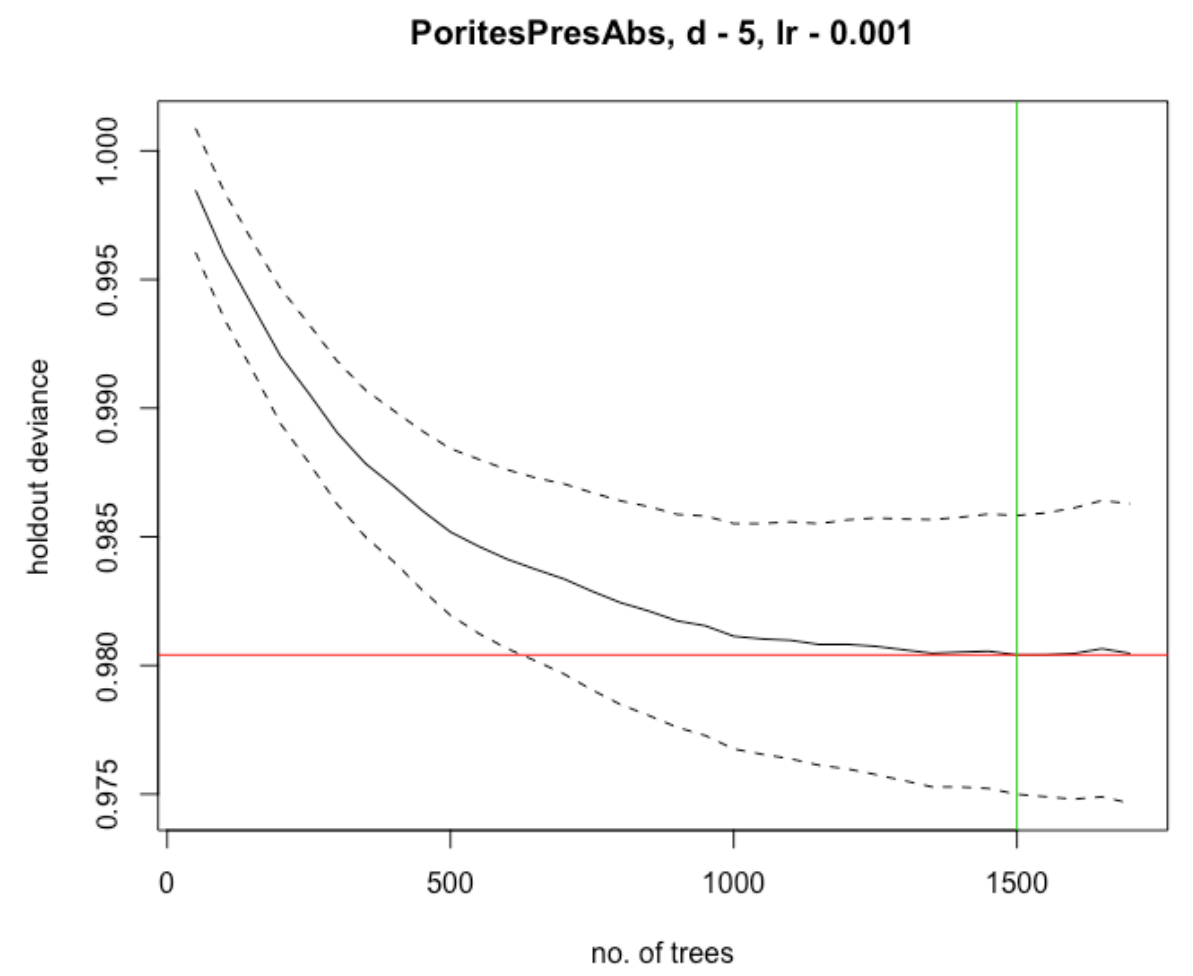


Figure C8. Deviance plot resulted from boosted regression tree predicting relative influence of all studied factors on presence/absence of all adult corals. Mean total deviance $=0.94$, mean residual deviance $=0.717$.

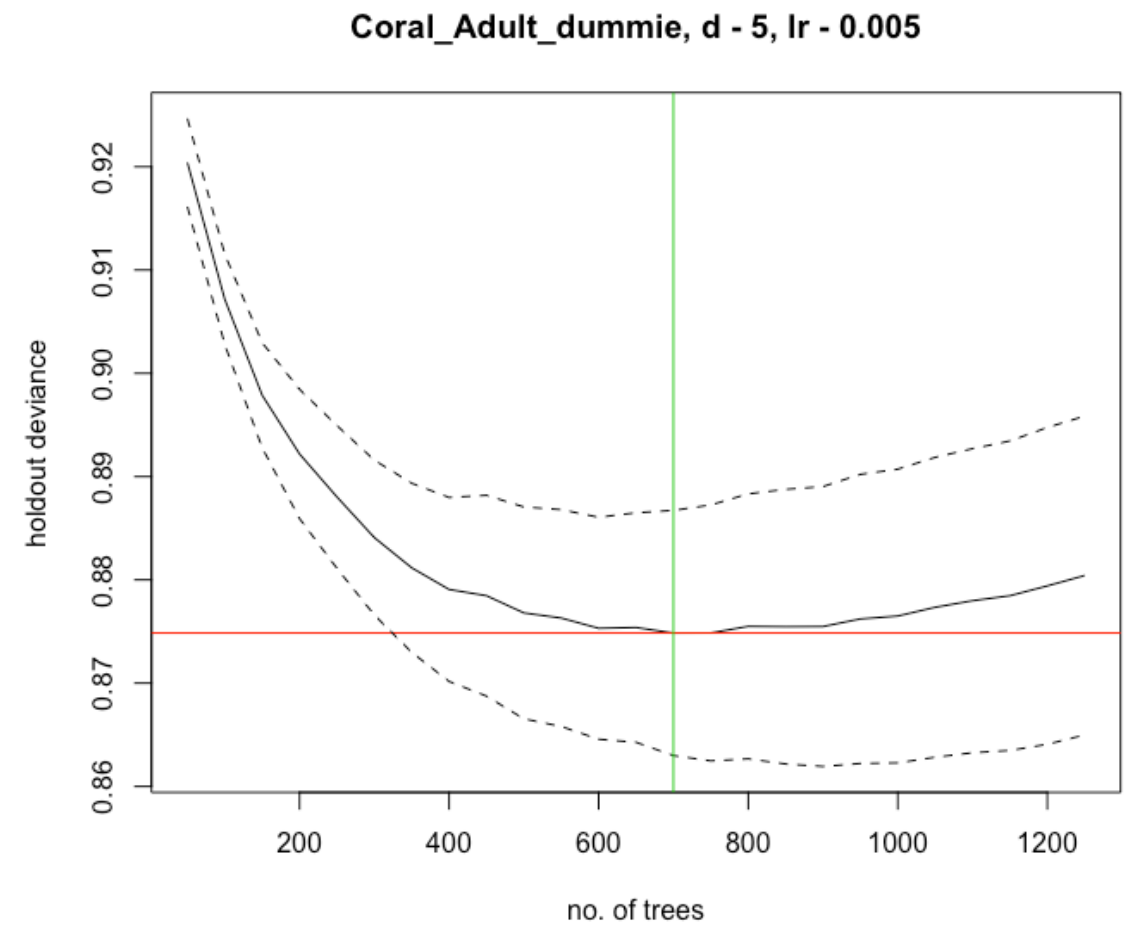


Appendix D: Supplementary tables and figures for chapter V

Table D1. List of data resources for temporal analysis (published, unpublished). The first four columns (Year, Month, Zone, and Site and Habitat) indicate where and when the data (published or unpublished) of percent cover of coral, algae and sponge were collected. The farthest right column indicates the data source (list of data source references at the end)

\begin{tabular}{|c|c|c|c|c|c|c|}
\hline Year & Month & $\begin{array}{c}\text { Zon } \\
\text { e }\end{array}$ & Site & $\begin{array}{c}\text { Cor } \\
\text { al }\end{array}$ & $\begin{array}{c}\text { Macroalg } \\
\text { ae }\end{array}$ & $\begin{array}{c}\text { Data } \\
\text { source }\end{array}$ \\
\hline 2009 & September & 0 & La Puntilla & 3.5 & NA & 1 \\
\hline 2009 & September & 1 & Calle 70 & 5.8 & NA & 1 \\
\hline 2009 & September & 1 & Calle 180 & 6.5 & NA & 1 \\
\hline 2009 & September & 1 & $\begin{array}{l}\text { Jaimanitas } \\
\text { Marina }\end{array}$ & 6 & NA & 1 \\
\hline 2009 & September & 1 & Hemingway & 13.8 & NA & 1 \\
\hline 2009 & September & 1 & Santa Fe & 15.5 & NA & 1 \\
\hline 2009 & September & 2 & Baracoa & 6.3 & NA & 1 \\
\hline 2004 & NA & 1 & La Puntilla & 7 & NA & 1 \\
\hline 2004 & NA & 1 & Calle70 & 6 & NA & 1 \\
\hline 2007 & NA & 0 & La Puntilla & NA & NA & 1 \\
\hline 2007 & NA & 1 & Calle 70 & 8.5 & NA & 1 \\
\hline 2009 & NA & 1 & La Puntilla & 3.5 & NA & 1 \\
\hline 2009 & NA & 1 & Calle 70 & 5.5 & NA & 1 \\
\hline 2014 & NA & 0 & La Puntilla & 9.7 & NA & 1 \\
\hline 2014 & NA & 1 & Calle 70 & 2.65 & NA & 1 \\
\hline 2011 & August & 0 & $\begin{array}{c}\text { Boya Roja } \\
\text { Parque Antonio }\end{array}$ & NA & 42.42 & 2 \\
\hline 2011 & August & 0 & Maceo & NA & 9.34 & 2 \\
\hline 2011 & August & 0 & Malecon Y 12 & NA & 39.44 & 2 \\
\hline 2011 & August & 0 & La Puntilla & NA & 35.46 & 2 \\
\hline 2011 & August & 1 & Calle 30 & NA & 24.73 & 2 \\
\hline 2011 & August & 1 & Acuario & NA & 22.03 & 2 \\
\hline 2011 & August & 1 & Santa Fe & NA & 32.74 & 2 \\
\hline 2011 & August & 2 & Salado & NA & 33.24 & 2 \\
\hline 2011 & August & 3 & Calderas & NA & 38.84 & 2 \\
\hline 2012 & February & 0 & Boya Roja & 0.7 & 49.43 & 2 \\
\hline
\end{tabular}




\begin{tabular}{|c|c|c|c|c|c|c|}
\hline \multicolumn{7}{|c|}{ Parque Antonio } \\
\hline 2012 & February & 0 & Maceo & 0.1 & 19.64 & 2 \\
\hline 2012 & February & 0 & Malecon Y 12 & 0.9 & 51.75 & 2 \\
\hline 2012 & February & 0 & La Puntilla & 6.4 & 43.88 & 2 \\
\hline 2012 & February & 1 & Calle 30 & 6.6 & 29.67 & 2 \\
\hline 2012 & February & 1 & Acuario & 5.1 & 31.75 & 2 \\
\hline 2012 & February & 1 & Santa Fe & 9 & 39.82 & 2 \\
\hline 2012 & February & 2 & Salado & 6 & 37.08 & 2 \\
\hline 2012 & February & 3 & Calderas & 12.1 & 41.35 & 2 \\
\hline 2004 & Junio & 3 & Henequen & 17 & NA & 3 \\
\hline 2004 & Junio & 3 & Rio Mosquito & 18 & NA & 3 \\
\hline 2004 & Junio & 2 & Salado & 25 & NA & 3 \\
\hline 2004 & Junio & 2 & Santa Fe & 26 & NA & 3 \\
\hline 2004 & Junio & 1 & Acuario & 14 & NA & 3 \\
\hline 2004 & Junio & 2 & Cojimar & 12 & NA & 3 \\
\hline 2004 & Junio & 2 & Guanabo & 22 & NA & 3 \\
\hline 2004 & Junio & 2 & Guanabo & 24 & NA & 3 \\
\hline 2004 & Junio & 3 & Bacunayagua & 38 & NA & 3 \\
\hline 2000 & January & 1 & Acuario & 17.3 & 83.2 & 4 \\
\hline 2000 & January & 1 & Barlovento & 12.7 & 79.1 & 4 \\
\hline 2000 & January & 2 & Salado & 14 & 74.2 & 4 \\
\hline 2004 & April & 2 & Guanabo & 16.8 & 50 & 5 \\
\hline 2004 & April & 2 & Guanabo & 20.7 & 43 & 5 \\
\hline 2004 & April & 2 & Guanabo & 23.9 & 43 & 5 \\
\hline 2004 & Sept & 2 & Guanabo & NA & 56 & 5 \\
\hline 2004 & Sept & 2 & Guanabo & NA & 54 & 5 \\
\hline 2004 & Sept & 2 & Guanabo & NA & 52 & 5 \\
\hline 2016 & May & 1 & Santa Fe & 14.7 & 75 & t study \\
\hline 2016 & May & 1 & Calle 30 & 16.9 & 66 & t study \\
\hline 2016 & May & 1 & Calle 16 & 16.1 & 60 & t study \\
\hline 2016 & May & 2 & Baracoa & 6.9 & 71 & t study \\
\hline 2016 & May & 3 & Henequen & 12.3 & 72 & t study \\
\hline 2016 & May & 3 & Calderas & 11.1 & 62 & t study \\
\hline 2016 & May & 3 & Bacunayagua & 15.3 & 67 & t study \\
\hline
\end{tabular}




\begin{tabular}{|c|c|c|c|c|c|c|}
\hline 1995 & July & 3 & Herradura & 31 & NA & 6 \\
\hline 2000 & July & 3 & Herradura & 14 & 23 & 6 \\
\hline 1997 & NA & 0 & NA & 0.7 & NA & 7 \\
\hline 1997 & NA & 0 & NA & 7.3 & NA & 7 \\
\hline 1997 & NA & 1 & NA & 10.8 & NA & 7 \\
\hline 1999 & NA & 1 & NA & 16.3 & NA & 7 \\
\hline 2000 & NA & 0 & NA & 0 & NA & 7 \\
\hline 2000 & NA & 0 & NA & 7.1 & NA & 7 \\
\hline 2000 & NA & 1 & NA & $\begin{array}{c}8.7 \\
11.2\end{array}$ & NA & 7 \\
\hline 2003 & August & 1 & Calle 16 & $\begin{array}{c}5 \\
12.3\end{array}$ & NA & 8 \\
\hline 2003 & August & 1 & Calle 190 & 7 & NA & 8 \\
\hline 2004 & September & 1 & Calle 70 & 6 & NA & 9 \\
\hline 2004 & September & 1 & $\mathrm{IdO}$ & 9 & NA & 9 \\
\hline 2004 & September & 1 & Club Havana & 8.1 & NA & 9 \\
\hline 2007 & September & 1 & Calle70 & 8.6 & NA & 9 \\
\hline 2007 & September & 1 & $\mathrm{IdO}$ & 13 & NA & 9 \\
\hline 2007 & September & 1 & ClubHavana & 11.8 & NA & 9 \\
\hline 2007 & September & 1 & $\begin{array}{l}\text { Calle } 180 \\
\text { Rincon De }\end{array}$ & 6.7 & NA & 9 \\
\hline 2001 & February & 2 & $\begin{array}{c}\text { Guanabo } \\
\text { Rincon De }\end{array}$ & 30 & 40 & 10 \\
\hline 2002 & April & 2 & Guanabo & 35 & 10 & 10 \\
\hline 2004 & July & 0 & La Puntilla & 7 & NA & 11 \\
\hline 2004 & July & 1 & $\begin{array}{c}\text { Santa Fe } \\
\text { Marina }\end{array}$ & 12.5 & NA & 11 \\
\hline 2004 & July & 1 & Hemingway & 11 & NA & 11 \\
\hline 2004 & July & 1 & $\mathrm{IdO}$ & 9 & NA & 11 \\
\hline 2004 & July & 1 & Calle 70 & 6 & NA & $\begin{array}{c}11 \\
\text { Gonzal } \\
\text { ez- } \\
\text { Diaz P } \\
\text { (Unpu } \\
\text { blished }\end{array}$ \\
\hline 2008 & June & 0 & Rio Almendares & 3 & 81 & $\begin{array}{c}\text { data) } \\
\text { Gonzal } \\
\text { ez- } \\
\text { Diaz P } \\
\text { (Unpu } \\
\text { blished }\end{array}$ \\
\hline 2008 & July & 0 & Este & 3 & 89 & data) \\
\hline
\end{tabular}




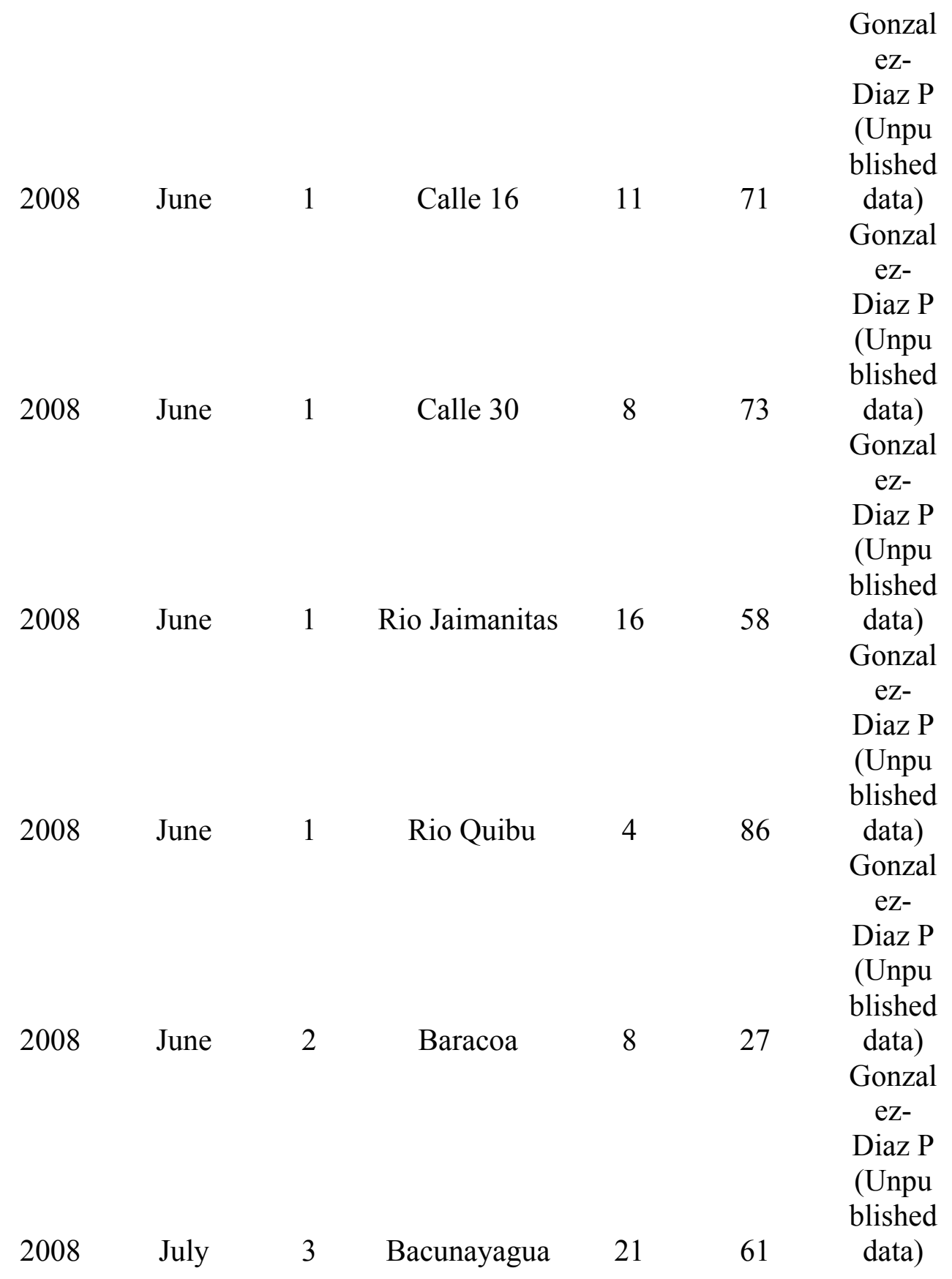

\section{References of data sources}

1- Alcolado-Prieto P, et al. 2010. Research project report Mazco (Library, Institute of Oceanology, Cuba)

2- Alcolado-Prieto P. 201. Master Thesis. (Library, Center of Marine Investigation, Cuba) 
3- Caballero H, Alcolado PM, Semidey A. 2009. Condición de los arrecifes de coral frente a costas con asentamientos humanos y aportes terrígenos: El caos del litoral habanero., Cuba. Rev Mar Cost 1:49-72

4- Caballero H, De la Guardia E. 2003. Arrecifes de coral utilizados como zonas de colectas para las exhibiciones en el Acuario Nacional de Cuba. Rev Invest Mar 24(3):205-220

5- Caballero H, Rosales D, Alcala A. 2005. Estudio diagnostico del arrecife coralino del Ricon de Guanabo, Ciudad Habana, Cuba. 1. Corales, Esponjas y Gorgonaceos. Rev Invest Mar 27(1): 49-59

6- De la Guardia E, Gonzalez-Diaz P, Varona G, Gonzalez-Ferrer S, Superes W. 2003. Variaciones temporales y espaciales en la comunidad bentonica del arrecife de Playa Herradura, provincia Habana, Cuba. Rev Invest Mar 24(2):117-126

7- Gonzalez-Diaz P, de la Guardia E and Gonzalez-Sanson G. 2003. Efecto de efluentes terrestres sobre las comunidades bentónicas de arrecifes coralinos de Ciudad de la Habana, Cuba. Rev Invest mar 24(3):193-204

8- Gonzalez-Ontivero O, Macias D, De la Guardia E. 2007. Evaluación de los corales escleractineos y gorgonias en dos localidades de Ciudad de la Habana, Cuba. Rev Invest Mar 28 (1): 21-27

9- Hernandez-Munoz et al. 2007. Research project report Mazco (Library, Institute of Oceanology, Cuba)

10-Castellanos S, Lopeztegui A, de la Guardia E. 2004. Monitoreo Reef check en el arrecife coralino "Rincon de Guanabo", Cuba. Rev Invest Mar 25(3):219-230

11- Marcos-Sardinas et al. 2004. Research project report Mazco (Library, Institute of Oceanology, Cuba) 
Table D2. Frequency and intensity of bleaching events from 2003-2015 were obtained from the yearly coral bleaching technical report published by Dr. Pedro Alcolado (Alcolado 2003-2016) from the "Volunteer Monitoring Network of Early Coral Reef Warning" (Red de monitoreo voluntario de alerta temprana de arrecifes coralinos)

\begin{tabular}{lllc} 
Year & Region & \multicolumn{1}{c}{ Qualitative } & Bleaching level (\%) \\
2003 & Havana & Very low (Nulo) & 0 \\
2005 & Havana & Very high (Muy alto) & $51-75$ \\
2006 & Havana & High (Alto) & $31-50$ \\
2007 & Havana & Very high (Muy alto) & $51-75$ \\
2008 & Havana & Low (Pobre) & $0-10$ \\
2009 & Havana & Critical (Casi total) & $76-100$ \\
2010 & Havana & Very high (Muy alto) & $51-75$ \\
2011 & Havana & Medium (Moderado) & $11-30$ \\
2012 & Havana & Low (Pobre) & $0-10$ \\
2013 & Havana & Medium (Moderado) & $11-30$ \\
2014 & Havana & Very high (Muy alto) & $51-75$ \\
2015 & Havana & Very high (Muy alto) & $51-75$
\end{tabular}


Table D3. Hurricane information, date, location and intensity, was extracted from the National Oceanographic and Atmospheric Administration (https://coast.noaa.gov/hurricanes/) and the Cuban Weather Forecast Department (Departamento de pronosticos, ISMET 2017). The " $x$ " indicates the province(s) where the Hurricane impacted

\begin{tabular}{|c|c|c|c|c|c|c|c|c|}
\hline Name & Year & $\begin{array}{l}\text { Mo } \\
\text { nth }\end{array}$ & Day(s) & Cat & $\begin{array}{l}\text { Pinar } \\
\text { del Rio }\end{array}$ & $\begin{array}{l}\text { Hava } \\
\text { na }\end{array}$ & $\begin{array}{l}\text { Ha } \\
\text { van } \\
\text { a } \\
\text { Cit } \\
\mathbf{y}\end{array}$ & $\begin{array}{l}\text { M } \\
\text { ata } \\
\text { nz } \\
\text { as }\end{array}$ \\
\hline Michelle & 2001 & Nov & $4-5$ & 4 & & $\mathrm{x}$ & $\mathrm{x}$ & $\mathrm{x}$ \\
\hline Isidore & 2002 & Sep & $20-21$ & 1 & $\mathrm{x}$ & & & \\
\hline Lili & 2002 & Oct & 1 & 1 & $\mathrm{x}$ & & & \\
\hline Charley & 2004 & Aug & 13 & 3 & & $\mathrm{x}$ & $\mathrm{x}$ & \\
\hline Iván & 2004 & Sep & $13-14$ & 4 & $\mathrm{x}$ & & & \\
\hline Arlene & 2005 & Jun & $9-10$ & 1 & $\mathrm{x}$ & & & \\
\hline Dennis & 2005 & Jul & $8-9$ & 1 & & $\mathrm{x}$ & $\mathrm{x}$ & \\
\hline Katrina & 2005 & Aug & $26-27$ & 5 & $\mathrm{x}$ & $\mathrm{x}$ & $\mathrm{x}$ & \\
\hline Rita & 2005 & Sep & $20-21$ & 5 & $\mathrm{x}$ & $\mathrm{x}$ & $\mathrm{x}$ & \\
\hline Wilma & 2005 & Oct & $23-24$ & 5 & $\mathrm{x}$ & $\mathrm{x}$ & $\mathrm{x}$ & \\
\hline Ernesto & 2006 & Aug & $28-30$ & 1 & & & $\mathrm{x}$ & $\mathrm{x}$ \\
\hline Noel & 2007 & Oct & $29-4$ & 1 & & & & $\mathrm{x}$ \\
\hline Gustav & 2008 & Aug & $25-4$ & 4 & $\mathrm{x}$ & $\mathrm{x}$ & $\mathrm{x}$ & $\mathrm{x}$ \\
\hline Ike & 2008 & Sep & $1-14$ & 4 & $\mathrm{x}$ & $\mathrm{x}$ & $\mathrm{x}$ & $\mathrm{x}$ \\
\hline Paloma & 2008 & Nov & $5-9$ & 3 & & & & $\mathrm{x}$ \\
\hline
\end{tabular}




$\begin{array}{lllllllll}\text { Paula } & 2010 & \text { Oct } & 14-15 & 2 & \mathrm{x} & \mathrm{x} & \mathrm{x} & \mathrm{x} \\ \text { Isaac } & 2012 & \text { Aug } & 26-27 & 1 & & & & \mathrm{x}\end{array}$


Figure D1. Relative abundance of brooder corals (gray) and broadcaster corals (black) across sites. Zone 1 (Calle 16, Calle 30 and Santa Fe), Zone 2 (Baracoa and Calderas) and Zone 3 (Henequen and Bacunayagua)

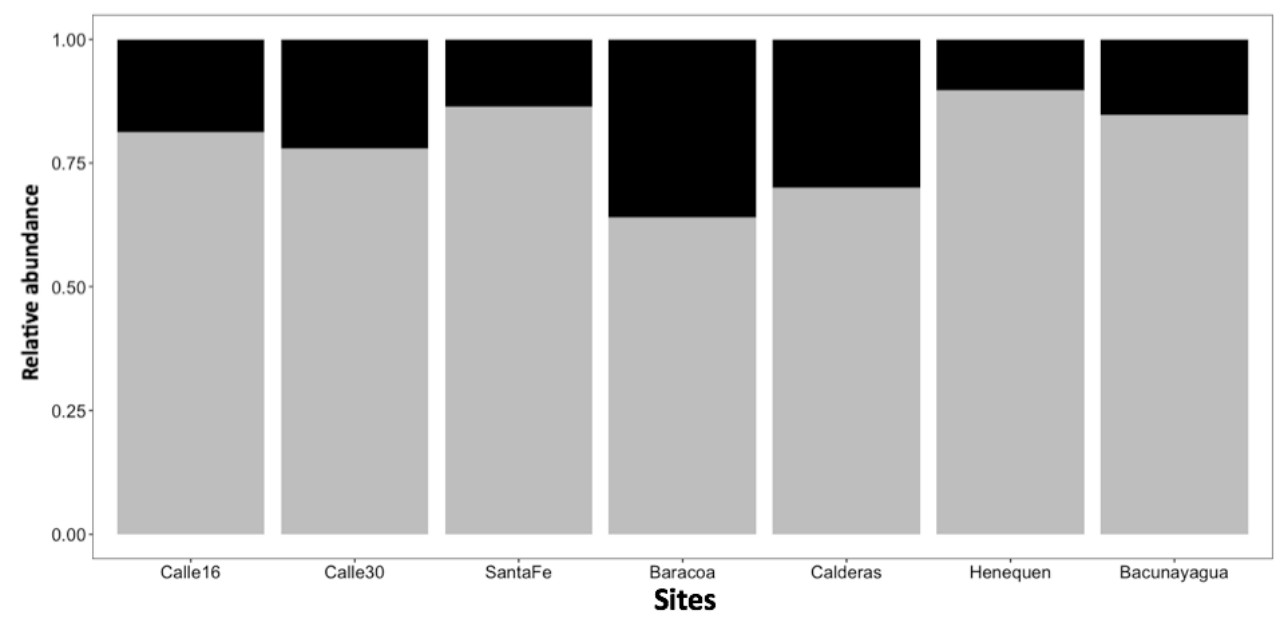


VITA

\section{ALAIN DURAN}

Born, Havana, Cuba

2001-2007

B.A., Biology

University of Havana, Cuba

2007-2009

Institute of Oceanology, Cuba

2011-2013

M.S., Biology

Florida International University

Florida, USA

2013-2018

Ph.D. Biology

Florida International University

Florida, USA

\section{PUBLICATIONS}

$>$ Duran, A., D. E. Burkepile, L. Collado-Vides, V. M. Ferrer, S. P. Gonzalez, L.

Palma, A. Ramos and A. A. Shantz (2018) Fishing, pollution, climate change, and the long-term decline of coral reefs off Havana, Cuba. Bull Mar Sci 94:Doi.10.5343/bms.2017.1061

> Collado-Vides, L, Duran A, Armenis E, et al. 2017. Seasonal recruitment and survival strategies of Palisada cervicornis comb. Nov. (Ceramiales, Rhodophyta) in coral reefs. Journal of Phycology. DOI.10.1111/jpy.12567

$>$ Duran, A., L. Collado-Vides and D. Burkepile. 2016. Seasonal regulation of herbivory and nutrient effects on macroalgal recruitment and succession in a Florida coral reefs. PeerJ 4:e2643; DOI 10.7717/peerj.2643.

$>$ Rodriguez-Barreras, R., A. Duran, J. Lopez-Morell and A. M. Sabat. 2015. Effect of fish removal on the abundance and size structure of the sea urchin Diadema antillarum: a field experiment. Marine Biology Research.

http://dx.doi.org/10.1080/17451000.2015.1064140

$>$ Collado-Vides, L., V. Cassano, A. Senties, J. Diaz-Larrea, A. Medeiros, A. Duran and M. T. Fujii. 2014. Spread of the introduced species Laurancia caduciramulosa (Rhodomelaceae, Rhodophyta) to the northwest Atlantic: A morphological and molecular analysis. Phytotaxa. 183 (2): 93-107.

$>$ Cobian, D., J. H. Albernas, A. Duran and S. Perera. 2013. Structure and composition of fish's communities in the northeast zone of San Antonia's Bank, Cuba. Ecovida. 4(1): 12-25 
Semidey, A., L. Busutil, J. Espinosa, N. Gonsalez-Rodriguez, A. Duran, S. Alvarez and J. L. Hernandez. 2013. Inventory of Marine Species in the Keys north of Gulf of Batabano, SW of Cuba. Serie Ocenologica. 13. 95-109.

> Cobian, D., J. I. Hernandez-Albernas, A. Duran, P. P. Chevalier, A. L. Cardenes, D. Rosales and K. Cantelar. Coral reef ichtyofauna of Guanahacabibes National Park, Pinar del Rio, Cuba. 2012. Revista electrónica ECOVIDA. 3(1): 16 pp.

$>$ Alcolado, P. and A. Duran. 2011. System of scales for the classification and scoring of benthic and ichthyofaunal conditions in coral reefs of Cuba and the Wider Caribbean. Serie Oceanologica (8): 25-29.

$>$ Duran, A. and R. Claro. 2009. Impacts of Hurricane Ike on coral reef fishes in Santa Lucia turistic area, Camaguey, Cuba. Serie Oceanologica (5):111-127.

$>$ Duran, A. and R. Claro. 2009. Feeding activity of herbivorous fishes and their impact on coral reef with different levels of anthropogenic degradation. Rev. Biol. Trop. 57 (3): 687-697.

\section{PRESENTATIONS}

$>$ Kelly E. Speare, C. Fuchs, A. Duran and Deron E. Burkepile 2016. Interactions of coral recruits and juvenile coral with sediment and algae on reefs in the Florida Keys. International Coral Reef Symposium. Hawaii, June 19-24, 2016.

$>$ Fuchs. C., T. C. Adam, A. Duran, et al., 2016. Sediment removal increases turf algae grazing and alters algal community composition on coral reefs. International Coral Reef Symposium. Hawaii, June 19-24, 2016.

$>$ Duran, A. et al. 2016. Influence of coral reef composition on feeding preferences of Caribbean herbivorous fishes. International Coral Reef Symposium. Hawaii, June 19-24, 2016.

$>$ Duran. A. 2016. Herbivory impact of macroalgal dynamics of Florida Keys. Graduate Student Appreciation Week. March, $28^{\text {th }}$. Florida International University

$>$ Duran et al., 2016. Multiple-scale analysis effect of structural complexity on herbivory and dynamics of benthic communities on Florida Keys coral reef. Oral Presentation. Florida International University BioSymposium. $2^{\text {nd }}$ place Awarded Talk.

$>$ Armenis, E. and A. Duran. 2016. Eco-morphological studies on a red algal species Laurencia cervicornis (Ceramiales, Rhodophyta) in south Florida. Poster presentation. Florida International University BioSymposium.

$>$ Moreno, S. W. Sanchez and A. Duran. 2016. Feeding behavior and species interactions of Caribbean herbivorous fishes. Poster presentation. Florida International University BioSymposium. 
$>$ Palma, L. and A. Duran. 2016. Sequential algal removal by herbivorous fishes on natural macroalgal assemblages. Poster presentation. Florida International University BioSymposium.

$>$ Duran et al., 2015. Herbivory and structural complexity as drivers of algal dynamics on a coral reef. Oral presentation. $37^{\text {th }}$ Meeting of the Assocaiton of Marine Laboratories of the Caribbean. Curacao, 2015.

> Cassano, V., M. Machin-Sanchez, A. I. Neto, M. C. Oliveira, A. Sentis, J. DiazLarrea, M. C. Gil-Rodriguez, L. Collado-Vives, A. Medeiros, A. Duran and M. T. Fujii. 2013. A DNA barcode approach of the Laurencia complex (Ceramiales, Rhodophyta) in the tropical and subtropical Atlantic Ocean. International Phycology Conference, Orlando 2013.

$>$ Duran, A., L. Collado-Vides and D. Burkepile. Influence of structural complexity on coral reef macroalgal assemblages. $35^{\text {th }}$ Annual Southeastern Phycological Colloquy. September 27-28, 2013. Dauphin Island, Alabama. Oral presentation.

$>$ Duran, L. Collado-Vides and D. Burkepile. Effect of multiple ecological drivers on recruitment and succession of coral reef macroalgal communities. 36th Scientific Conference of the Association of the Marine Laboratories of the Caribbean. June 17-21, 2013. Ocho Rios, Jamaica. Oral presentation.

$>$ Duran, L. Collado-Vides and D. Burkepile.. Recruitment and post-settlement of coral reef macroalgae and their ecological drivers. 42nd Benthic Ecology Meeting. March 20-23, 2013. Savannah, Georgia. Oral presentation.

> Janina Rojas, Daphney Dorcius and A. Duran. Defensive behavior of Stegastes partitus and effects on coral reef fishes. 5th Annual Biology Research Symposium, Florida International University. February $2^{\text {nd }}, 2013$. Poster presentation.

$>$ Duran, A., L. Collado-Vides and D. Burkepile. Recruitment and succession of coral reef macroalgae assemblages under different ecological factors. 34th Annual Southeastern Phycological Colloquy. October $20^{\text {th }}, 2012$. University of North Florida. Jacksonville, Florida. Oral presentation.

$>$ Gonzales, N. and A. Duran. 2009. Fish community structure of Boca de Jaruco, Havana, Cuba. Colacmar. Cuba.

$>$ Duran, A. and J. Espinosa. 2009. Evaluación de la población de quinconte rosa (Cassis madagascariensis) en la costa sur de la cayería Los Indios, Golfo de Batabanó, Cuba. Colacmar. Cuba.

$>$ Duran, A. and R. Claro. 2008. Feeding activity of herbivorous fishes and their impact on coral reef with different levels of anthropogenic degradation. $11^{\mathrm{TH}}$ INTERNATIONAL CORAL REEF SYMPOSIUM, Poster presentation 